\title{
Tests of U.S. Rock Salt for Long-Term Stability of CAES Reservoirs
}

Applied Geomechanics, Inc. Baton Rouge, Louisiana
R. L. Thoms
R. M. Gehle

January 1986

Prepared by Applied Geomechanics, Inc. for Pacific Northwest Laboratory under Contract DE-AC06-76RLO 1830 with the U.S. Department of Energy

Pacific Northwest Laboratory Operated for the U.S. Department of Energy by Battelle Memorial Institute 


\title{
DISCLAIMER
}

This report was prepared as an account of work sponsored by an agency of the United States Government. Neither the United States Government nor any agency thereof, nor any of their employees, makes any warranty, express or implied, or assumes any legal liability or responsibility for the accuracy, completeness, or usefulness of any information, apparatus, product, or process disclosed, or represents that its use would not infringe privately owned rights. Reference herein to any specific commercial product, process, or service by trade name, trademark, manufacturer, or otherwise, does not necessarily constitute or imply its endorsement, recommendation, or favoring by the United States Government or any agency thereof. The views and opinions of authors expressed herein do not necessarily state or reflect those of the United States Government or any agency thereof.

\author{
PACIFIC NORTHWEST LABORATORY \\ operated by \\ BATTELLE \\ for the \\ UNITED STATES DEPARTMENT OF ENERGY \\ under Contract DE-AC06-76RLO 1830
}

\begin{tabular}{|c|c|}
\hline \multicolumn{2}{|c|}{ Printed in the United States of America } \\
\hline \multirow{2}{*}{\multicolumn{2}{|c|}{$\begin{array}{l}\text { Available from } \\
\text { National Technical Information Service }\end{array}$}} \\
\hline & \\
\hline \multicolumn{2}{|c|}{$\begin{array}{l}\text { National Technical Information Service } \\
\text { United States Department of Commerce }\end{array}$} \\
\hline \multicolumn{2}{|c|}{5285 Port Royal Road } \\
\hline \multicolumn{2}{|c|}{ Springfield, Virginia 22161} \\
\hline \multirow{2}{*}{\multicolumn{2}{|c|}{$\begin{array}{l}\text { NTIS Price Codes } \\
\text { Microfiche A01 }\end{array}$}} \\
\hline & \\
\hline \multicolumn{2}{|c|}{ Printed Copy } \\
\hline & Price \\
\hline Pages & Codes \\
\hline $001-025$ & A02 \\
\hline $026-050$ & $\mathrm{~A} 03$ \\
\hline $051-075$ & $\mathrm{~A} 04$ \\
\hline $076-100$ & A05 \\
\hline $101-125$ & $\mathrm{~A} 06$ \\
\hline $126-150$ & A07 \\
\hline 751-175 & $\mathrm{A} 0 \mathrm{~B}$ \\
\hline $176-200$ & $\mathrm{~A} 09$ \\
\hline $201-225$ & A 010 \\
\hline $226-250$ & A011 \\
\hline $251-275$ & A012 \\
\hline $276-300$ & A013 \\
\hline
\end{tabular}


TESTS OF U.S. ROCK SALT FOR LONG-TERM STABILITY OF

CAES RESERVOIRS

Appl ied Geomechanics, Inc.

Baton Rouge, Louisiana

R. M. Gehle

R. L. Thoms

January 1986

Prepared by Applied Geomechanics, Inc. for Pacific Northwest Laboratory under Contract DE-ACO6-76RL0 1830 with the U.S. Department of Energy

Pacific Northwest Laboratory

Richland, Washington 99352 


\section{、}




\section{FOREWORD}

Compressed air energy storage (CAES) is a technique for supplying electric power to meet peak load requirements of electric utility systems. Using low-cost power from baseload plants during off-peak periods, a CAES plant compresses air for storage in an underground reservoir--an aquifer, solutionmined salt cavity, or mined hard-rock cavern. During subsequent peak load periods, the compressed air is withdrawn from storage, heated, and expanded through turbines to generate peak power. This relatively new technology offers significant potential for reducing costs and improving the efficiency of electric power generation, as well as reducing petroleum fuel consumption.

Based on these potential benefits, the U.S. Department of Energy (DOE) sponsored a comprehensive program to accelerate commercialization of CAES technology. The Pacific Northwest Laboratory (PNL) was designated the lead laboratory for the CAES Program. As such, PNL was responsible for assisting the DOE in planning, budgeting, contracting, managing, reporting, and disseminating information. Under subcontract to PNL were a number of companies, universities, and consultants responsible for various research tasks within the program.

This document reports on laboratory tests to assess the effects of CAES on rock salt cavities within the U.S. This study was performed for PNL by Louisiana State University (LSU) under subcontract B-67966-A-0. The project inciuded conventional laboratory testing, as well as bench-scale testing in two southern-Louisiana sa1t mines. Stability criteria for long-term air storage were developed and are included in this report. The criteria are general in nature because of the site-specific differences in CAES host salt formations. Since project completion the authors have left LSU and are currently employed by Applied Geomechanics, Inc., Baton Rouge, Louisiana.

Landis D. Kannberg, Manager Underground Energy Storage Program 
This is a report on laboratory tests to assess the effects of compressed air energy storage (CAES) on rock salt within the U.S. The project included a conventional laboratory test phase, with triaxial test machines, and a benchscale test phase performed in salt mines in southern Louisiana. Limited numerical modeling also was performed to serve as a guide in selecting test layouts and for interpreting test data.

The conventional laboratory test phase incorporated assembly of specialized test machines for cyclic triaxial load applications. Six test machines were assembled with the capability of applying triaxial static or cyclic stresses and elevated temperatures to cylindrical test specimens of rock salt. Applied stress and temperature environments were selected to span effects on salt around typical operating CAES reservoirs (i.e., caverns). A typical test incorporated the following loading sequence: 1) static loads at room temperature for 4 to 5 days; 2) cyclic loads at room temperature for 4 to 5 days; and 3) continuation of cyclic loads, but with elevated temperatures, for 2 to 4 days. Frequently, elevated temperatures resulted in excessive specimen deformation that caused test termination.

The most significant findings from the laboratory triaxial test series were the apparent relative effects of cyclic loads compared to static loads. The analyses of these effects are included in subsequent pages of this report. These analyses may be usefut in assessing possible CAES effects on salt formations for which data exists from some previous static load test program.

Permeability tests also were performed as part of the conventional laboratory test program. Results were similar to other studies and showed that gas permeability decreased sharply with confining pressure and number of cycles of load application. Rock salt was found to be particularly sensitive to its degree of disturbance history. For example, specimens cut from cores 
drilled from floors in heave-prone areas within salt mines transmitted considerably more flow than specimens cut from cores drilled beneath mine pitlars. (Obvious joint permeability was not present in any of the specimens tested.)

A majority of salt specimens tested were cut from cores donated to this project by the Department of Energy (DOE) Program for Storage Petroleum Reserve (SPR). This provided salt core from a larger number of sources than would have been otherwise possible. However, a significant degree of uncertainty was also introduced into interpretation of test data because of the essentially unknown degree of disturbances associated with drilling, transport, and storage of the SPR cores prior to their use in the CAES Program.

The bench-scale laboratory test phase in two salt mines of southern Louisiana was considered very productive. Testing was initiated in the Jefferson Island (JI) salt mine, but the program was later moved to the cote Blanche (CB) mine when flooding occurred at the Jefferson Island site. Tests included cyclic pressurization of boreholes with monitoring of diametric displacements and acoustic emissions. Some qualitative permeability tests also were performed with refrigerant gas. Minihydrofracture tests were performed, accompanied by acoustic emissions ( $A E$ ) monitoring. The $A E$ monitoring proved to be effective in detecting fractures caused by applied Toads.

Although more difficult to perform, the in situ mine tests were considered more representative of operational CAES reservoir conditions. The presence of minimally disturbed salt around the test holes was the major advantage of mine tests, along with a more representative configuration of the test specimen. That is, a model CAES reservoir drilled hole was subjected to cyclic air pressure loadings in undisturbed and continuously confined salt. Limited numerical modeling was used to interpret data from the in situ tests, but with the usual degree of uncertainty associated with assumed boundary conditions. 


\begin{abstract}
Test results generally were corroborative of the conventional laboratory and the bench-scale in situ test phases. Reservoir stability criteria for long-term air storage were developed and incorporated in this report. These were based on the test results and other findings from this study. The stability criteria were somewhat general because of anticipated site-specific differences in potential CAES host rock salt formations. A proposed method for field testing salt formations for CAES reservoir suitability concludes this report.
\end{abstract}




\section{CONTENTS}

FOREWORD............................. . 1 . . . . . . .

SUMMARY . . . . . . . . . . . . . . . . . . . . . V

FIGURES .............................. . . . xi

TABLES. . . . . . . . . . . . . . . . . . . . . . . xi

NOMENCLATURE.............................. . XV

1.0 GENERAL INTRODUCTION AND OVERVIEW. . . . . . . . . . . . . . . . . 1.1

1.1 OBJeCtives OF TEST PROGRAM. . . . . . . . . . . . . . . . . 1.1

1.2 SIGNIFICANCE OF TEST DATA . . . . . . . . . . . . . . . . 1

1.3 OVERALL METHODOLOGY OF TEST PROGRAM . . . . . . . . . . . . 1.1

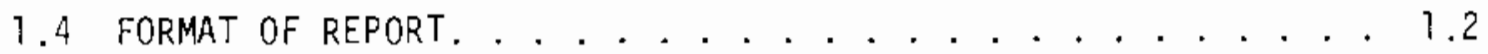

2.0 MAJOR FINDINGS AND RECOMMENDATIONS . . . . . . . . . . . . . . . 2.1

2.1 FINOINGS. . . . . . . . . . . . . . . . . . 2.1

2.2 RECOMMENDATIONS . . . . . . . . . . . . . . . . . 2.2

3.0 LABORATORY TESTS . . . . . . . . . . . . . . . . . . . . . . . . 3.1

3.1 METHODOLOGY AND PLAN FOR LABORATORY TESTING . . . . . . . . . 3.1

3.2 INDEX TESTS ON SALT FROM DIFFERENT SOURCES. . . . . . . . . . 3.2

3.3 LABORATORY DEVELOPMENT FOR LONG-TERM CYCLIC TESTS . . . . . 3.5

3.4 SAMPLE PREPARATION AND TEST PROCEDURE . . . . . . . . . . . 3.10

3.5 LONG-TERM TEST DATA ANALYSES. . . . . . . . . . . . . . . 3.14

4.0 IN SitU PRESSURE TESTS IN SALT MINES . . . . . . . . . . . . . . . . 4.1

4.1 Methodology of IN Situ testing. . . . . . . . . . . . . . 4.1

4.2 TEST Site deVElOPMENT . . . . . . . . . . . . . . . . . 4.2

4.3 TEST AND MONITORING EQUIPMENT . . . . . . . . . . . . 4.7 
4.4 LOW-PRESSURE AIR BOREHOLE TEST. . . . . . . . . . 4.14

4.5 HIGH-PRESSURE OIL BOREHOLE TEST . . . . . . . . . 4.21

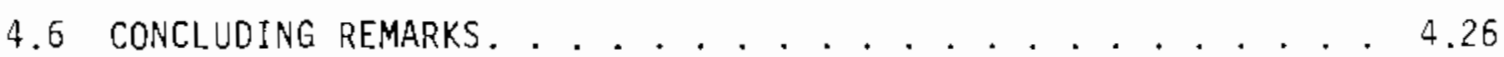

5.0 PERMEABILITY TESTS . . . . . . . . . . . . . 5.1

5.1 LABORATORY PERMEABILITY TESTS PERFORMED . . . . . . . . . . 5.1

5.2 LABORATORY PERMEABILITY TESTS PROPOSED. . . . . . . . . . . . . 5.4

5.3 IN Situ PERMEABILITY TESTS PERfORMED. . . . . . . . 5.10

5.4 IN SITU PERMEABILITY TESTS PROPOSED . . . . . . . . . 5.12

5.5 CONCLUdING REMARKS. . . . . . . . . . . . . 5.13

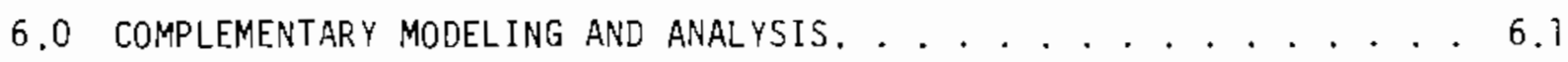

6.1 ROLE OF COMPLEMENTARY MODELING AND ANALYSIS . . . . . . . 6.1

6.2 Typical CAES CAVERN . . . . . . . . . . . . . . 6.1

6.3 STRESS DISTRIBUTION FOR TEST SITES IN SALT MINES. ..... 6.1

6.4 OTHER NUMERICAL AND ANALYTICAL SOLUTIONS. . . . . . . . 6.3

6.5 CONCLUDING REMARKS. . . . . . . . . . . . . . . 6.4

7.0 PROPOSED SITE-SUITAEILITY FIELD TEST FOR CAES CAVERNS. . . . . . 7.1

7.1 NEED AND SIGNIFICANCE OF A FIELD TEST FOR SITING CAES

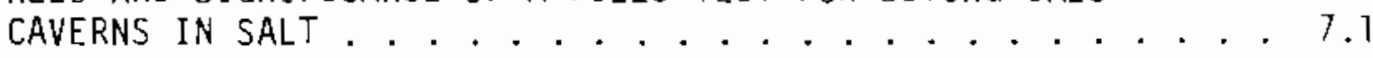

7.2 FACTORS AFFECTING CAVERNS CLOSURE IN SALT FORMATIONS. . . . . . 7.1

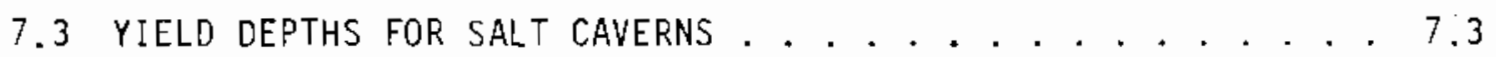

7.4 DIMENSIONAL. ANALYSIS OF VOLUME CHANGE FOR OPENINGS IN SALT. . 7.4

7.5 IMPlementation. . . . . . . . . . . . . . . . 7.9

7.6 CONCLUSION. . . . . . . . . . . . . . . . . 7.12

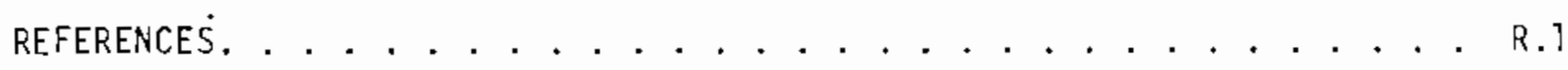




\section{FIGURES}

3.1 Brazilian Test Setup.................... . . . . . 3

3.2 Brazilian Test Specimen, Post-Failure............. 3.4

3.3 Typical Brazilian Test Data for Rock Salt. . . . . . . . . . . . 3.4

3.4 Brazilian Test Results for Salt from Different Sources.... . . 3.5

3.5 Schematic of Long-Term Cyclic Test Units . . . . . . . . . . . 3.6

3.6 Control Components Schematic . . . . . . . . . . . . . . 3.7

3.7 Pressure Jacket and Platens for Triaxial Specimens . . . . . . . 3.8

3.8 Test Units in CAES Laboratory. . . . . . . . . . . . . . . 3.9

3.9 Triaxial Test Setup. . . . . . . . . . . . . . . . . . . 3.9

3.10 Cutting Test Specimen from Core. . . . . . . . . . . . . . . 3.10

3.11 Trimming Specimen on Lathe................. . . 3.11

3.12 Typical Static-Cyclic Creep of Salt Specimen . . . . . . . . 3.15

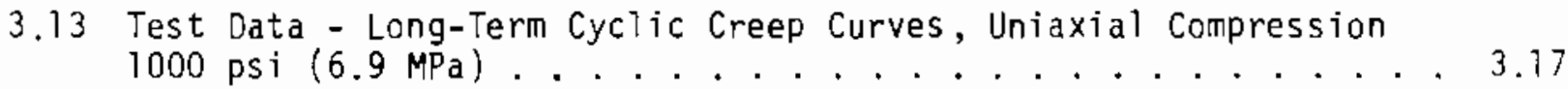

3.14 Test Data - Long-Term Cycic Creep Curves, Uniaxial Compression 2000 psi (13.8 MPa). . . . . . . . . . . . . . 3.18

3.15 Test Data - Long-Term Cyclic Creep Curves, Triaxial Extension

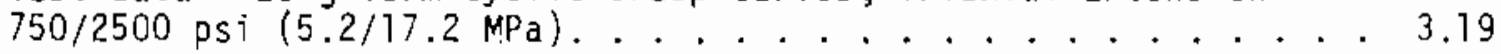

3.16 Test Data - Long-Term Cyclic Creep Curves, Triaxial Extension $1000 / 3500$ psi $(6.9 / 24.1 \mathrm{MPa}) . . . . .2 . . .20$

3.17 Test Data - Long-Term Cyclic Creep Curves, Triaxial Compression

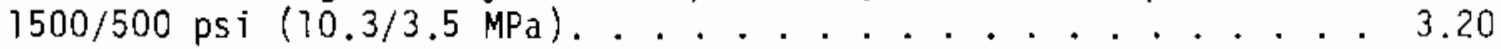

3.18 Test Data - Long-Term Cyclic Creep Curves, Triaxial Compression

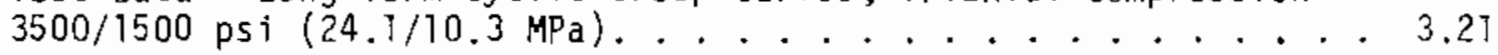

3.19 Cyclic Load Effects on Displacements.............. 3.22

3.20 Cyclic Load Effects on Creep Rates............... 3.23 
4.1 Shed at First Test site in Jefferson Island Salt Mine. . . . . 4.2

4.2 Work Underway at Second Test Site in Jefferson Island Salt

Mine..................... . . . 4.4

4.3 Test Hole Slant-Drilled Beneath Mine Pillar. . . . . . . . . . . 4.5

4.4 Instrumentation Shack in Cote Blanche Salt Mine.......... . 4.7

4.5 Instrumentation for High-Pressure Tests. . . . . . . . . . . . 4.9

4.6 Apparatus at In Situ Test Site............... 4. 40

4.7 Head of Pressurized Borehole with Instrumentation. . . . . . . . . 4.10

4.8 Hole Caliper Device Inserted into Test Hole. . . . . . . . . . 4.11

4.9 Hole Caliper and Stopper after Removal from Hole . . . . . . . . . 4.12

4.10 Test Shack in Jse at Cote Blanche Site........... 4. . . . . 3

4.11 Monitoring and Recording Instrumentation in Shack. . . . . . . 4.13

4.12 Recorded Initial and Cyclic Air-Pressurization Test Data. . . . 4.15

4.13 Transcribed Air-Pressurization Test Data - Cyclic Load Phase . . 4.16

4.14 Transcribed Air-Pressurization Test Data - Monotonic

Increasing and Constant Load Phases. . . . . . . . . . . 4.17

4.15 Configuration of Test Holes for Hydraulic Fracturing . . . . . . 4.22

4.16 Recorded Test Data at Fracturing . . . . . . . . . . . . . . 4.23

5.1 Permeability Test Cell. . . . . . . . . . . . . . 5.2

5.2 Permeability Versus Confining Pressure . . . . . . . . . . 5.3

5.3 Specimen and Solution Domain. . . . . . . . . . . . . . . . . 5.6

5.4 Pressure Decay for Longitudinal Flow . . . . . . . . . . . . . 5.9

5.5 Pressure Decay for Radial Flow . . . . . . . . . . . . . . 5.9

5.6 Apparatus for Tracer Gas Cross-Borehole Test . . . . . . . . . . 5.11

5.7 Freon Gas Bottle Connected to Test Hole............ 5. . . . . 
6.1 Stress Distribution Around a Typical CAES Cavern . . . . . . . . . 6.2

7.1 Effective Overburden for CAES Salt Cavern. . . . . . . . . . . 7.2

7.2 Borehole Testing Schematic............... 7.70

\section{TABLES}

3.1 Load Conditions for Laboratory Tests . . . . . . . . . . . . . 3.3 
$+$ . 


\section{NOMENCLATURE}

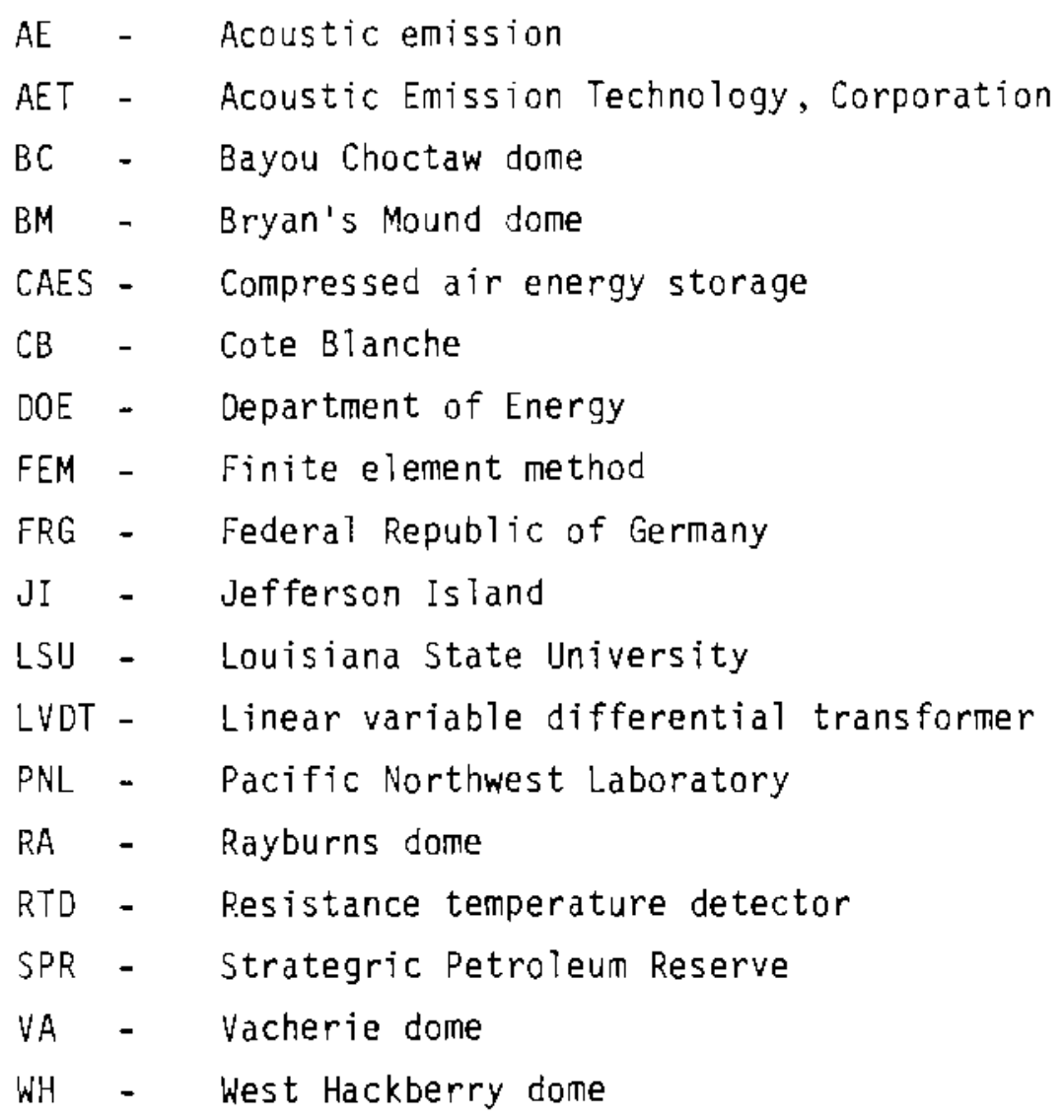




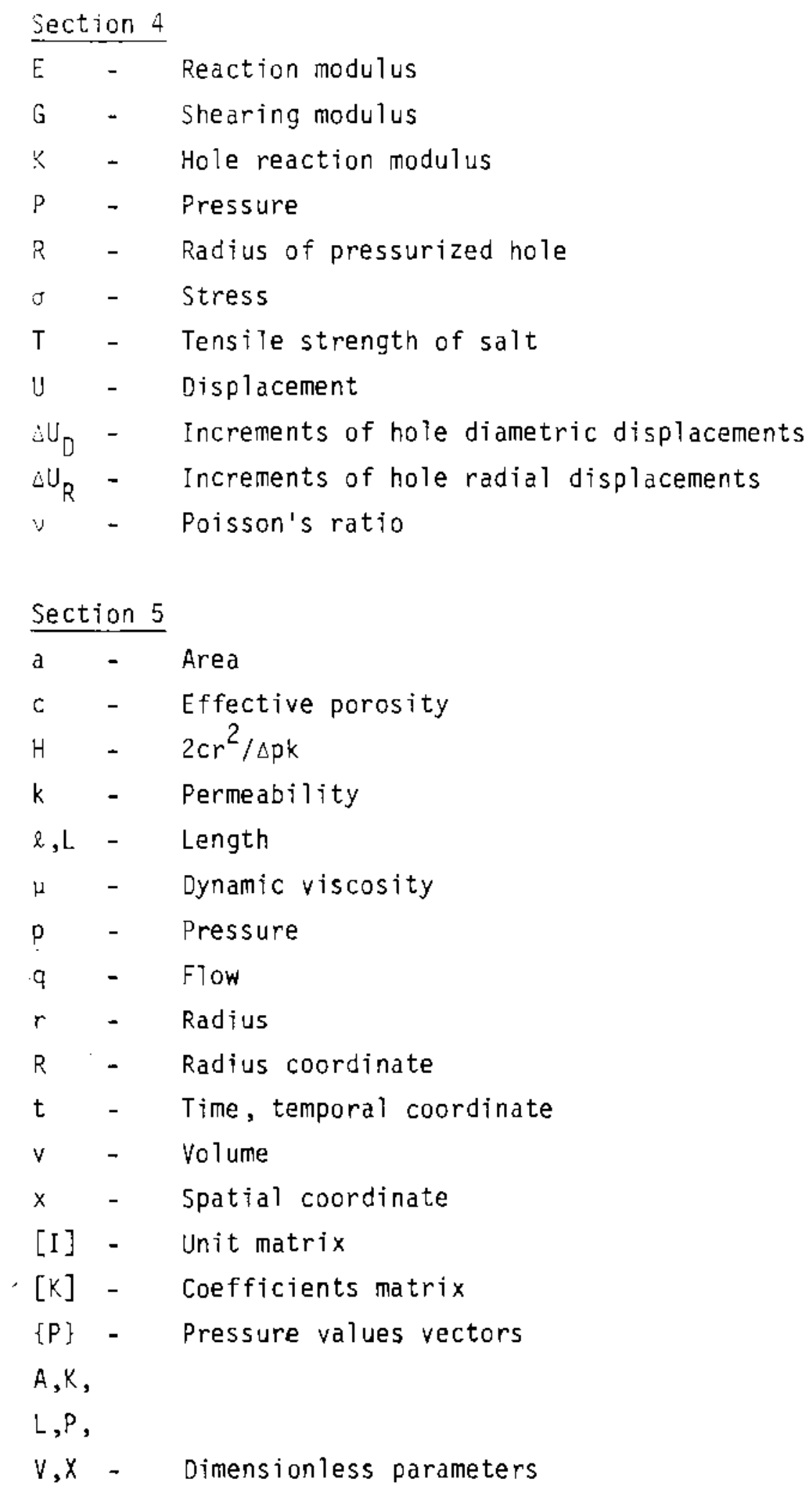




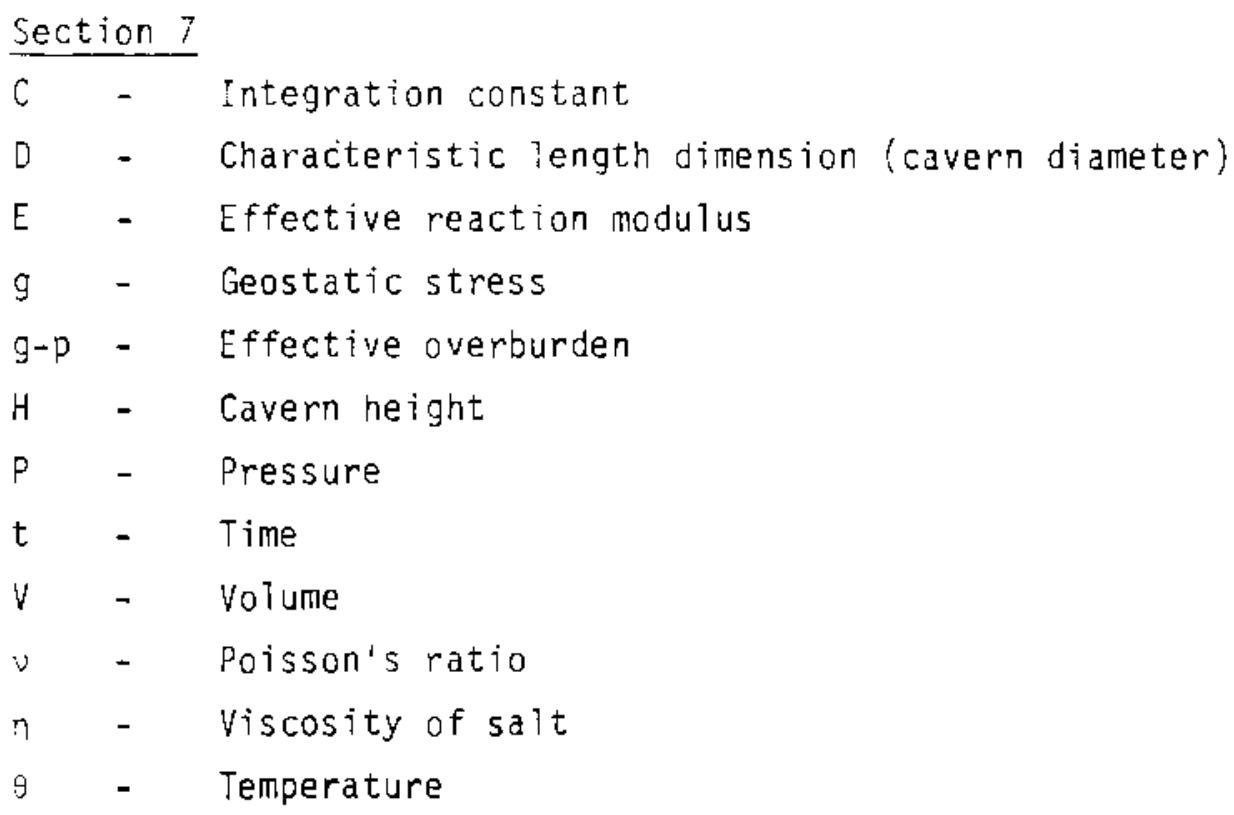



TESTS OF U.S. ROCK SALT FOR LONG-TERM STABILITY OF CAES RESERVOIRS

\subsection{GENERAL INTRODUCTION AND OVERVIEW}

\subsection{OBJECTIVES OF TEST PROGRAM}

The overall objectives of this study were to develop and implement a laboratory testing program to determine the mechanical response of rock salt subjected to compressed air energy storage (CAES) loading environments and to formulate criteria for long-term stability of CAES caverns.

\subsection{SIGNIFICANCE OF TEST DATA}

Laboratory tests were performed to obtain a data base for salt behavior under cyclic CAES loading conditions. CAES loading effects on U.S. salt domes had not been studied previously, and thus, data were lacking. A successfui CAES facility had been constructed in the Huntorf Dome in the Federal Republic of Germany; salt was procured from Huntorf to provide test data comparisons with salt from U.S. domes. Thus, this project was significant because it provided data for U.S. domes related directly to CAES applications. It also furnished a basis for comparison of U.S. salt behavior to the behavior of salt cores from the existing CAES facility at Huntorf.

\subsection{OVERALL METHODOLOGY OF TEST PROGRAM}

The laboratory tests program consisted of two phases: 1) a conventional laboratory program incorporating time-dependent cyclic tests with triaxial cells and loading machines, and 2) a series of bench-scale, in situ tests performed in salt mines of southern Louisiana.

By performing both conventional laboratory tests and bench-scale in situ tests it was considered more probable that the effects of retrieving specimens from the host rock salt formation could be accounted for. Rock salt tends to disaggregate more readily than stronger rocks. The effects of specimen coring 
and handing during shipping can have significant effects on test results. An in situ bench-scale test phase coupled with a more conventional laboratory test phase was deemed appropriate to enhance confidence in the ?aboratory tests. The methodology of each individua? testing phase is described in more detait in Sections 3 and 4 .

\subsection{FORMAT OF REPORT}

This report consists of two main test phases. Laboratory and in situ strength tests are described in Sections 3 and 4 , respectively. Permeability testing was considered a related, but separate topic, and is reported in Section 5. A limited, but useful complementary modeling study was performed, and is described in section 6. Finally, a proposed field test is outlined. The authors believe this test would be highly useful in a feasibility or preliminary design phase for CAES reservoirs at proposed specific sites in rock salt formations. 


\subsection{MAJOR FINDINGS AND RECOMMENDATIONS}

The findings and recommendations listed in the following text are based on results and experience gained from the overall CAES test project. Backup data and more detailed discussions and recommendations are included in Sections 3 through 6 .

\subsection{FINDINGS}

- P.ock salt displays generally good resistance to cyclic load effects within stress environments associated with operations of CAES facilities.

- U.S. dome salt and Huntorf dome salt from West Germany displayed simiTar behavior in laboratory tests. Since a CAES facility is performing satisfactorily at Huntorf, U.S. dome salt also appears satisfactory as a host rock for CAES reservoirs.

- The mechanical response of salt to relatively high-frequency, smallamplitude cyclic loads appears as short-term elastic strains superimposed on long-term creep typical of quasi-static tests of rock salt.

- Effects of infrequent depressurizations for initial brine evacuation and subsequent maintenance may be more severe for caverns than long-term CAES operations. This assumes CAES involves cyclic, relatively small amplitude pressure variations about mean values associated with static cavern storage (e.g., 0.70 to 0.85 of 1 ithostatic values at casing seat or shoe).

- The onset of cyclic loads, following a static load phase, caused an increase in short-term displacements and creep rate in laboratory salt specimens. The increased creep rate, while significant for long-term cavern stability considerations, still appeared to be of acceptabie magnitude for CAES applications. 
- Laboratory test results for rock salt appeared very sensitive to specimen processing history. Original location in-mine !disturbed or undisturbed zones), coring techniques, handling, specimen preparation, and storage method apparently affected salt behavior during tests.

- In situ pressurized borehole tests yielded data generally consistent with laboratory results. Cyclic, approximately linear hole displacements resulted from short-term, small-amplitude cyclic variations in hole pressure. Over a longer time interval, cyclic hole displacements tended to form a band of essentially constant width and with mean values that generaliy followed the displacement behavior of the hole with constant pressure.

- Acoustic emissions, monjtored with minifracturing of test boreholes, displayed greatly increased activity immediately prior to and during hole fracturing (as indicated by pressure variation data).

- Permeability of rock salt depends on confining pressure, degree of disturbance, and fluid used for specimen cutting or test hole drilling (as well as testing). Relatively undisturbed and continuously confined salt beneath mine pillars and outside of "anomalous zones" displayed immeasurably small values of permeability over time periods of around 2 hours. By contrast, induced permeability with obviously large values was exhibited in disturbed or unconfined zones, such as within 10 to $20 \mathrm{ft}$ horizontally of pillar faces.

\subsection{RECOMMENDATIONS}

- Field tests appropriate to site studies for CAES reservoirs should be developed for rock salt formations. Field tests should be considered an essential component of CAES site feasibility studies because of the rock salt sensitivity to the processing necessary to perform laboratory tests. 
- Bedded salts were not studied specifically in this project. However, their use as host formations for natural gas storage caverns indicates strong potential for their use as CAES reservoirs. Differences in geological structure of bedded and dome salt formations should be taken into account when designing CAES reservoirs and operational pressure cycles. In particular, bedied salts are generally assigned a smaller hydrofracture gradient vaiue than dome sait. This implies use of smaller peak pressure values for CAES caverns in bedded salts than the values for caverns at similar depths in dome salt.

- A microseismic monitoring system should be installed during CAES reservoir construction to provide cavern performance data during the later operational phase. Ongoing microseismic monitoring should be used to assess cavern response to operating CAES pressure cycles. It should be recognized that a significant time period may be required to gain experience in relating recorded microseisms to cavern response (from a few months to around 2 years to account for seasonal variations).

- Local experiences in natural gas storage, if any, should be thoroughly sought out and reviewed during preliminary site feasibility studies for CAES reservoirs. Local experience and practice in natural gas storage can be used as tentative bases for planning CAES operating pressure cycles until more specific data are available. 


\section{.}




\subsection{LABORATORY TESTS}

\subsection{METHODOLOGY AND PLAN FOR LABORATORY TESTING}

A significant number of parameters had to be considered for cyclic tests of rock salt, as the material is nontinear, time-dependent and temperaturesensitive. Thus, a suite of tests was performed that included both simple index tests for salt strength and a matrix of long-term cyclic triaxial extension tests with a thermal loading phase.

Section 3.2 describes the index strength tests (indirect tension or Brazilian) performed to check the effects of sources of rock salt. More complicated long-term cyclic tests were conducted on a selected suite of samples and were limited to load conditions likely to span environments associated with operational CAES reservoirs in salt. A relativeiy simple finite element method (FEM) analysis was performed on a typical CAES cavern to obtain an estimate of operational stresses to be used in experimental design. Details of that analysis are presented in section 5 of this report. Based on that analysis, a range of load values were selected for testing rock salt specimens.

Temperature values selected for testing were based mainly on naturaliy occurring formation temperatures in salt. The values of around $740^{\circ} \mathrm{F}\left(60^{\circ} \mathrm{C}\right)$ are somewhat greater than formation temperatures of around $120^{\circ} \mathrm{F}\left(49^{\circ} \mathrm{C}\right)$ that occur in U.S. Gulf Coast salt domes at depths of 2000 to $3000 \mathrm{ft}(610$ to 915 $\pi)$, and greater still than temperatures in bedded salt formations at similar depths. However, these temperatures are realistic, as some near-field temperatures will increase above formation temperatures due to injection of nonambient air from the CAES compressors.

A major consideration for long-term cyclic testing of rock salt was determining the effects of the cyclic loads relative to static loads. Considerable data are available for static creep tests of sait, and it would be beneficial if some estimate of salt behavior under cyclic loads could be based on static creep test data already on hand. Accordingly, tests were performed in three stages: 
- static load application--until strongly transient creep behavior diminished at room temperature

- cyclic load application-- again until strongly transient creep behavior diminished at room temperature

- cyclic load application--at moderately elevated temperatures until salt behavior could be typified or until the specimen failed.

The latter occurred only occasionally and was exclusive to triaxial extension test conditions.

Table 3.1 lists load conditions for a matrix of long-term cyclic tests or specimens from a typical salt source. Two specimens were associated with each of the three columns of the table. The specimens were subjected initially to load conditions in the top row (Phase 1), and sequentially to conditions in the middle and bottom rows (Phases 2 and 3 , respectively). Based on the FEM analys is presented in Section 5.1 , the three load conditions were selected to spanstress conditions around a typical CAES reservoir in a salt formation with the cavern top at a depth of around $2000 \mathrm{ft}(610 \mathrm{~m})$.

\subsection{INDEX TESTS ON SALT FROM DIFFERENT SOURCES}

Salt cores were obtained from six different sources for index strength tests. The Brazilian or indirect tension test was used for index testing because it is relatively well known and simple to perform (Bieniawski and Hawkes 1977). The test consists of applying diametrically opposing point (line) loads across short cylinders and loading to failure. Figures 3.1 and 3.2 illustrate the Brazilian test setup for the CAES study. Figure 3.3 depicts data collected from a typical test.

Figure 3.4 displays results from a suite of Brazilian tests. Sources of salt specimens are indicated on the figure. It should be noted that the abscissa for strength values begins at 170 psi (1.17 MPa) rather than zero, and thus, the different salts yield more closely grouped strength values than perhaps would be first perceived by the reader. 
TABLE 3.1. Load Conditions For Laboratory Tests

\begin{tabular}{|c|c|c|c|}
\hline \multirow{2}{*}{ Stage ${ }^{(a)}$} & $\begin{array}{l}\text { Uniaxial } \\
\text { Compression }\end{array}$ & $\begin{array}{l}\text { Triaxial } \\
\text { Extension }\end{array}$ & $\begin{array}{l}\text { Triaxial } \\
\text { Compression }\end{array}$ \\
\hline & \multicolumn{3}{|c|}{ Axial Stress/Lateral Stress, SA/SL (psi) } \\
\hline \multirow{2}{*}{$\begin{array}{l}\text { Constant } \\
\text { loads }\end{array}$} & $1000 / 0$ & $750 / 2500$ & $1500 / 500$ \\
\hline & $2000 / 0$ & $1000 / 3500$ & $3500 / 1500$ \\
\hline \multirow[t]{2}{*}{$\begin{array}{l}\text { Cyclic } \\
\text { loads }\end{array}$} & 500 to $1000 / 0$ & $\begin{array}{l}450 \text { to } 750 / \\
2250 \text { to } 2500\end{array}$ & $\begin{array}{l}1000 \text { to } 5000 / \\
0 \text { to } 500\end{array}$ \\
\hline & 1000 to $2000 / 0$ & $\begin{array}{l}750 \text { to } 1000 / \\
3000 \text { to } 3500\end{array}$ & $\begin{array}{l}3000 \text { to } 3500 / \\
1000 \text { to } 1500\end{array}$ \\
\hline $\begin{array}{l}\text { Cyclic loads, } \\
\text { elevated } \\
\text { temperatures }\end{array}$ & $140^{\circ} \mathrm{F}\left(60^{\circ} \mathrm{C}\right)$ & $\begin{array}{l}140^{\circ} \mathrm{F}\left(60^{\circ} \mathrm{C}\right) \\
00 \mathrm{psi}=6.89\end{array}$ & $140^{\circ} \mathrm{F}\left(60^{\circ} \mathrm{C}\right)$ \\
\hline
\end{tabular}

(a) Typical test proceeded in stages from constant to cyclic load conditions to cyclic load conditions to cyclic load at elevated temperature.

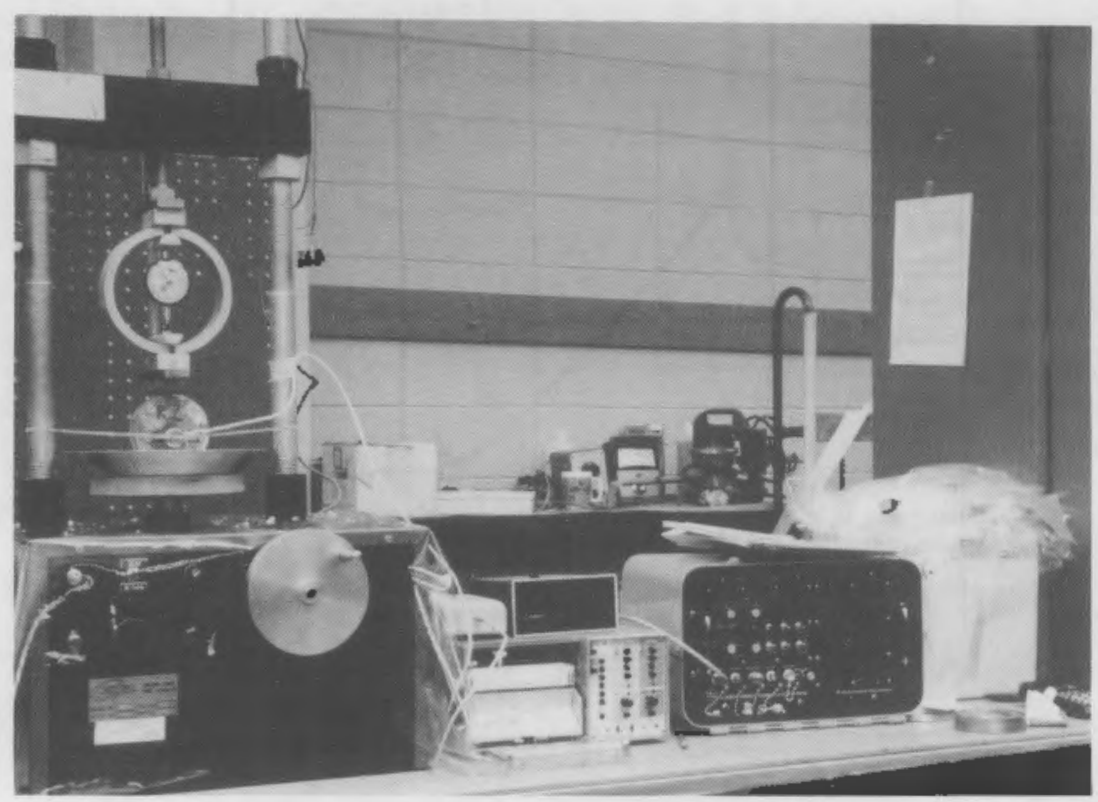

FIGURE 3.1. Brazilian Test Setup 


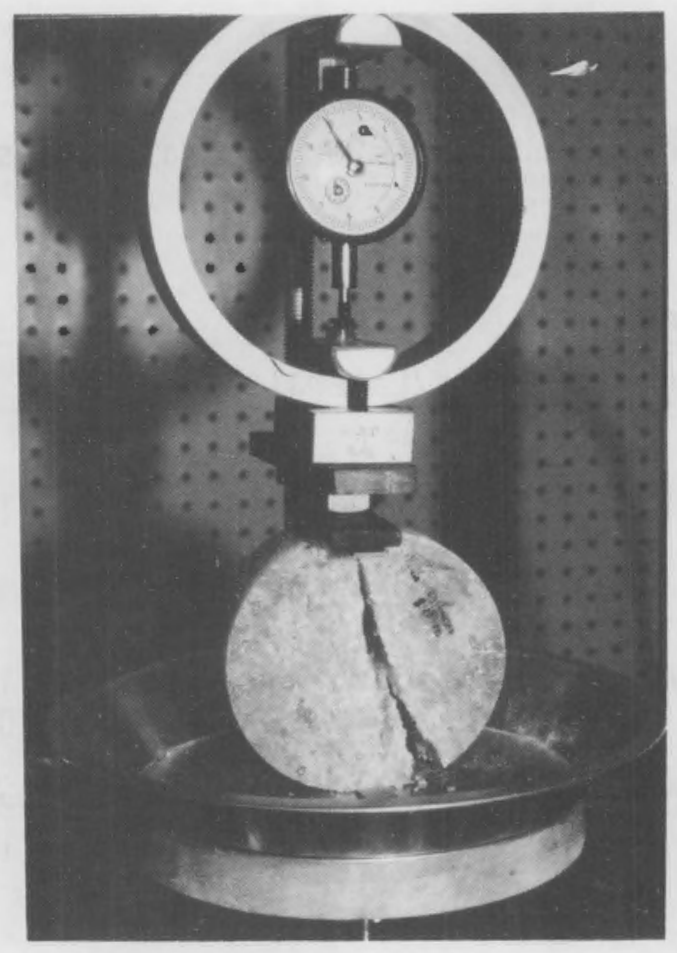

FIGURE 3.2. Brazilian Test Specimen, Post-Failure

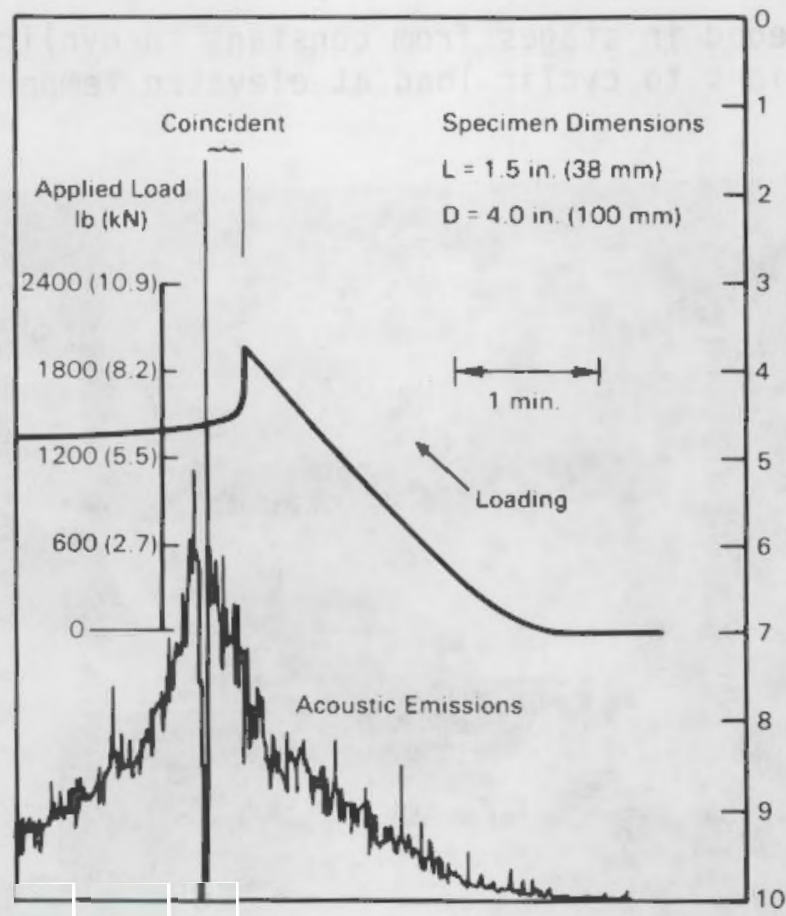

FIGURE 3.3. Typical Brazilian Test Data for Rock Salt 


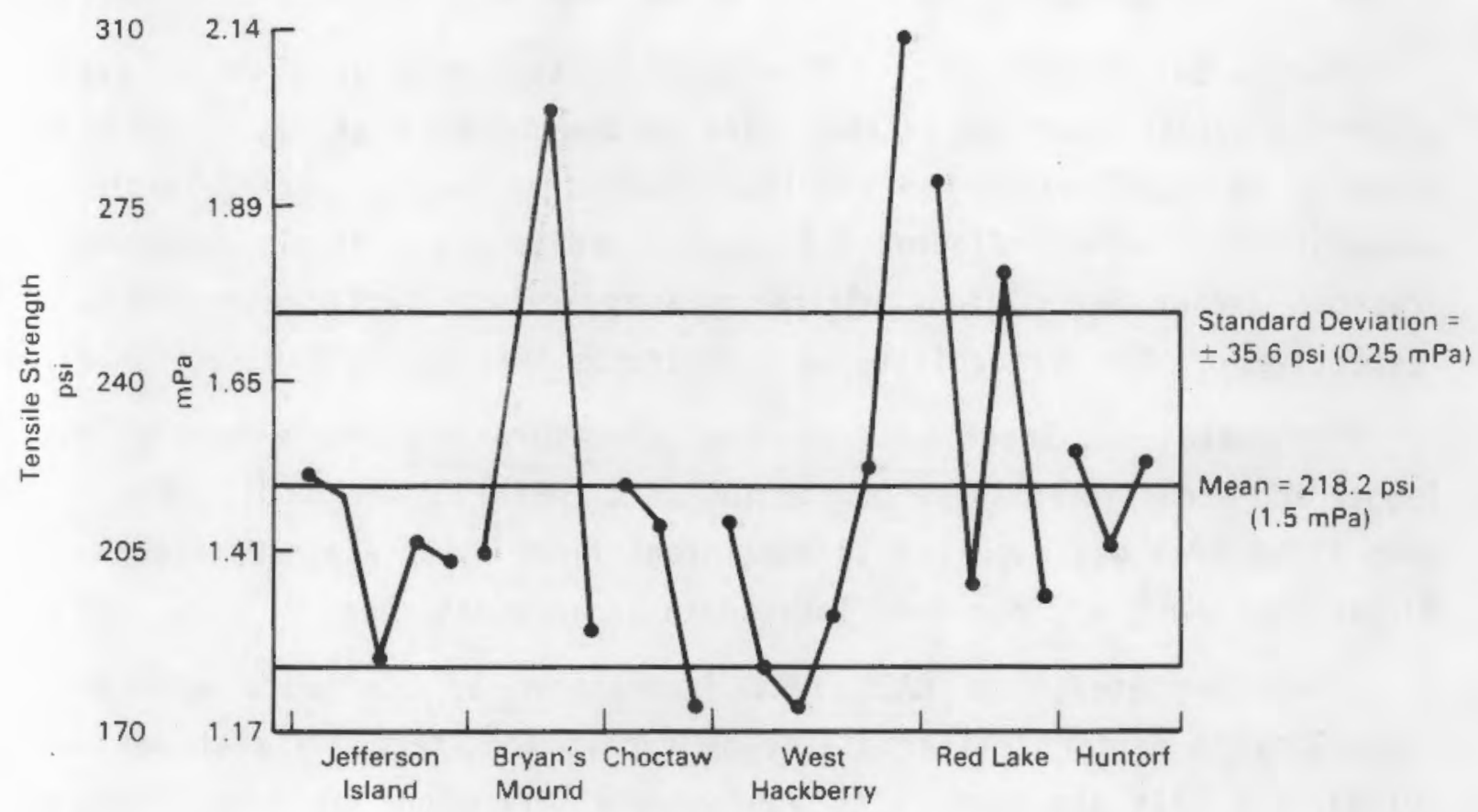

FIGURE 3.4. Brazilian Test Results for Salt from Different Sources

\subsection{LABORATORY DEVELOPMENT FOR LONG-TERM CYCLIC TESTS}

The simulation of CAES load environments for rock salt requires consideration of a relatively large number of test parameters over long-term periods. To perform a significant number of long-term tests a parallel pipeline test capability was deemed essential; thus, an early decision was made to develop a number of test machines specialized to simulate CAES conditions around reservoirs in rock salt. Subsequently, six specialized machines capable of performing CAES-related tests were developed for this study. The design of the test machines was initiated by considering an existing design by obert for static creep tests (Obert 1963). The test machines consisted of four basic components:

- load frame

- pressure jackets and platens 
- air-to oil-pressure intensifiers

- control units.

Figure 3.5 schematically depicts the basic components of a typical test unit.

Design and development of the controls component and valving system governing cyclic load application were unique to this study, along with redesign and modification of the load platens to permit thermal loading and permeability testing. Figures 3.6 and 3.7 depict the controls component and pressure jacket and platens enclosing a typical triaxial test specimen, respectively. The permeability test apparatus is discussed in section 5 .

Peripheral equipment used in the laboratory included a central data logger and acoustic emission monitoring unit (AET Pioneer 5000). Air at 200 psig ( $1.38 \mathrm{MPa})$ was supplied to the intensifiers by an air compressor with a 30 -gal $\left(0.114-m^{3}\right)$ storage tank located in an adjacent room.

When completed, the CAES test laboratory had six units with the capability to perform either static or cyclic long-term triaxial tests on cylindrical salt specimens with approximate dimensions of $4-i n$. (100-mm) diameter and 8 -in. $(200-\mathrm{mm})$ length. Heaters in the end caps allowed testing at moderate elevated temperatures in the salt of up to $140^{\circ} \mathrm{F}\left(60^{\circ} \mathrm{C}\right)$. Applied loads and resulting specimen displacement were monitored with pressure

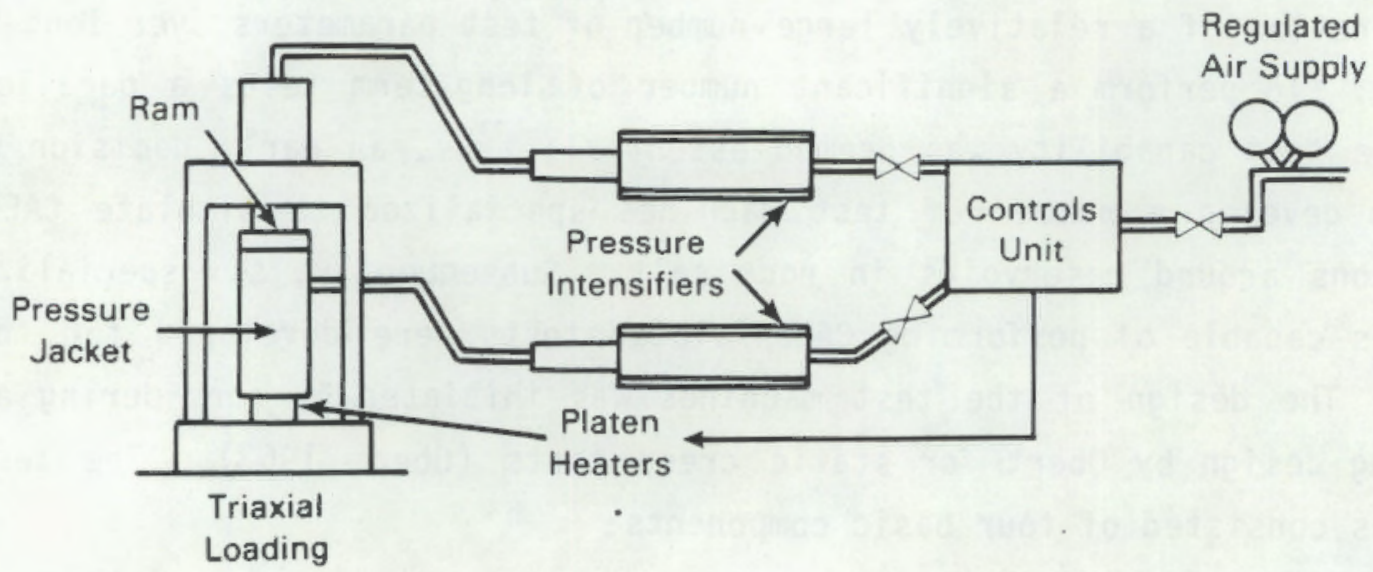

FIGURE 3.5. Schematic of Long-Term Cyclic Test Units 


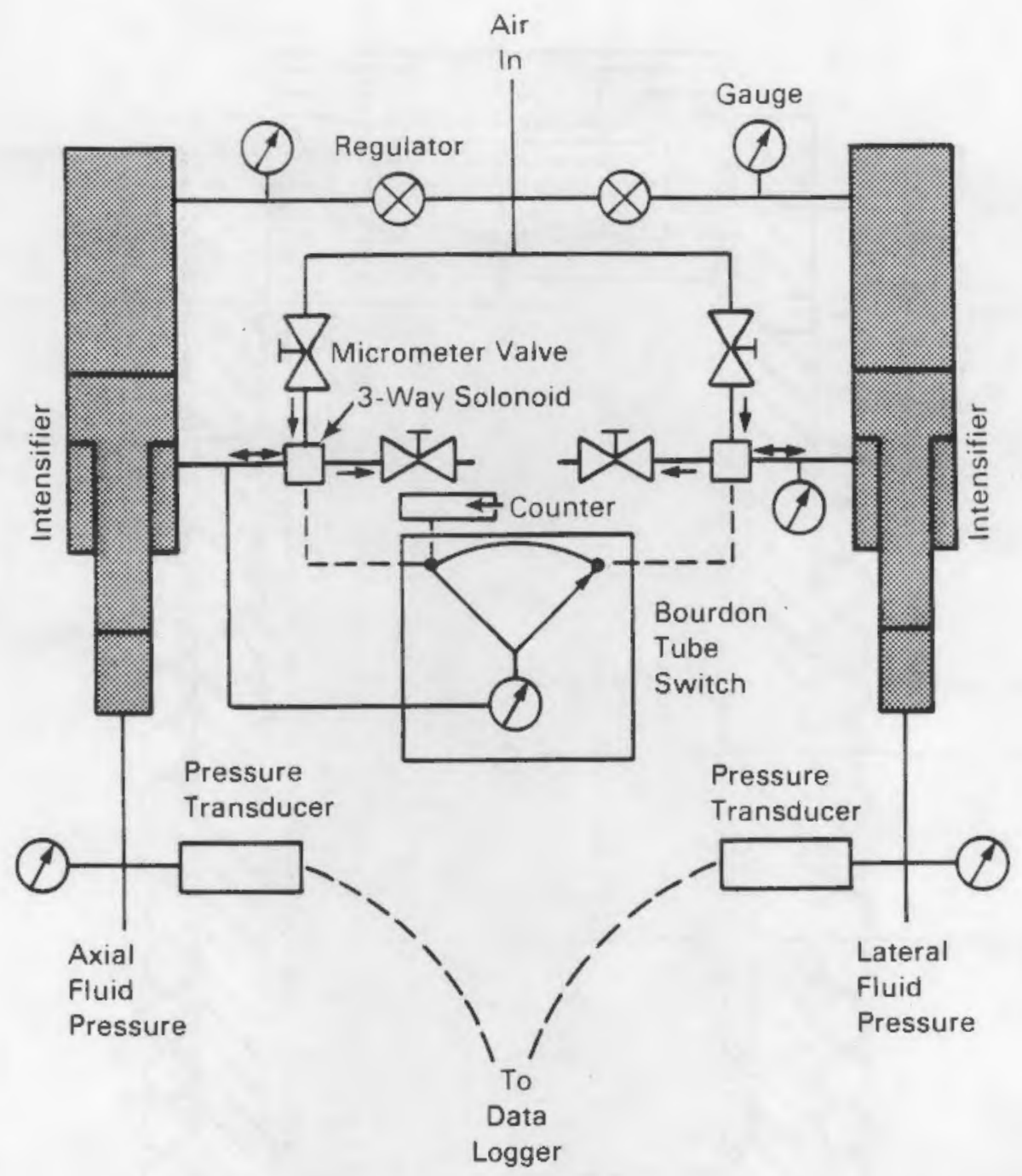

FIGURE 3.6. Control Components Schematic

transducers and precision gauge heads, respectively, and were recorded periodically on paper tape with a data logger. Temperatures were monitored by thermal sensors attached to the specimens and pressure jackets. Values were recorded on the data logger simultaneously with pressure and displacement values. Figures 3.8 and 3.9 show laboratory equipment used for the CAES study and a close-up of a test unit.

Acoustic emissions were monitored at random intervals on salt specimens, but were found to be most significant when failure by fracture was imminent. 


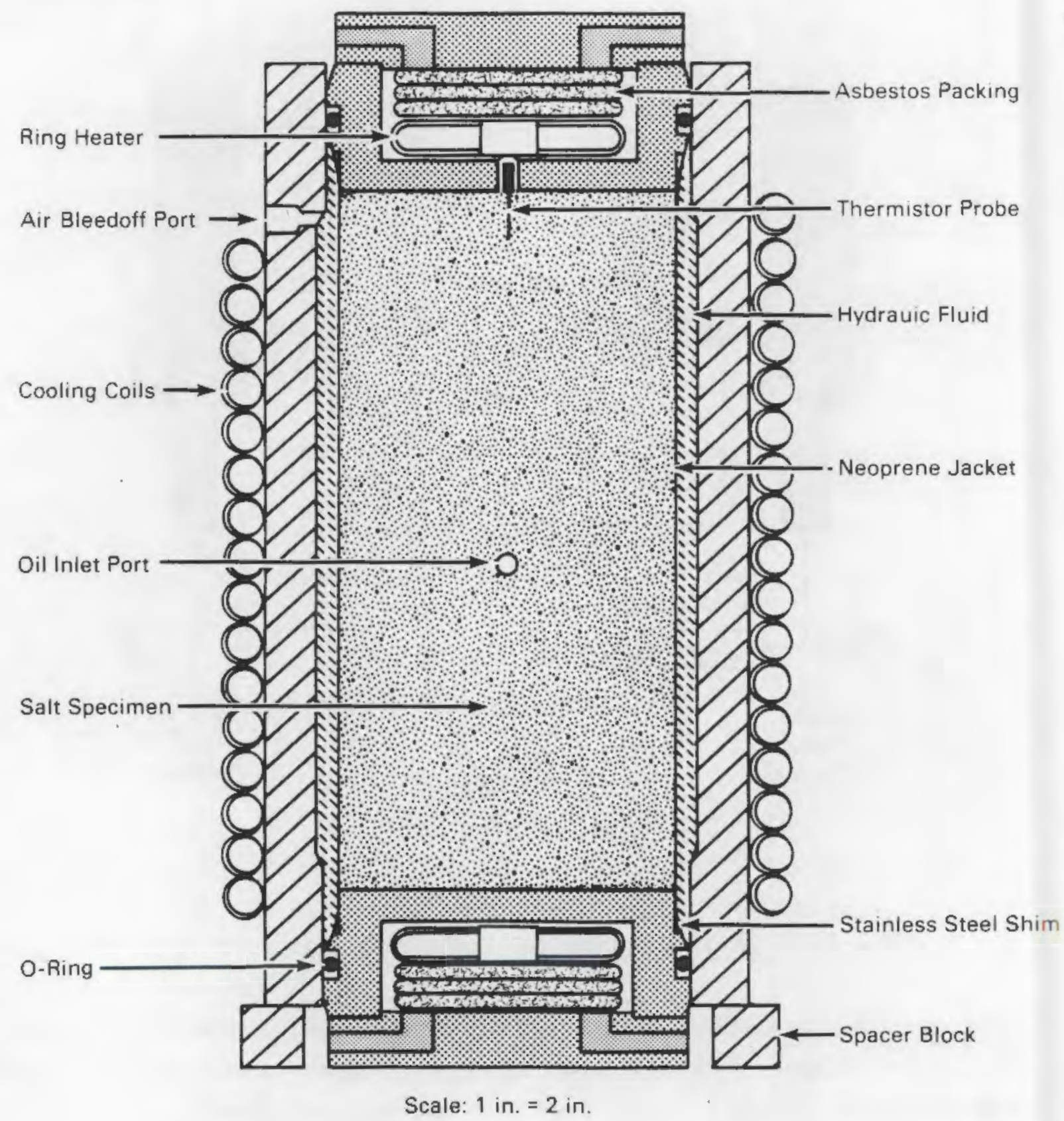

FIGURE 3.7. Pressure Jacket and Platens for Triaxial Specimens 


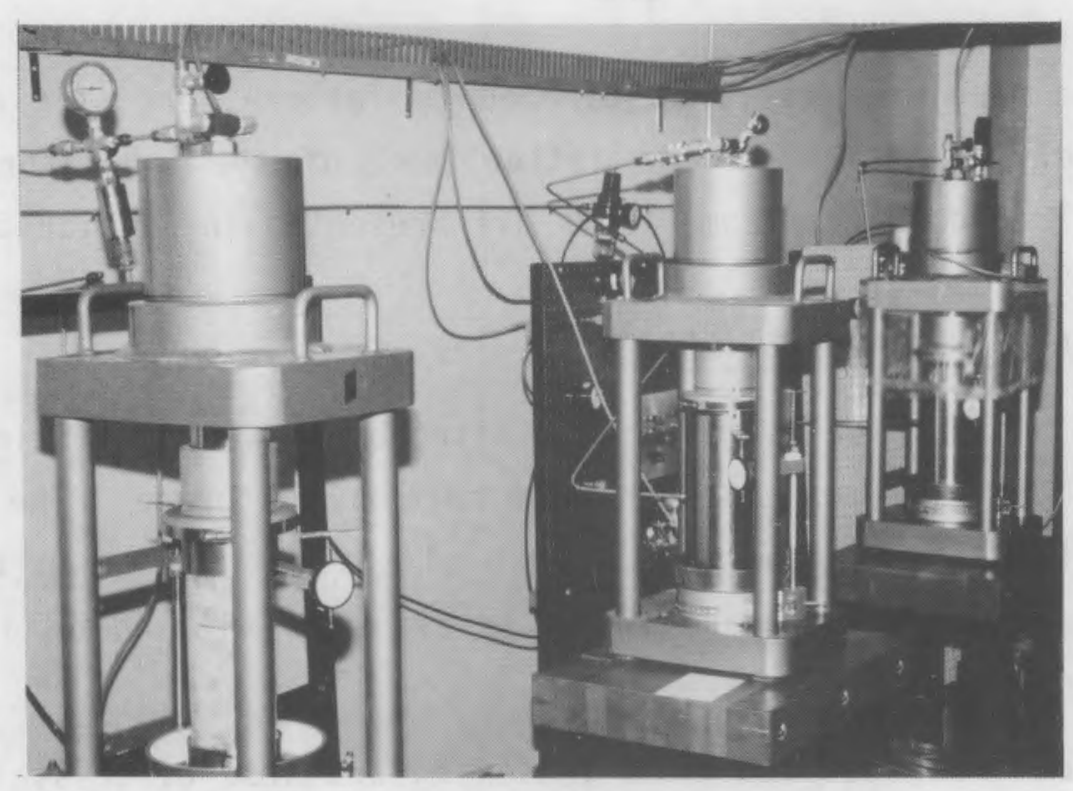

FIGURE 3.8. Test Units in CAES Laboratory

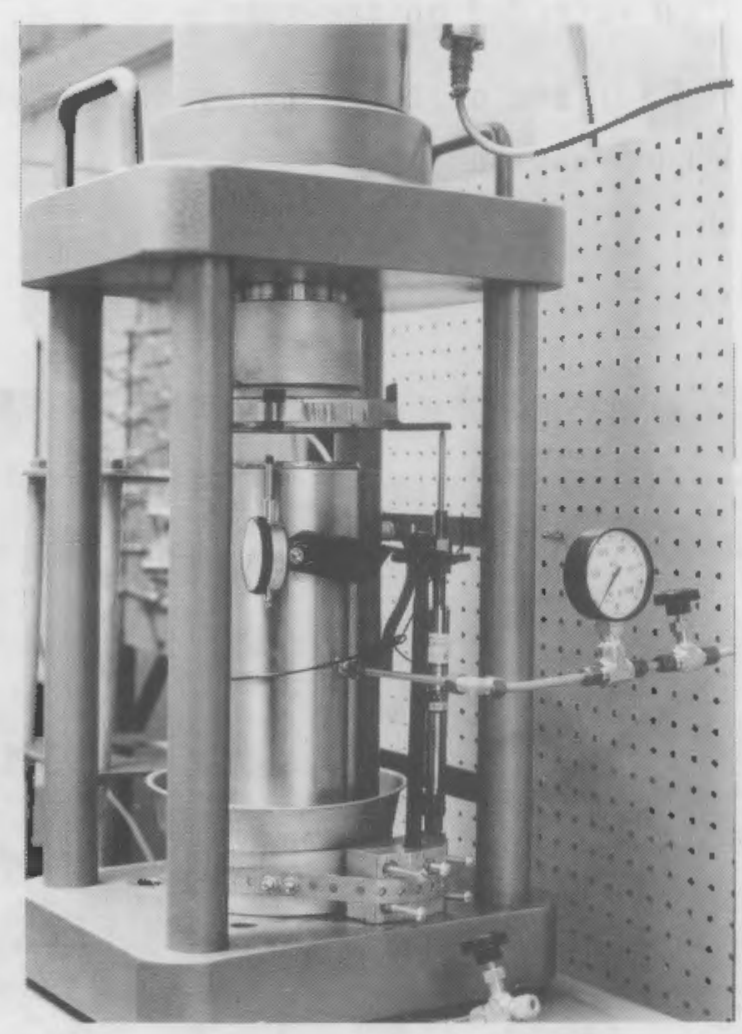

FIGURE 3.9. Triaxial Test Setup 
Since many of the specimens were not carried to failure, acoustic emissions were not routinely monitored in the latter part of the laboratory test program. Typical $A E$ data from some tests are presented in Section 3.5 .

\subsection{SAMPLE PREPARATION AND TEST PROCEDURE}

Preparation of a typical sample for testing began with the selection and retrieval of a 4 -in. $(10-\mathrm{cm})$ diameter salt core from storage. The selected core was then cut on the bandsaw to a length slightly larger than twice its diameter and its ends made square with its axis by trimming on a lathe (Figures 3.10 and Figure 3.11 ).

Trimming sometimes resulted in a loosening and loss of crystals at the sample ends. When this occurred, the loose crystals were removed and the sample ends rebuilt with epoxy; the repaired ends were then retrimmed. Origin and sample length were then recorded on the sample.

A sample was destined for one of three types of tests:

- unconfined uniaxial compression

- triaxial compression

- triaxial extension.

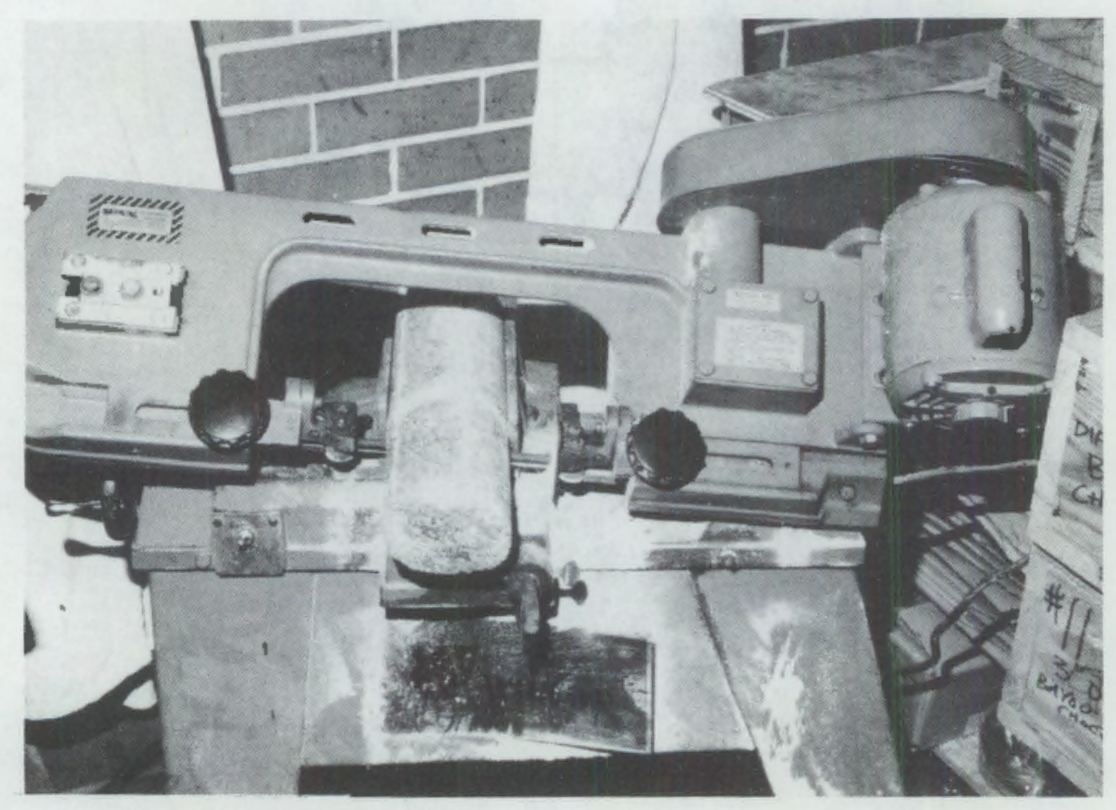

FIGURE 3.10. Cutting Test Specimen from Core 


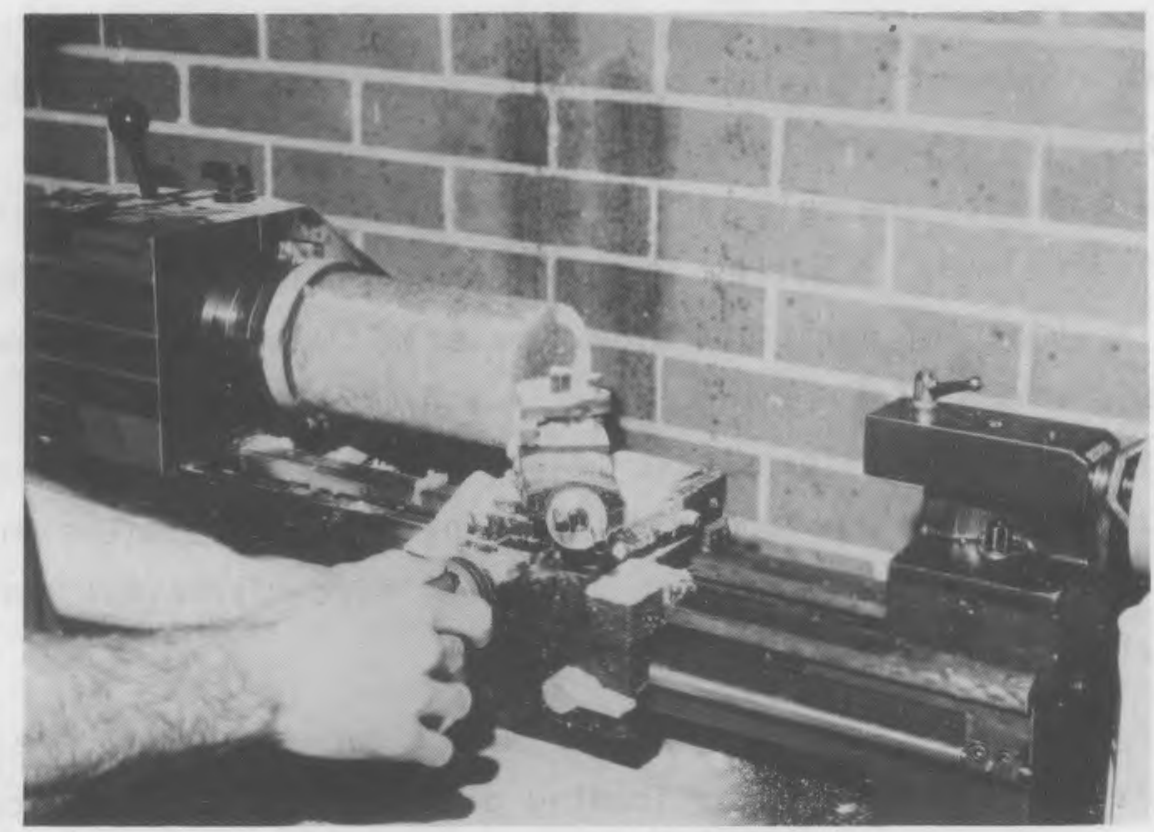

FIGURE 3.11. Trimming Specimen on Lathe

For uniaxial compression tests no further sample preparation was necessary and the sample was set aside for the later addition of platens and heaters and loading into a test frame. Samples to undergo triaxial testing required additional preparation to allow the application of differential axial and lateral pressures.

The difference between a sample set up for triaxial extension testing and one set up for triaxial compression testing was in the construction and installation of the loading platens. The construction of the platens for both tests was the same except for the addition of a tubular piece to the extension platens. This tube slipped over the end of the sample to protect the salt/ platen interface from penetration caused by a higher lateral than axial pressure. An early persistent problem in triaxial extension testing was the separation of the sample and platen during testing, causing test conditions to become hydrostatic. Addition of the tubular piece did not eliminate the problem but did reduce its frequency. Installation of the modified platens sometimes required a slightly reduced diameter at the sample ends. This was accomplished by lateral trimming on the lathe. 
For both types of triaxial testing the sample was installed within a pressure cell for the application of lateral and axial loads. Before sample placement into the cell, a 1/16-in. $(0.16-\mathrm{cm})$ thick neoprene sleeve was pulled over the sample to jacket it. A light coating of grease usually aided this task. A number of different sleeve materials were tried. They included latex rubber, heat-shrink tubing, butyl rubber and neoprene. Neoprene was found most satisfactory. The sleeve length before being pulled over the salt was adequate to accommodate the combined length of the platens and sample, taking into account axial shortening caused by circumferential stretching of the sleeve around the sample.

Once in place, the sleeve ends were rolled back to expose the salt stock and allow the positioning of the loading platens. For triaxial compression tests, the salt/platen interface was taped with strapping tape; for triaxial extension tests, the end of the tubular platen piece was overlapped with strapping tape. The sleeve was then rolled up around the platens and taped in place, again using strapping tape. This final taping was done primarily to prevent movement of the jacket during installation into the pressure cell.

The platens were outfitted with lubricated 0-rings in glands provided and the jacketed sample inserted into a pressure cell, as depicted in Figure 3.7 . Origin and sample length information was attached to the pressure cell for identification and the assemblage set aside for placement into a loading frame. On all tests, final preparation before loading included the addition of heating elements and asbestos insulation into cavities in the loading platens.

The 8 -in. long prepared sample with upper and lower load/heating platens in place was installed between the loading platens of a test frame. The loading ram was then lowered to seat the sample; installation and preliminary adjustments of monitoring devices were performed.

For temperature monitoring, a resistance temperature detector (RTD) unit was adhered directly to the salt at sample midheight in unconfined uniaxial tests, and to the outside of the pressure cell in triaxial tests. Axial 
displacement of the sample was detected using both a dial indicator for visual monitoring and a linear variable differential transformer (LVDT) transducer for automated data collection. Displacement was measured as the movement of the upper test frame loading platen. Applied pressure (axial and lateral) were obtained using both sight gauges and pressure transducers. A multichannel, printing data logger recorded data from the RTD, LVDT, and pressure transducers, as well as time, for later analysis.

For some tests, acoustic emissions were monitored. An acoustic pickup was glued directly to the salt at midheight for unconfined tests; and for triaxial tests the pickup was attached to the upper test frame loading platen.

The test loads were slowly applied. No exact data on loading rate was collected; but, for tests where acoustic emissions were being monitored, the loading rates were adjusted to maintain a reduced level of acoustic activity.

For unconfined uniaxial compression tests, the axial pressure was increased to test magnitude. For triaxial compression tests, the void between the pressure jacket interior and the salt sample was filled with oil and the axial and lateral pressures increased to test magnitude, with the axial pressure always leading lateral pressure. For triaxial extension tests, the void between the pressure jacket interior and the salt sample was filled with 011 and the axial and lateral pressures increased to maintain hydrostatic load conditions up to the magnitude of the lateral test pressure. After a few hours, the axial pressure was slowly decreased to triaxial extension test magnitude.

A load intensifier was used to obtain the test loading pressures. As a sample deformed, $0 i 1$ used in the load intensifier was displaced. This required a periodic refilling or draining, as the intensifier's upper or lower displacement limit was approached. Refilling was typically performed by isolating the test sample at whatever load it was presently under and using a hand pump to replenish the intensifier oil supply. Draining was performed in the same fashion, using the empty oil reservoir of the hand pump to collect the excess oil. Pressure was equalized between the sample and the intensifier and the sample reintroduced to the load maintainance of the intensifier. 
Testing of completed samples was performed using Table 3.1 as a guide for application of load magnitudes and using the apparatus described previously in Section 3.3.

\subsection{LONG-TERM TEST DATA ANALYSES}

A major consideration for CAES in rock salt is the effect of long-term cyclic loads on creep closure of caverns. If closure of the caverns is accelerated to rates that project unacceptable volume loss in reservoirs, the caverns are unstable for CAES purposes.

As noted previously, significant static creep test data are available in the literature. Much of this was generated by programs in the U.S. and the Federal Republic of Germany for the disposal/storage of radioactive wastes in rock salt. The Strategic Petroleum Reserve of the U.S. DOE also has been the source of information on oil storage caverns in Gulf Coast salt domes. Such data form an extensive base for estimating Tong-term creep behavior of salt from different sources under cyclic loads, provided a correlation exists between static-load creep and cyclic-load creep for CAES loading environments. Accordingly, tests were carried out to determine the correlation between static and CAES cyclic load effects.

Figure 3.12 is a schematic of salt specimen displacement versus time for a typical laboratory test. A measure of cyclic load relative influence on salt response is indicated by the ratios:

$$
C D=\frac{(D C-D S)}{D S} \times 100=\frac{\Delta D}{D S} \times 100
$$

and

$$
C R=\frac{R C}{R S}
$$

$C D$ represents the percentage of transient offset displacement, from the extrapolated static displacement, associated with initiation of cyclic loading. DS, DC, RS, and RC are best explained in Figure 3.12. Times TS and TC, whence displacements DS are referenced, correspond to 4 days ( $96 \mathrm{hr}$ ) after 


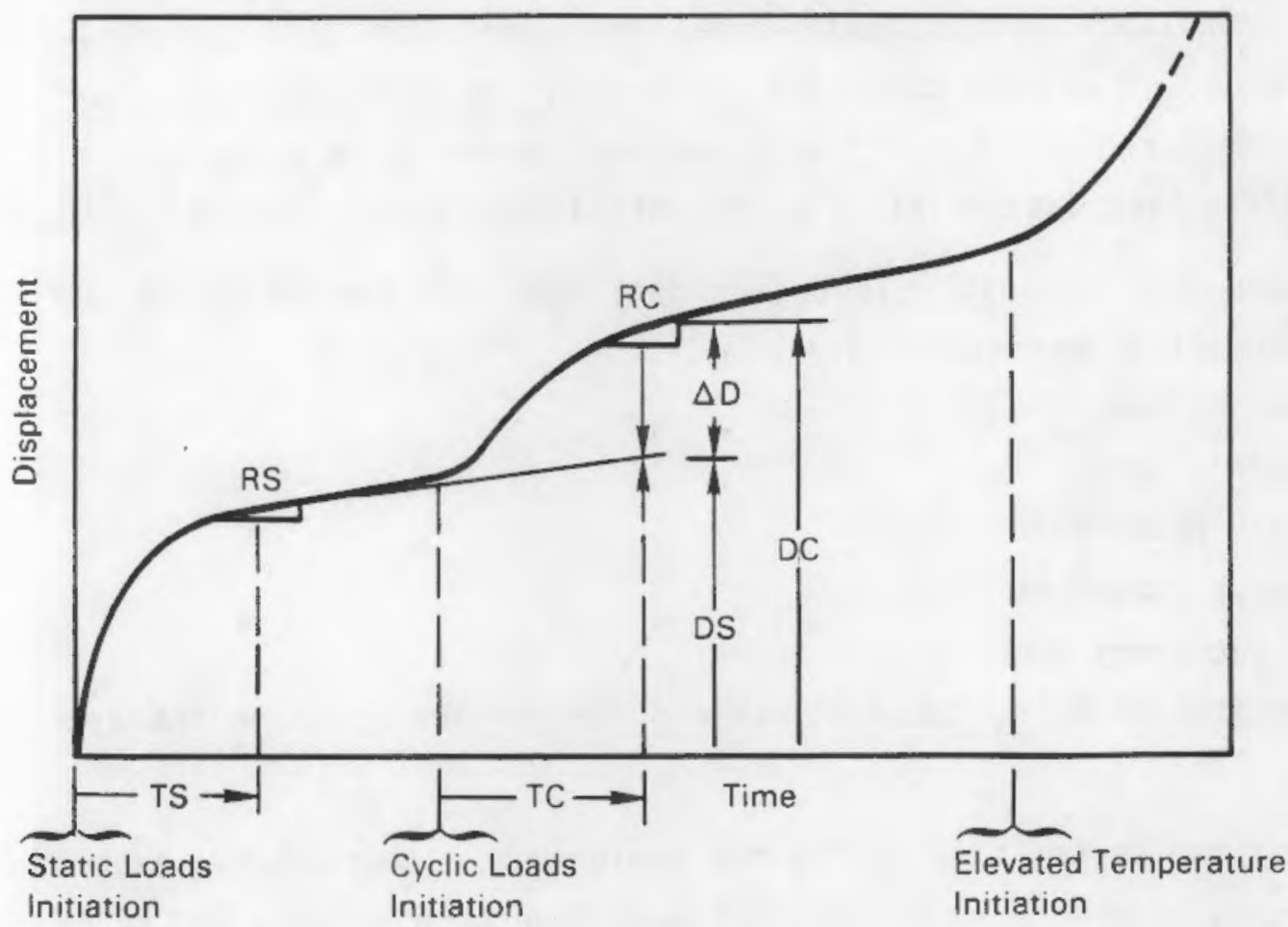

FIGURE 3.12. Typical Static-Cyclic Creep of Salt Specimen

initiation of static and cyclic loads, respectively. From laboratory tests, a significant portion of transient salt creep appeared to have occurred within around 4 days $(96 \mathrm{hr}$ ) after load application; thus, the selection of $96 \mathrm{hr}$ for reference time.

CR represents the ratio of cyclic creep rate to static creep rate for the specimen. For long-term projections of CAES cavern closure, this ratio is the more significant. However, the estimate also is more tentative because it is based on tests that are relatively short-term compared to CAES operations ranging into decades.

The laboratory test data obtained using the previously described test units and procedures were analyzed by using the concepts outlined here. Many of the specimens were not carried to failure in the classic geotechnical sense of displaying loss of load-carrying capacity. However, rock salt seldom fails in this sense, but rather by exhibiting creep closure rates that implicitly 
impose unacceptable limits, with time, on amounts of usable underground storage space. Thus, the concept of analyzing the effects of long-term cyclic loads, as compared to static loads, was considered to be a rational approach for analyzing test data relative to potential CAES cavern design applications.

Figures 3.13 through 3.18 depict data obtained from tests on salt from U.S. Gulf Coast domes including:

- Vacherie dome

- Rayburn's dome

- Bryan's Mound dome

- Bayou Choctaw dome

- West Hackberry dome.

Loads were imposed using Table 3.1 as a guide and are noted in the associated figures.

All of the tests indicated in the table were attempted for each of the salt sources; however, data reported here have been reduced and screened in the data interpretation phase of the study. The presented figures represent those tests judged sufficiently complete to yield significant findings. However, a classic dilemma of testing was apparent from the data screening process. Only the more rugged specimens survived the collection, specimen preparation, and testing processes to yield significant findings. Thus, a specimen bias was implicitly introduced in the laboratory phase. Screening of specimens and test data increased with degree of test complexity. For example, triaxial extension tests were considerably more difficult to perform than more traditional triaxial compression tests, particularly so for the cyclic phase. Early failure of triaxial extension tests was not uncommon; however, many times failures could not be assigned a primary mode, e.g., specimen separation or jacket penetration by confining oil. In summary, the presented data represent the distilled results of a significantly larger number of tests than indicated for the laboratory phase of this study. Data associated with weaker specimens do not appear. Similar situations have been confronted by other investigators in rock mechanics laboratory tests. 


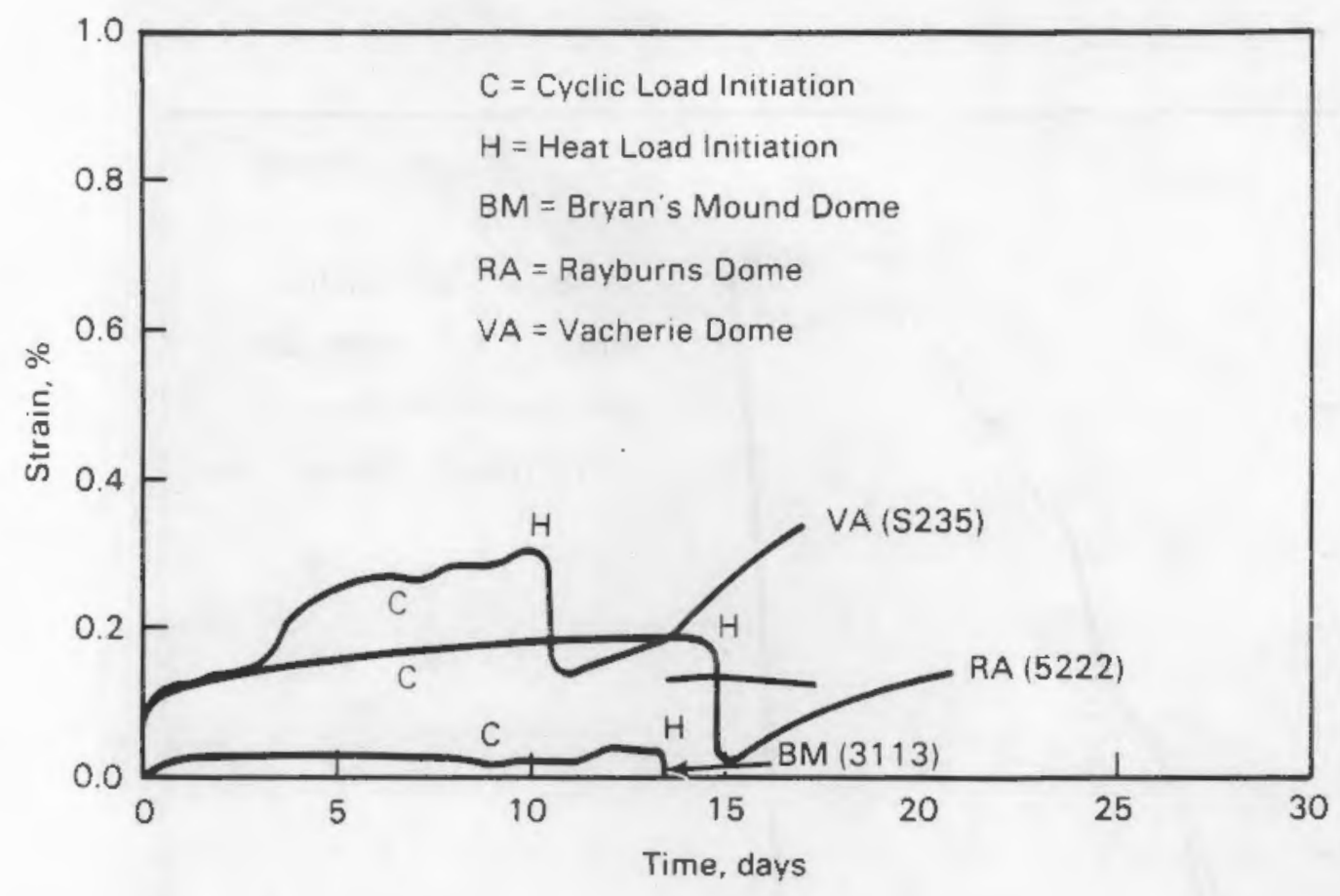

FIGURE 3.13. Test Data - Long-Term Cyclic Creep Curves, Uniaxial Compression, 1000 psi $(6.9 \mathrm{MPa})$

Another major effect on the laboratory test phase was associated with test specimen history. Rock salt tends to disaggregate more readily than many other rock types when subjected to impact loads and elevated humidity environments. Effects of cyclic daily temperature ranges are not well understood. Most specimens tested for this program were obtained from the DOE Strategic Petroleum Reserve Program for which controlled environments were not considered necessary for salt core storage. Handling of cores to avoid impact loads is essential to avoid altering rock salt character. From personal observation, salt cores could have been dropped and/or vibrated during recovery and transport, possibly altering the character of associated laboratory test specimens. Thus, a significant degree of uncertainty was introduced by the handling history of most salt cores prior to subsequent specimen preparation for laboratory tests. However, recovery of salt cores represents a considerable resource investment, and this study could not have been performed without the use of cores generously made available through other programs. 


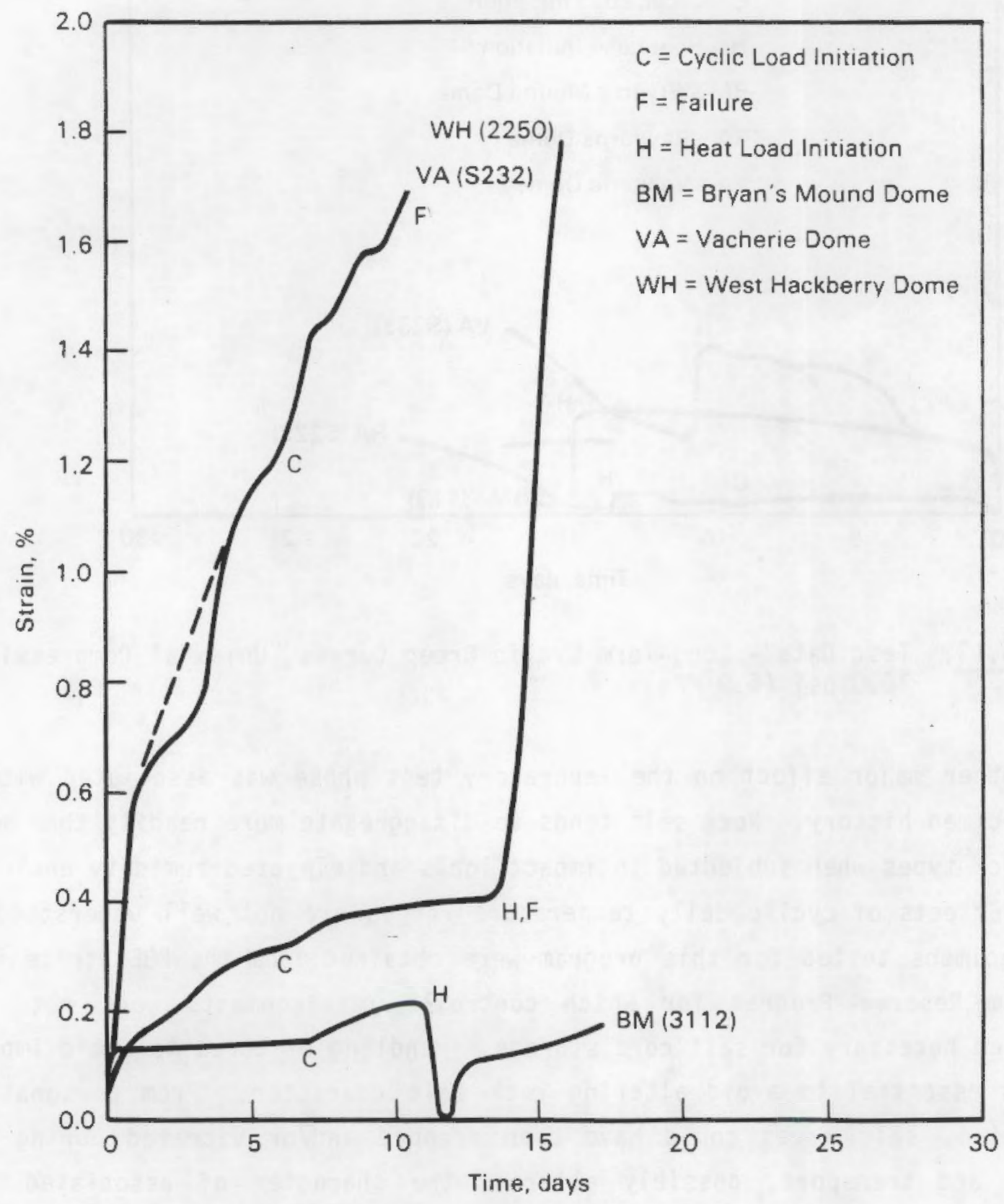

FIGURE 3.14. Test Data - Long-Term Cyclic Creep Curves, Uniaxial Compression, 2000 psi (13.8 MPa) 


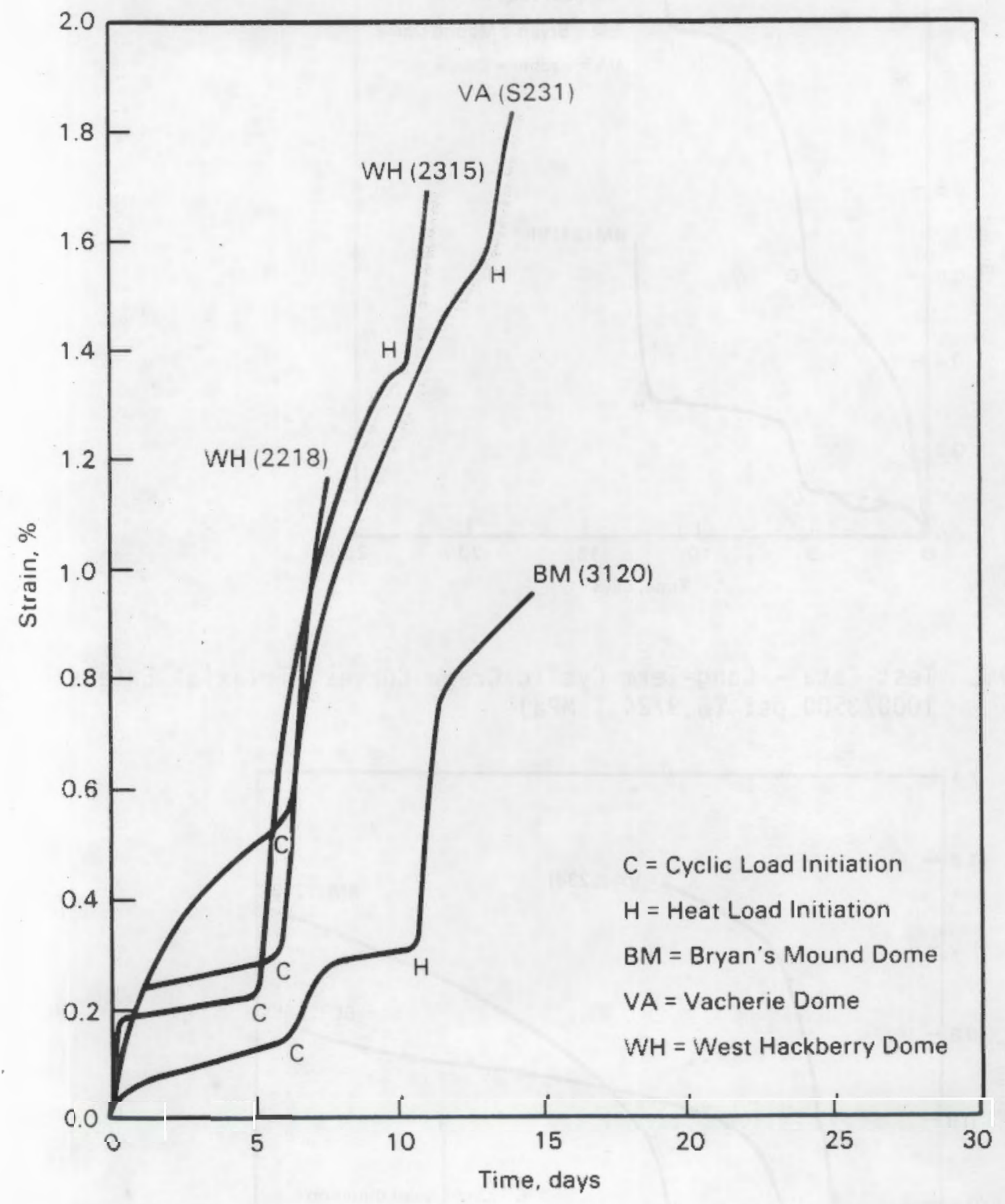

FIGURE 3.15. Test Data - Long-Term Cyclic Creep Curves, Triaxial Extension $750 / 2500$ psi $(5.2 / 17.2 \mathrm{MPa})$ 


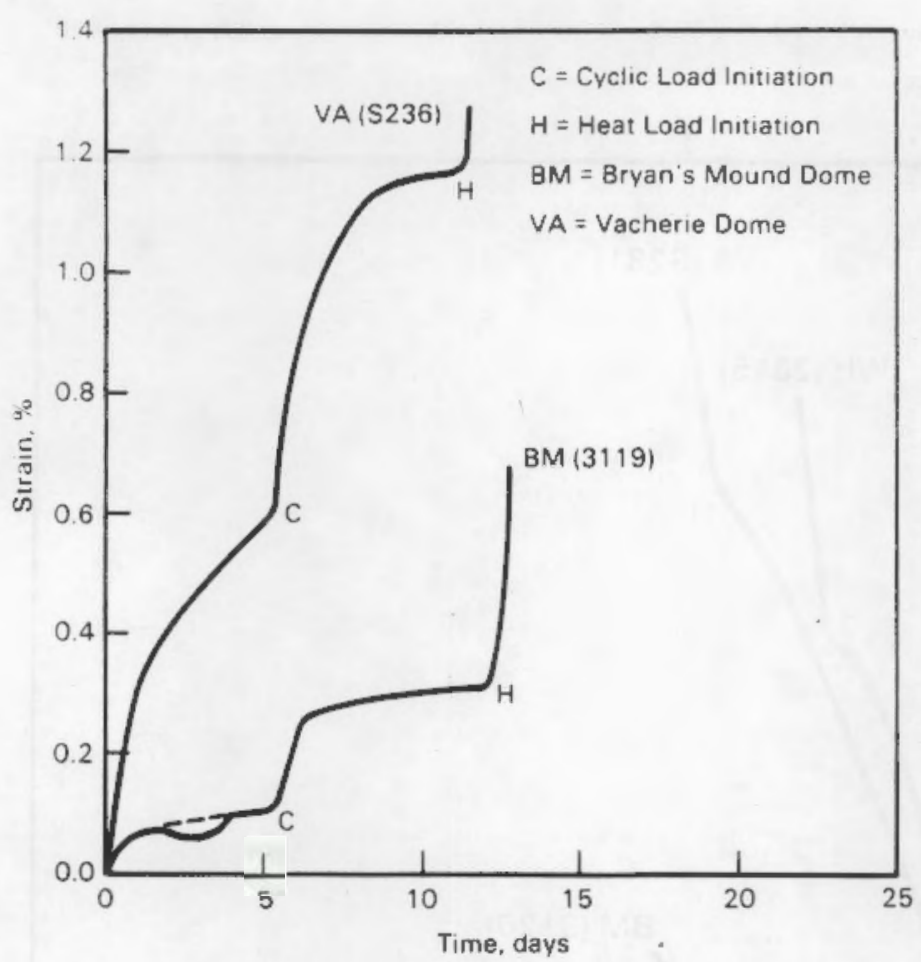

FIGURE 3.16. Test Data - Long-Term Cyclic Creep Curves, Triaxial Extension, $1000 / 3500$ psi $(6.9 / 24.1 \mathrm{MPa})$

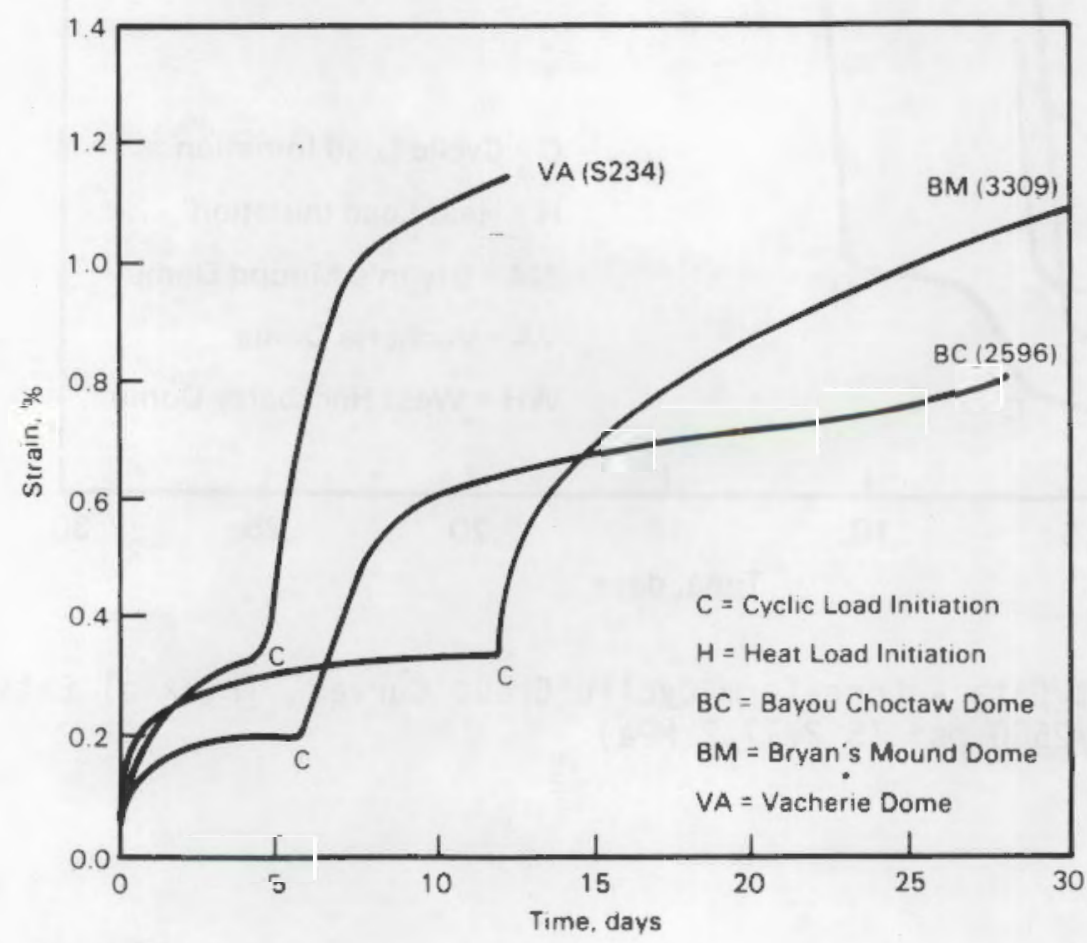

FIGURE 3.17. Test Data - Long-Term Cylic Creep Curves, Triaxial Compression, $1500 / 500$ psi $(10.3 / 3.5 \mathrm{MPa})$ 


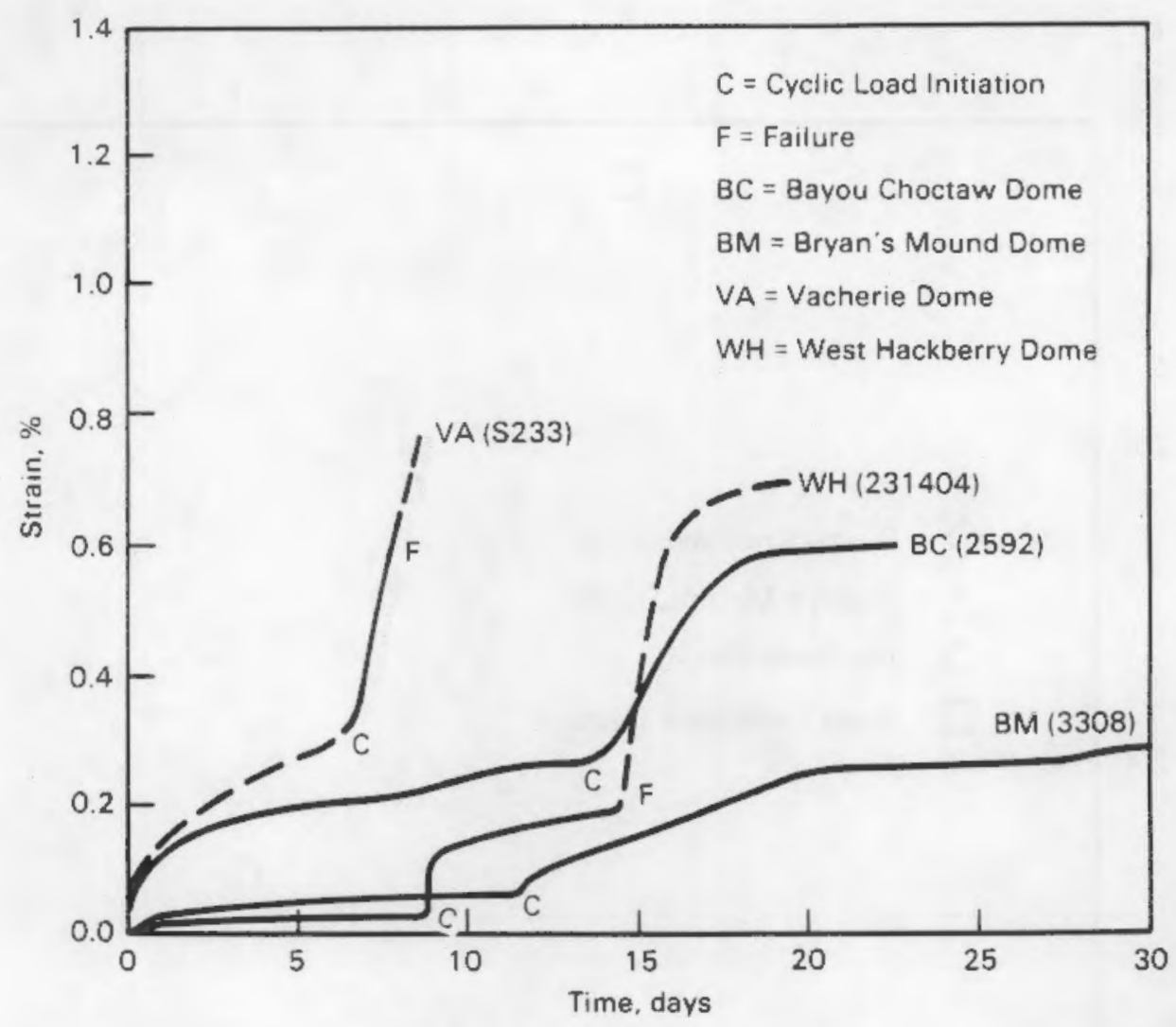

FIGURE 3.18. Test Data - Long-Term Cyclic Creep Curves, Triaxial Compression, $3500 / 1500$ psi $(24.1 / 10.3 \mathrm{MPa})$

Figures 3.19 and 3.20 summarize cyclic effects results obtained from the laboratory test data and application of the interpretations indicated by Figure 3.12 and Eqs. 3.1 and 3.2. Considerable data scatter is evident in Figures 3.19 and 3.20 ; nonetheless, certain observations can be noted:

- Similar trends of increased short-term displacements and creep rates occur due to cyclic load effects, as indicated by the parameters CD and CR, respectively.

- Cyclic load effects appeared to be almost insignificant for uniaxial load conditions and most pronounced for triaxial compression load conditions.

The fact that cyclic loads affect triaxial testing more than uniaxial testing was the most surprising result of the laboratory test phase of this study. 


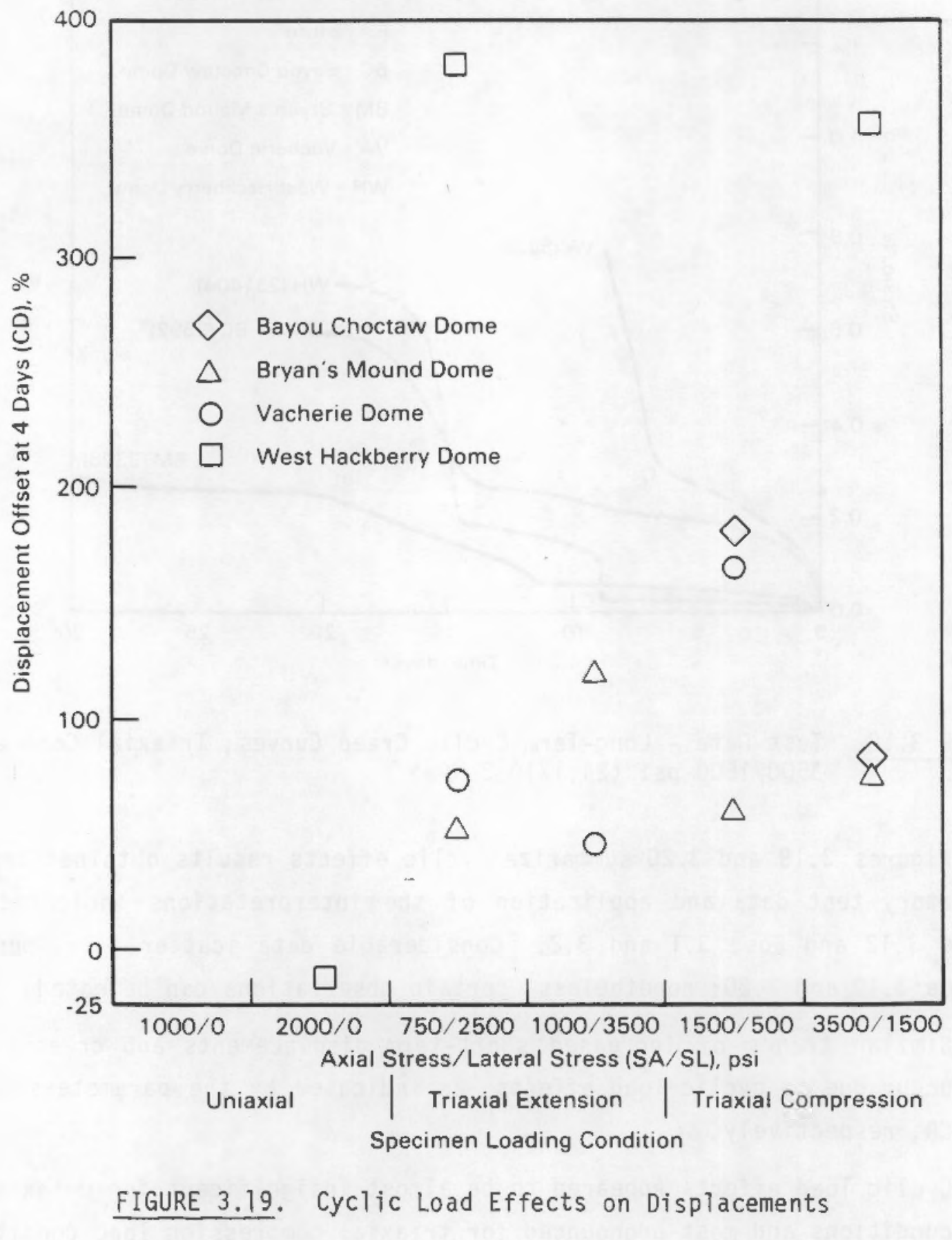




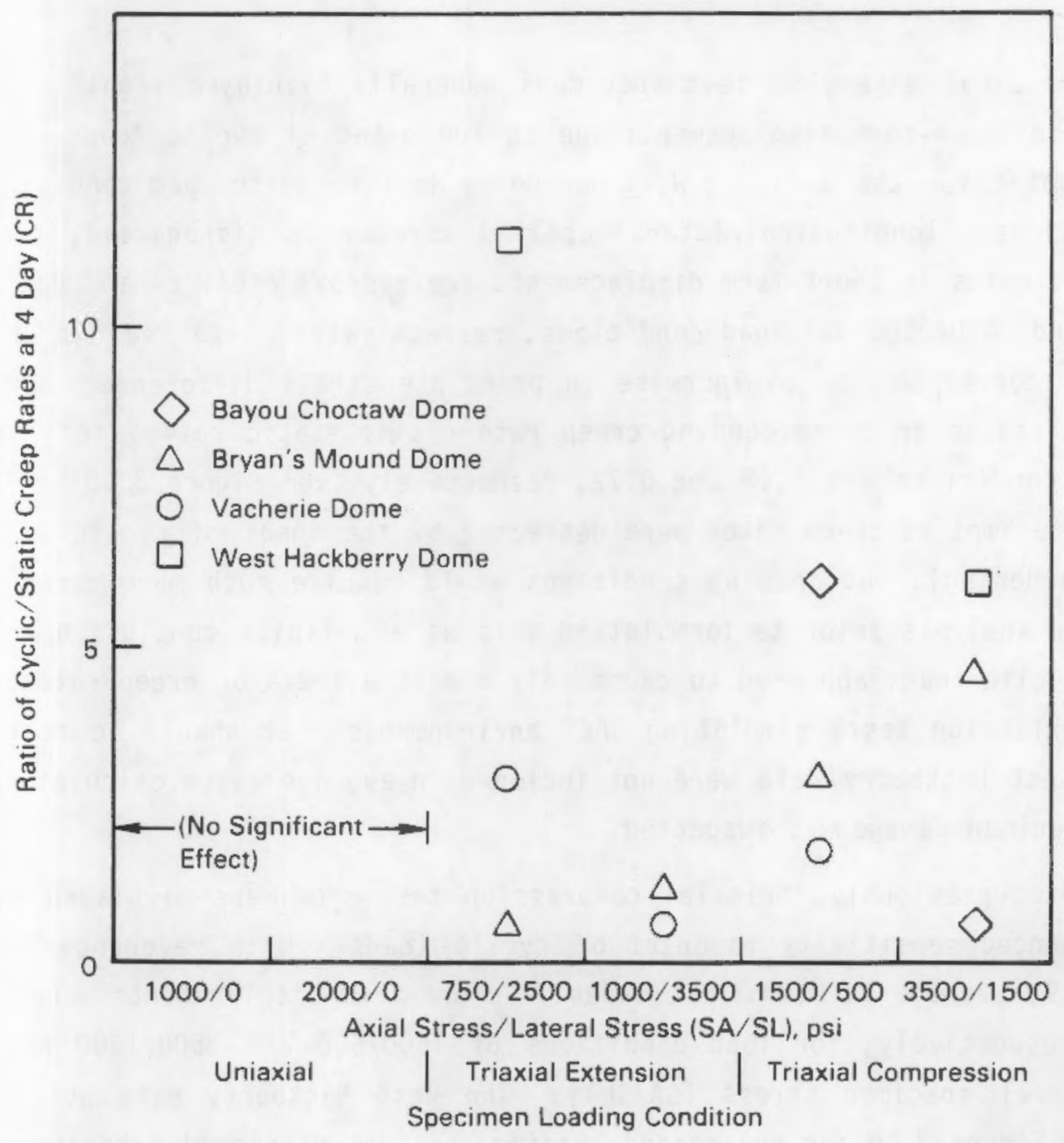

FIGURE 3.20. Cyclic Load Effects on Creep Rates

The uniaxial specimens were essentially unaffected by cyclic loads relative to increased short-term displacements or creep rates. The decrease in displacement indicated for the West Hackberry dome uniaxial specimen in Figure 3.19 probably was due to application of a smaller mean axial load value during the cyclic phase relative to the value of axial load applied during the preceding static phase. 
The triaxial extension test specimens generally displayed significant increases in short-term displacements due to the onset of cyclic loads. If the data point for the outlying West Hackberry specimen with load conditions of $750 / 2500$ psi (Tongitudinal/lateral applied stress) is disregarded, the average increases in short-term displacements are approximately 64 and $83 \%$ for $750 / 2500$ and $1000 / 3500$ psi load conditions, respectively. Note the two load conditions correspond to an increase in principle stress difference. The average increases in corresponding creep rate cyclic/static ratios for the same load conditions are 1.68 and 0.72 , respectively (see Figure 3.20 ). The latter value implies creep rates were decreased by the onset of cyclic loads (strain hardening), but loading conditions would require much more careful control and analysis prior to formulating this as a definite conclusion. In general, cyclic loads appeared to cause only modest effects on creep rates for triaxial extension tests simulating CAES environments. It should be noted that the West Hackberry data were not included in average value calculations because specimen damage was suspected.

As noted previously, triaxial compression test specimens displayed the most pronounced sensitivity to onset of cyclic loads. With reference to Figure 3.19 , average values of increases in short-term displacements were 136 and $78 \%$, respectively, for 10 ad conditions of $1500 / 500$ and $3500 / 1500$ psi [axial/lateral specimen stress (SA/SL)]. The West Hackberry data point evident in Figure 3.19 for the second loading case was disregarded because of its extreme value.

Creep rate values increased with the onset of cyclic loads for triaxial compression specimens, as indicated in figure 3.20. Average values of cyclic/static creep ratios were 3.6 and 3.7 , respectively, for load conditions of $1500 / 500$ and $3500 / 500$ psi SA/SL. Note the West Hackberry specimen was taken into account in calculating average creep rate values for the latter loading case because its creep behavior appeared in agreement with specimens from Bryan's Mound and Bayou Choctaw. Thus, the large increase in short-term displacements with cyclic loads for this specimen appeared due to a transient close packing of previously loosened crystals under relatively large confining 
pressures. This would be consistent with the previously stated premise that specimen history has a major impact on subsequent behavior under laboratory test conditions.

In summary, cyclic load effects on laboratory specimens generally produced increases in short-term displacements and creep rates. Of these two behavior characteristics, the creep rate is more significant for long-term stability considerations for CAES cavern reservoirs. Furthermore, the increase in short-term displacements observed in laboratory test specimens with the onset of cyclic loads may be due largely to a transient repacking of rock salt crystals. Increased creep rates due to the onset of cyclic loads still appear to be of acceptable magnitudes for long-term CAES reservoir stability considerations. That is, for a cavern designed conservatively for static loads, the effect on creep closure due to relatively small-amplitude cyclic loads with mean values approximately equal to the static load values probably would be insignificant.

As noted previously, a number of uncertainties (main?y in specimen collection) were apparent in the laboratory testing phase of this study. Therefore, the authors strongly recommend that site-specific field tests be performed prior to final CAES cavern design in any salt formation. Section 7 includes a description of a field test proposed for site suitability studies for CAES caverns. In the authors' opinion, predictions of cavern performance based on field test data would enjoy considerably more confidence than predictions based on laboratory test data and numerical modeling alone. 



\subsection{IN SITU PRESSURE TESTS IN SALT MINES}

\subsection{METHODOLOGY OF IN SITU TESTING}

In situ testing was essential to this study to correlate laboratory test results to field conditions. One must understand the relationship between sample and in situ response to determine mass rock salt behavior from laboratory tests. Thus, the decision was made at the outset to pressure test salt surrounding test holes in salt mines that were accessible in southernLouisiana.

Tests on salt surrounding boreholes have the following advantages:

- A relatively large volume of material is tested, reducing possible scale effects.

- Rock salt around boreholes is relatively undisturbed and continuously confined, unlike extracted cores.

- Temperature and surface humidity are essentially constant around boreholes that are sealed until tests are initiated.

The main disadvantage of in situ tests on salt is the uncertainty in measuring the initial stress field. General agreement does not exist at this time as to the best method for determining in situ stress states in rock salt because of its nonlinear, time-dependent behavior. Methods currently are being developed to determine initial stress states in salt, mainly through the radioactive waste storage/disposal programs in both the U.S. and West Germany.

The general plan for in situ testing was to drill 4 to 12 test holes in salt mines, and then to perform both static and cyclic air pressurization tests on the holes, while monitoring diametrical hole displacement and acoustic emissions. Permeability tests in and between (crosshole) boreholes also were planned. As the program progressed, significant modifications to the test were developed and implemented, both to recognize and take advantage of existing conditions at the underground test sites. For example, high-pressure $0 i 1$ pressurization tests of boreholes (until hydrofracture) were incorporated 
in the later stages of the in situ work. More detail on such development is presented in Section 4.2 .

\subsection{TEST SITE DEVELOPMENT}

The first in situ test site consisted of a group of five vertical, 4-in. $(100-\mathrm{mm})$ diameter holes drilled into the floor of the Jefferson Island (JI) salt mine at the $1300-\mathrm{ft}$ level. The site was covered with a portable shed approximately $12 \mathrm{ft} \times 30 \mathrm{ft}(3.7 \mathrm{~m} \times 9.1 \mathrm{~m})$ in dimension. The shed was transported underground and assembled by LSU personne1. Diesel fuel was used as a drilling fluid for the holes to avoid glazing the salt surface and thereby reducing its apparent permeability (Aufricht and Howard 1961) (see Figure 4.1).

One of the main objectives of performing tests in the mine was to obtain data on essentially undisturbed rock salt. However, after some time it became evident that the exposed floor of the JI mine was disturbed in the near field by extensional strains typical of underground rock openings. In this case, the salt floor deformed vertically into the room, leaving horizontal partings

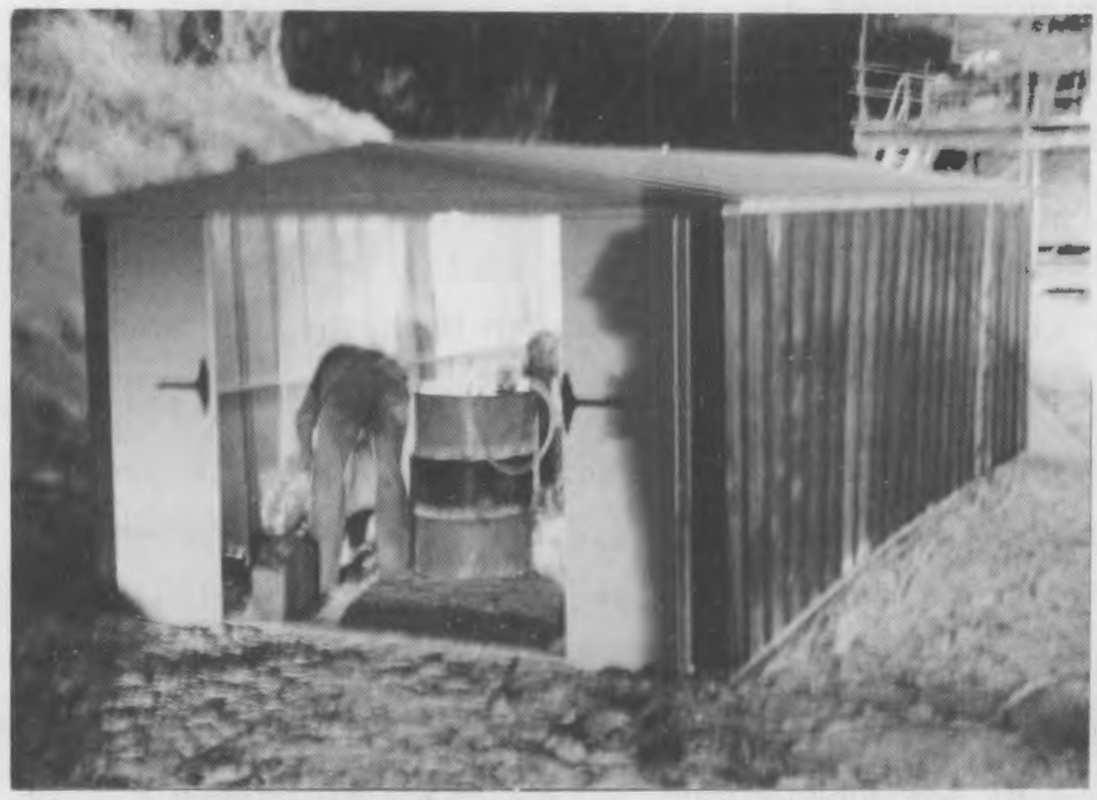

FIGURE 4.1. Shed at First Test Site in Jefferson Is land Salt Mine 
of fractions of an inch within the first few feet of rock. A very preliminary low pressurization test was performed on one hole within the shed before the possible presence of partings was recognized. The site was abandoned for safety reasons when the partings were discovered, as high-pressure air could have intercepted a parting and caused an explosive upheaval of salt. This site abandonment was subsequently justified when a horizontal parting was later encountered within $20 \mathrm{ft}(6.1 \mathrm{~m})$ of the shed site during the core drilling.

Testing of horizontal holes into pillars or abutment zones also was considered. However, the unconfined salt near the surface of pillars tends to disaggregate more readily and large extensional strains can result in surface cracking and spalling or formation of scales. Further, significant amounts of permeability frequently are induced in the few tens of feet of pillar surface. Blasting with explosives during conventional mining also could contribute to loosening of the salt fabric in pillar surfaces and in the roof. However, mining faces typically are undercut prior to blasting, uncoupling the salt in the floor from dynamic stress wave effects.

Salt beneath a mine pillar was concluded to be the most appropriate for CAES testing because of

- continuous confinement

- relatively large overburden stress field transmitted through the pillar

- uncoupling of salt by undercutting from blast effects

- ready access from mine rooms.

Therefore, the CAES in situ testing was moved to a second site in the JI mine, as illustrated in Figure 4.2 .

The main disadvantage of the second site was diminished safety due to proximity to a pillar face. Scales develop with time at pillar-roof junctions in salt mines, which can pose rock-fall hazards to personnel and equipment. Precautions, such as scaling and installing safety netting at test sites prior to emplacement of test equipment, are prudent in mines where scales may develop. 


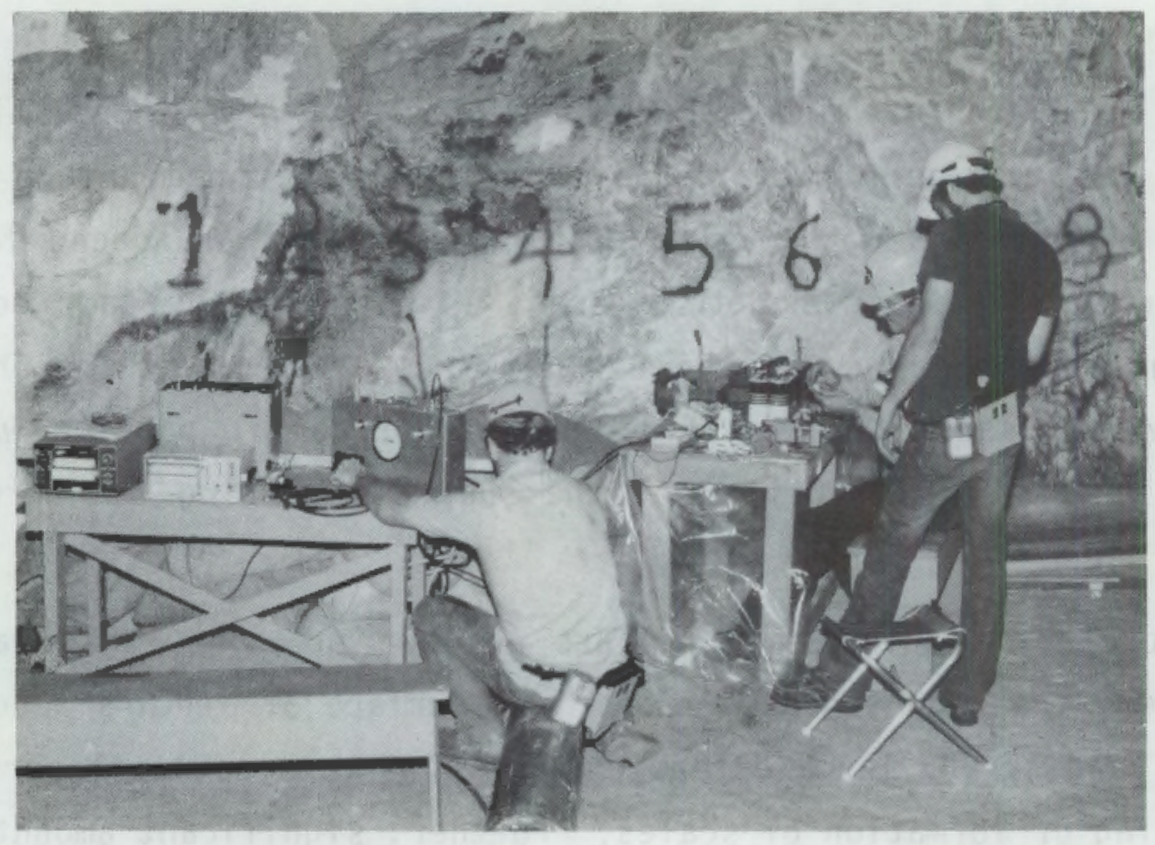

FIGURE 4.2. Work Underway at Second Test Site in Jefferson Island Salt Mine

Figure 4.3 is a cross-section schematic of the test slant-hole configuration developed for the in situ test phase of this study. With this arrangement, the salt around the test holes was essentially undisturbed and confined by the pillar above. This schematic applies to the second site in the JI mine and to the third test site developed in the Cote $B 1$ anche (CB) mine.

Site development began by drilling test holes. Eight holes of 2-in. $(50-\mathrm{mm})$ diameter were slant-drilled approximately parallel to depths of $20 \mathrm{ft}$ $(6 \mathrm{~m})$ with spacing from 12 to $36 \mathrm{in.} \mathrm{(300} \mathrm{to} 900 \mathrm{~mm}$ ). Nominal 1-1/2 in. schedule 40 aluminum pipes with outside and inside diameters of 1.90 and 1.61 in. (48.3 and $40.9 \mathrm{~mm}$ ), respectively, were used to case the holes to depths of $10 \mathrm{ft}(3 \mathrm{~m})$. To case the holes, urethane foam plugs were rammed down the hole to approximately $10 \mathrm{ft}(3 \mathrm{~m})$. A small amount of epoxy resin was poured into the holes and the casing pipes, with ends sealed with foam plugs, were sunk into the epoxy and set against the foam hole plugs. After the epoxy set, the plugs were cored with a hole saw made from thin-walled tubing. The remainder of the hole annulus was then filled with epoxy to the hole surface. Details of outfitting the pipe casing for instrumentation are described in the next section. 


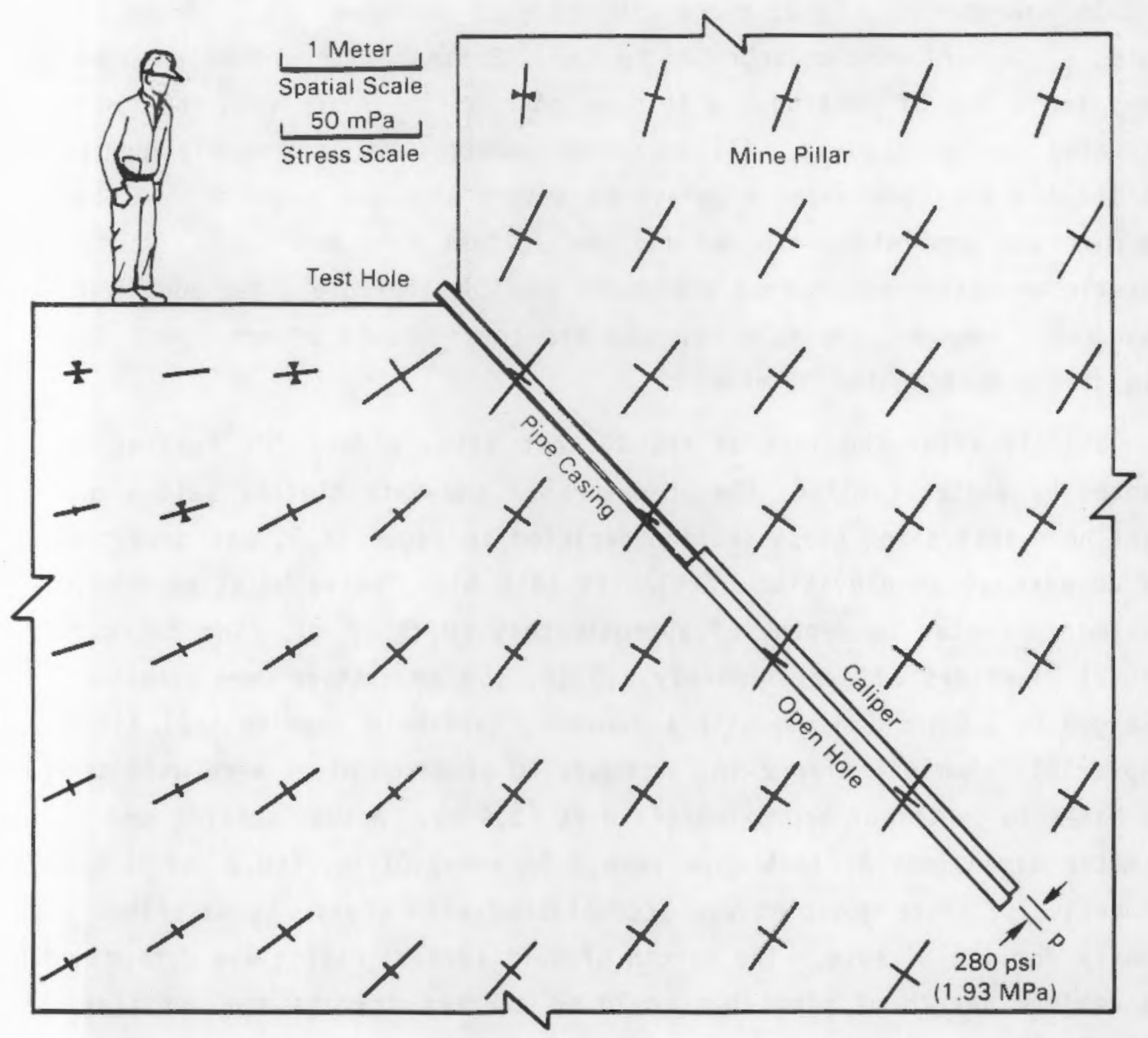

FIGURE 4.3. Test Hole Slant-Drilled Beneath Mine Pillar

Additional site preparation work in the JI mine consisted of building a shield levee of salt bags around the cased holes, for safety purposes. During tests with pressurized air, personnel and most of the test equipment were behind the levee, and thus, were protected from possible explosive effects. Initial tests performed at the JI site also are described in later sections. Unfortunately, these were preliminary and calibrated, quantifiable data was not able to be collected. 
On November 20, 1980, three LSU research personnel (R.L. Thoms, R.M. Gehle, R. Kayser) went underground to the CAES test site and began preparations for a day of testing. Within an hour of their arrival, the mine was evacuated due to flooding. All personnel underground were safely evacuated, but the LSU test personnel experienced a very atypical event in field work. The mine was completely flooded and the JI test site was lost. Portable acoustic emissions monitoring equipment and considerable other equipment was abandoned. However, the main loss was the considerable effort spent on test site development in the JI mine.

Shortly after the loss of the JI test site, access for testing was granted by Domtar Limited, the operators of the Cote Blanche salt mine. A slant hole test site, cross section depicted in Figure 4.3, was developed in the $C B$ mine at an elevation of $1370 \mathrm{ft}(418 \mathrm{~m})$. Twelve holes were slantdrilled by Domtar to depths of approximately $20 \mathrm{ft}(6 \mathrm{~m})$. The holes had initial diameters of approximately $2.3 \mathrm{in.}(58 \mathrm{~mm})$; these were subsequently enlarged to $2.5 \mathrm{in.}(64 \mathrm{~mm})$ with a two-man, hand-held reaming tool fit to a 2-hp drill. Nominal size 2-in. schedule 40 aluminum pipes were used to case the holes to depths of approximately $8 \mathrm{ft}(2.4 \mathrm{~m})$. Actual outside and inside diameter dimensions of this pipe were 2.34 and $2.07 \mathrm{in}$. (60.3 and $52.5 \mathrm{~mm}$ ), respectively. Pipe grouting was accomplished with epoxy, as described previously for the JI site. The length of $8-\mathrm{ft}(2.4-\mathrm{m})$ casing was determined by the maximum length of pipe that could be carried through the ventilation control air lock in the CB mine. After test hole preparations, approximately $12 \mathrm{ft}(3.7 \mathrm{~m})$ of rock salt wall was left exposed for test purposes. This salt was carefully isolated from brine effects (e.g., glazing) during any part of the test program.

Other work associated with the CB site preparation included emplacement of a shield levee of salt bags around the high pressure test site and installation of a small [4- $\times 8-\times 8-\mathrm{ft}(1.2-\times 2.4-\times 2.4-\mathrm{m})]$ instrumentation/ storeroom building. The building was fabricated at LSU, then disassembled and transported underground in the $C B$ mine to the CAES test site. There it was reassembled and used to house and protect instrumentation and equipment. The shack at the $C B$ test site is depicted in figure 4.4 . 


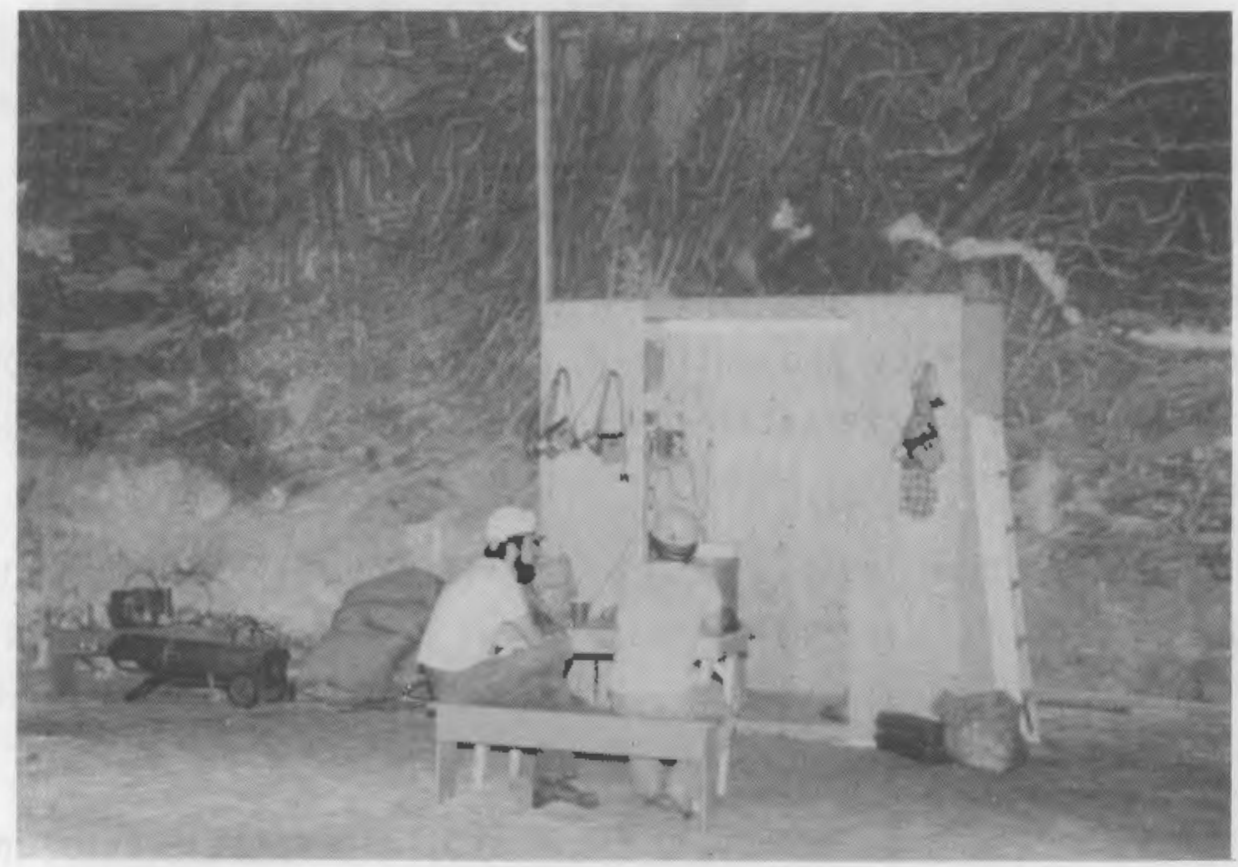

FIGURE 4.4. Instrumentation Shack in Cote Blanche Salt Mine

When site preparation was finished at the CB mine, the owner had provided test holes surrounded by relatively undisturbed and confined rock salt. The near-surface salt was sealed from test effects by grouted metal pipe casing. The initial stress-state in the salt, as indicated by a nonlinear finite element analysis (Section 6), was of a magnitude that would be anticipated for an operational CAES cavern at greater depths. This is discussed in more detail in Sections 4.4 and 4.5 relative to analysis of test data.

\subsection{TEST AND MONITORING EQUIPMENT}

Three quantities were monitored during the in situ borehole tests:

- applied fluid pressure (air and oil)

- diametric displacement

- acoustic emissions from the surrounding salt.

Some preliminary work also was done to measure elevated salt temperatures resulting from electrical resistance heaters placed in test holes. However, apparatus for simultaneously heating and pressurizing the test boreholes was not fabricated because of time and financial constraints. 
Air pressure was supplied to the test holes with conventional air bottles transported underground by LSU personnel. The bottles were fitted with regulators and a control unit that consisted essentially of an off-the-shelf pressure limiting and bourdon-tube type control switch coupled to valves with adjustable orifices for inlet and outlet air flow. Limits and rates of air pressure buildup and decay were attained by an iterative adjustment technique for each test.

For air pressurization tests, the regulated air supply was connected to the test hole via tubing. For high-pressure oil tests, the regulated air supply was connected to an air-to-oil pressure intensifier and the highpressure oil supply was connected to the test hole.

Figure 4.5 is a schematic depicting the essential test elements for the high-pressure (hydrofracing) oil pressurization test. A similar arrangement was made for the low-pressure air pressurization test except the air-to-oil pressure intensifier was eliminated. Also, the air pressurization was carried out in the same hole containing the hole caliper device indicated in the figure. Figures 4.6 and 4.7 show the $C B$ site including components of the CAES test setup. The hole casing pipe ends are visible in both figures. Figure 4.8 shows a hole caliper device being inserted into a test hole.

After insertion of the caliper, the pipe ends were sealed with an aluminum stopper consisting of an aluminum cylinder with encircling 0 -rings and interior longitudinal holes through the cylinder. Brass rods with tapered shoulders and threaded ends were covered with heat-shrink tubing and glued into the holes with silicon rubber. Instrumentation cables were attached to both ends and a central hole was threaded to accept nominal, standard 1/4-in. pipe fittings for the pressurized fluid connection.

The aluminum stopper assembly with two encircling 0-rings slid into a hollow cylinder with polished interior (for sealing). One end of the hollow cylinder was threaded to screw into a nominal, 2-in. standard pipe coupling on the end of the casing pipe. Teflon tape was used in all threaded connections for sealing and lubrication. The stopper assembly permitted sealing and 


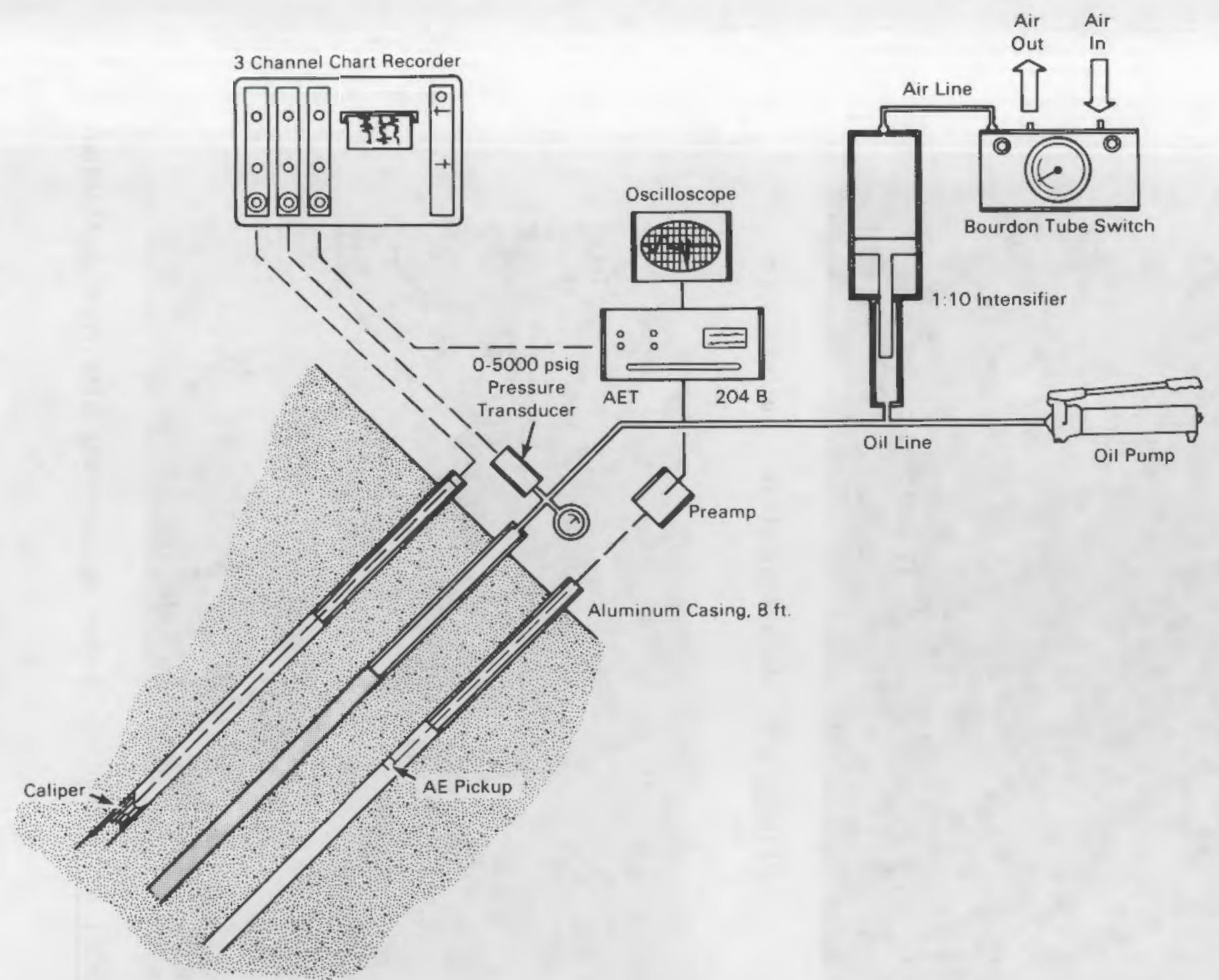

FIGURE 4.5. Instrumentation for High-Pressure Tests 


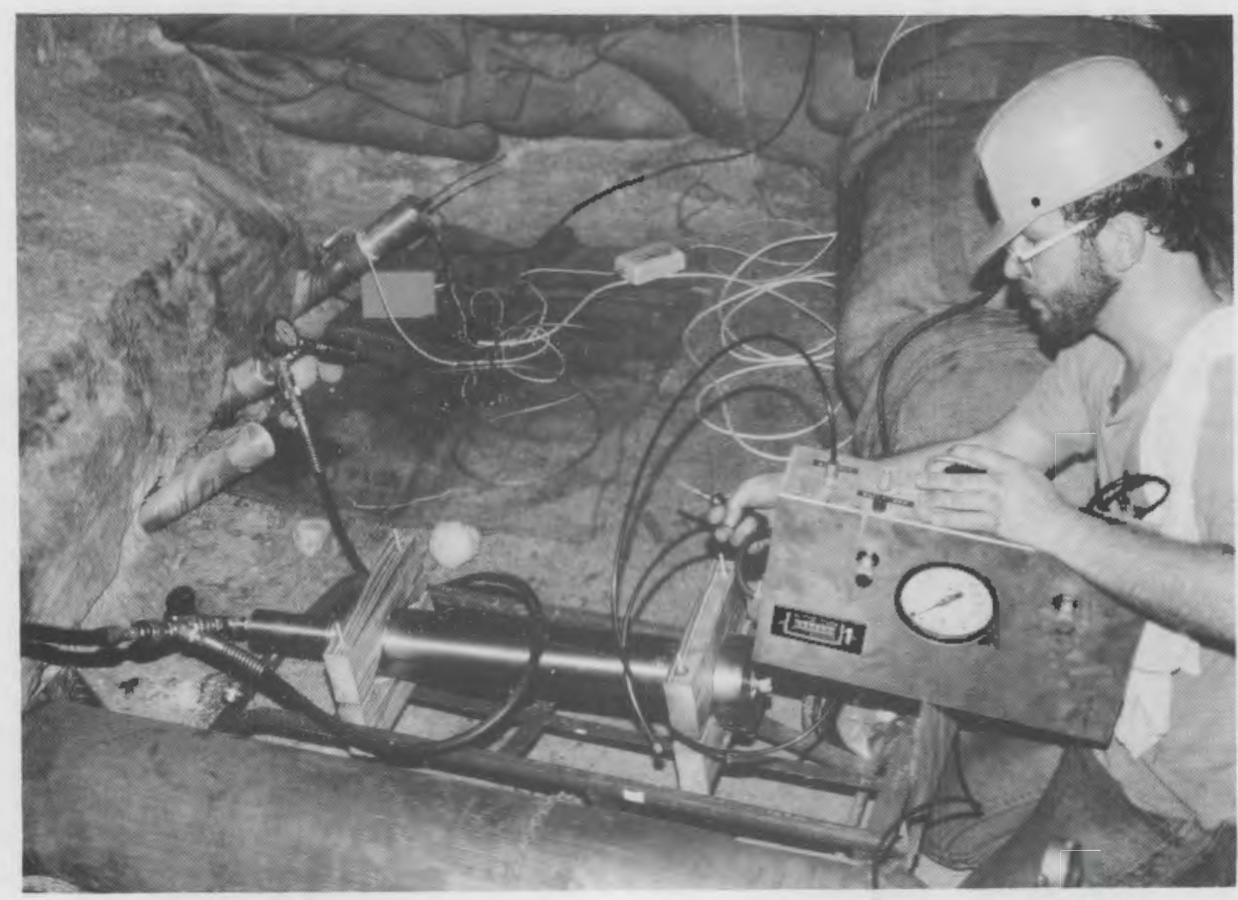

FIGURE 4.6. Apparatus at In Situ Test Site

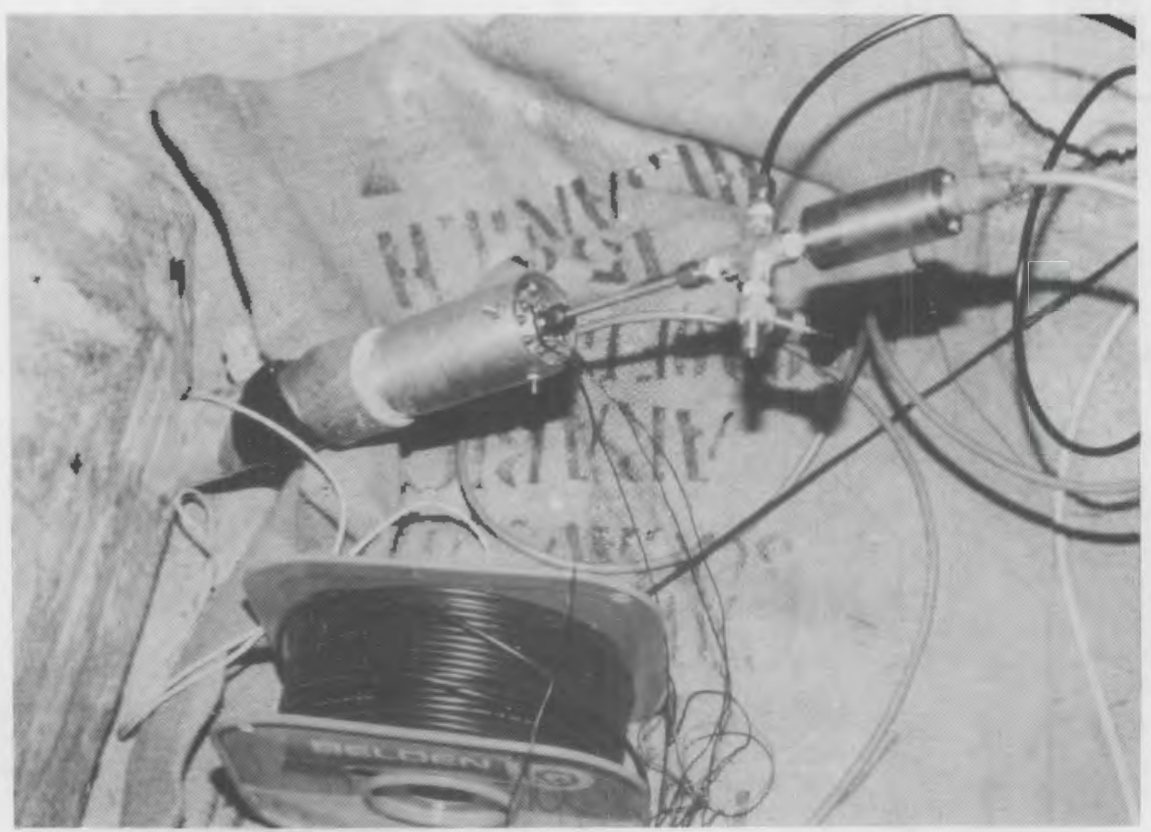

FIGURE 4.7. Head of Pressurized Borehole with Instrumentation 


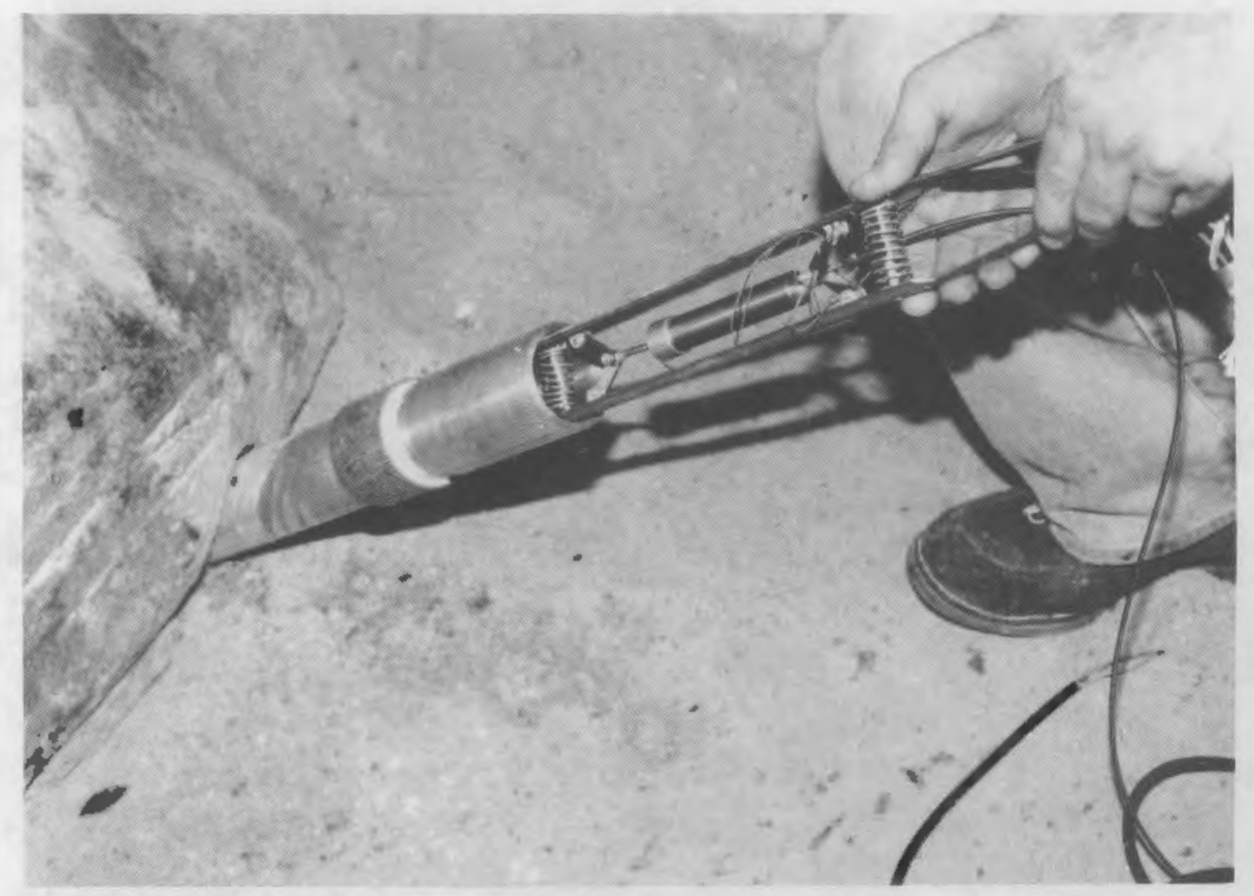

FIGURE 4.8. Hole Caliper Device Inserted into Test Hole

accessing the test holes without twisting cables of downhole instrumentation. After test completion, it was possible to retrieve all fittings except the grouted-in pipe casing and coupling. Figure 4.9 shows the borehole caliper and stopper after removal from a test borehole.

Diametric displacement of test holes were monitored by the previously noted borehole caliper device shown in Figures 4.8 and 4.9 . This device was developed by $\mathrm{Mr}$. Charles Powe11, consultant to the LSU CAES study.

With reference to Figures 4.8 and 4.9 , movement of the spring-loaded shoes of the device in a direction normal to its long axis was transformed via mechanical linkages into relative longitudinal displacement of the sensing LVDT core and coil mounted along the centerline. With prior calibration in a test machine in the LSU laboratory, the LVDT signal was interpreted in terms of relative displacement normal to the borehole's axis. This displacement was correlated with applied. borehole test pressures, as described in Sections 4.4 and 4.5 . 


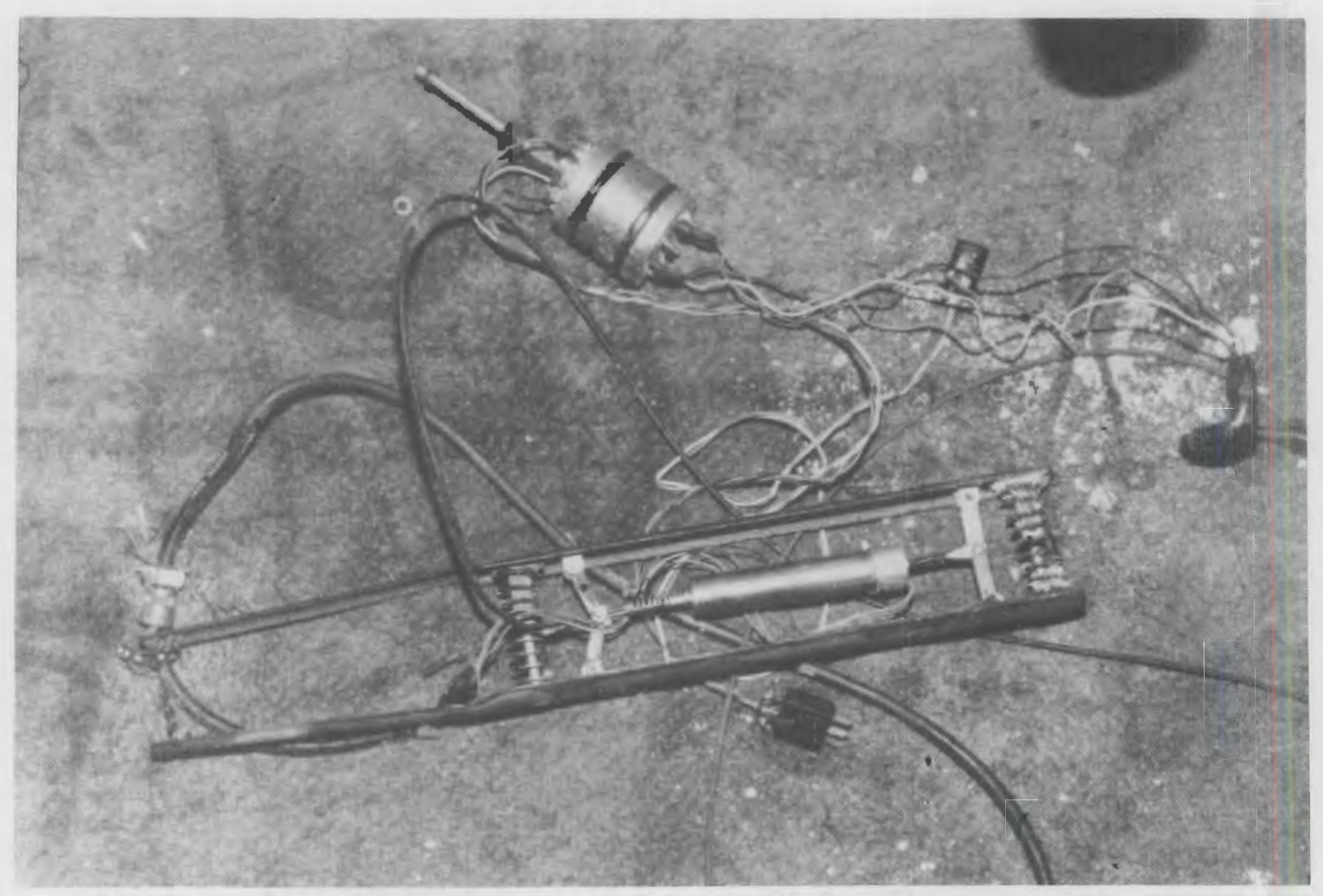

FIGURE 4.9. Hole Caliper and Stopper After Removal from Hole

Other monitoring equipment consisted of conventional bourdon tube pressure gauges for quick visual reference and electronic transducers. A portable acoustic emissions unit and sensors, manufactured by Acoustic Emissions Technology, Inc., was used to pick up and process AE signals from the loaded salt. A small portable oscilloscope was used as a visual check of AE character during testing.

Signals related to hole pressure, diametric displacement, and acoustic emissions were transmitted by cables to the instrument shack and recorded on a three-channe1, Easterline Angus strip chart recorder.

Figures 4.10 and 4.11 show the instrument shack and equipment used for monitoring and recording purposes. Other models of similar equipment were used from time to time during the in situ test program. The equipment shown in Figure 4.11 was used in the final stages of the in situ test program. 


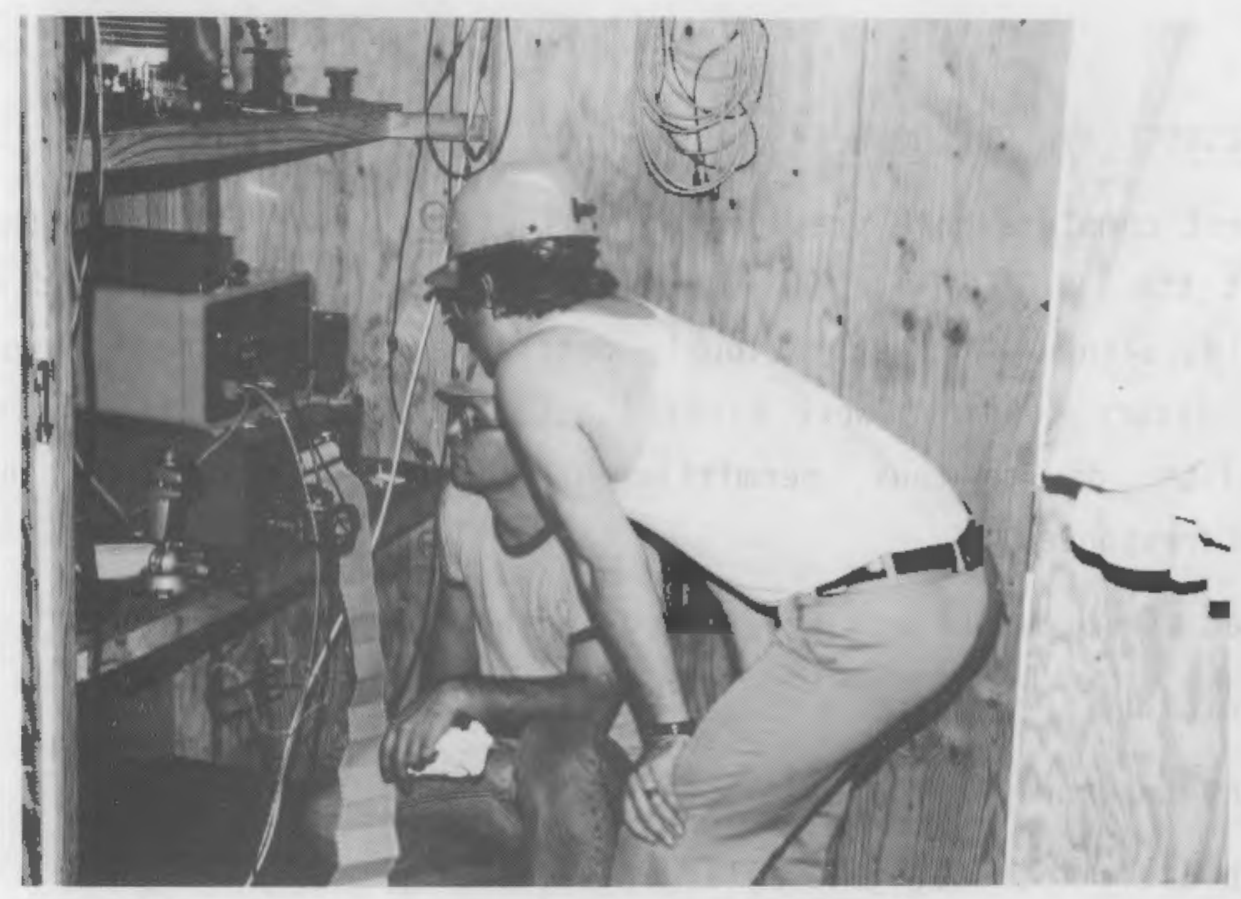

FIGURE 4.10. Test Shack in Use at Cote Blanche Site

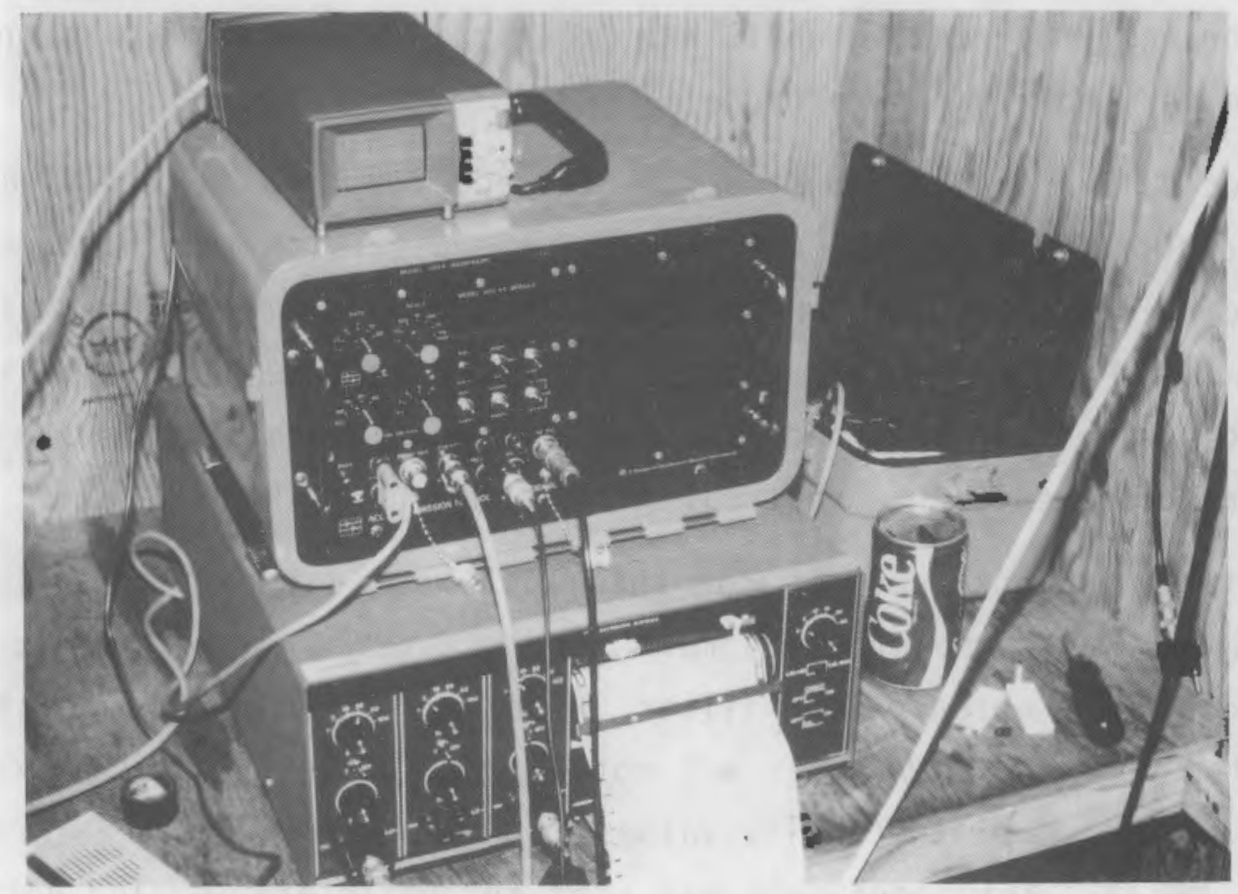

FIGURE 4.11. Monitoring and Recording Instrumentation in Shack at Cote Blanche Site. 


\subsection{LOW-PRESSURE AIR BOREHOLE TEST}

The first complete hole pressurization test with calibrated equipment was performed at the CB CAES site in May 1981. Pressurized air was used as the working fluid, along with the previously described test equipment. For this test, air pressure loadings were carried out in the hole outfitted with the borehole caliper device thus, permitting direct measurements of borehole displacement response.

Elevated air pressure was introduced in the following sequence:

- monotonically increasing

- constant pressure over a time interval

- monotonically increasing to a larger value of pressure

- constant pressure at this larger magnitude over a time interval

- cyclic pressure over a third time interval

- monotonically decreasing until atmospheric pressure value was indicated on the test hole pressure gauge.

Figures 4.12 and 4.13 depict data obtained from this test. Figure 4.12 contains selected portions of the recorded signals, with labels added. Note that Figure 4.12 is inverted in the sense that time proceeds from right to left. Figures 4.13 and 4.14 are time-compressed representations of selected transcribed portions of recorded data for applied air pressure and associated diametric displacements in a vertical plane containing the hole axis.

Acoustic emissions recorded for this test were not considered particularly meaningful because the equipment used consisted of only a frequency counter and pick-up, preamp, and filter. Interpretation of the resulting $A E$ data was difficult. However, it was noted that little AE activity could be associated with the relatively low values of applied air pressure [around 285 psig $(1.96 \mathrm{MPa})]$. This equipment was used in the interim period until more versatile $A E$ equipment could be obtained to replace that lost in the JI mine flooding (AET 204 GR portable unit). It was also noted that a working mine 


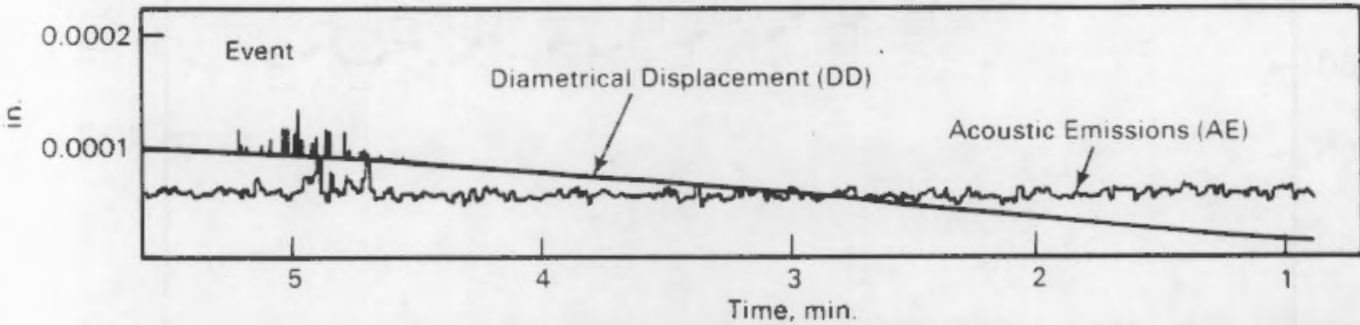

Hole Diameter

Increase

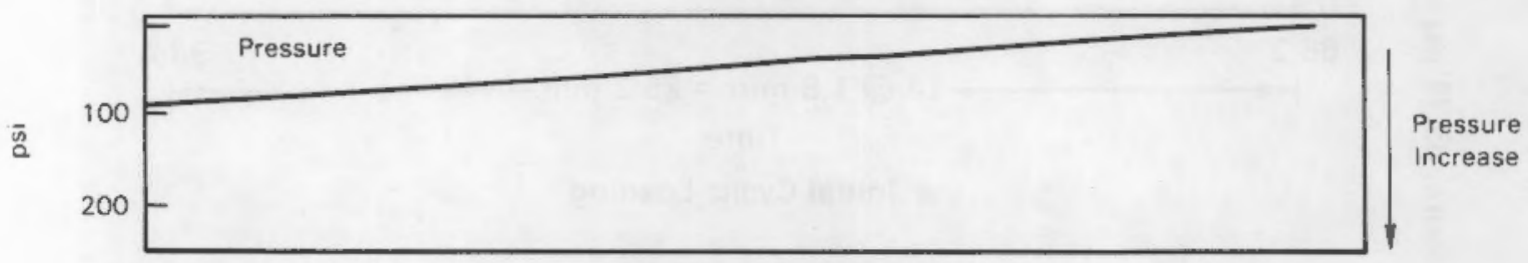

a. Initial Pressurization

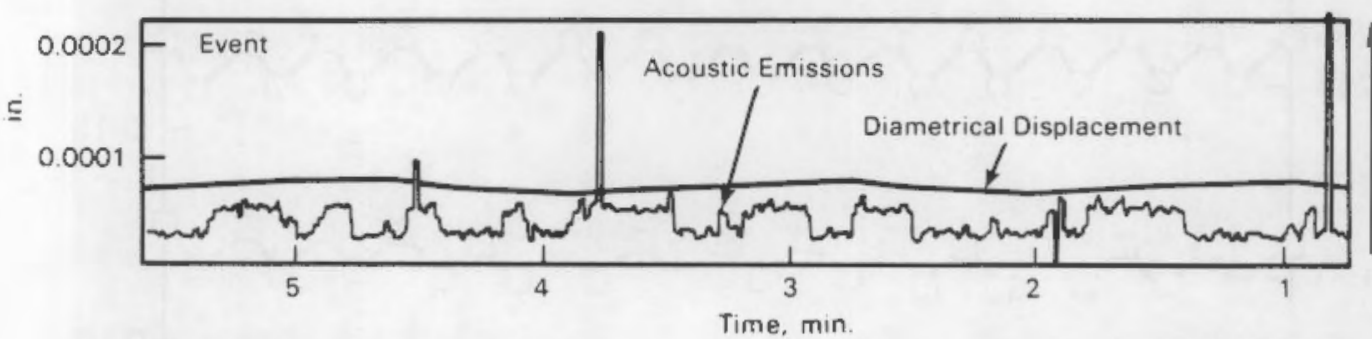

Hole Diameter Increase

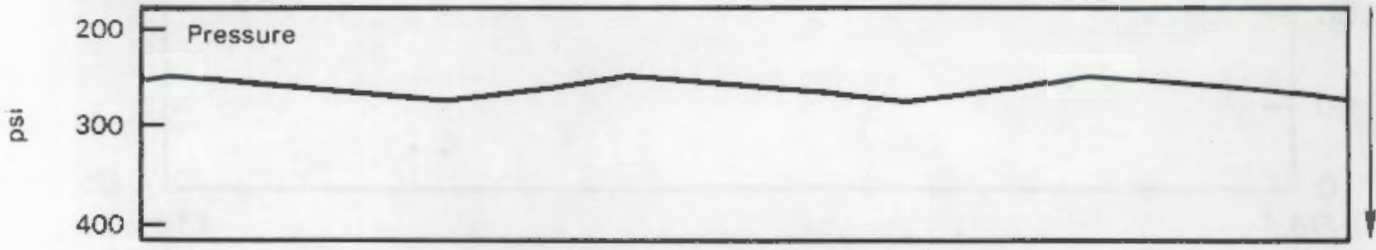

Pressure

Increase

b. Cyclic Pressurization

FIGURE 4.12. Recorded Initial and Cyclic Air-Pressurization Test Data 


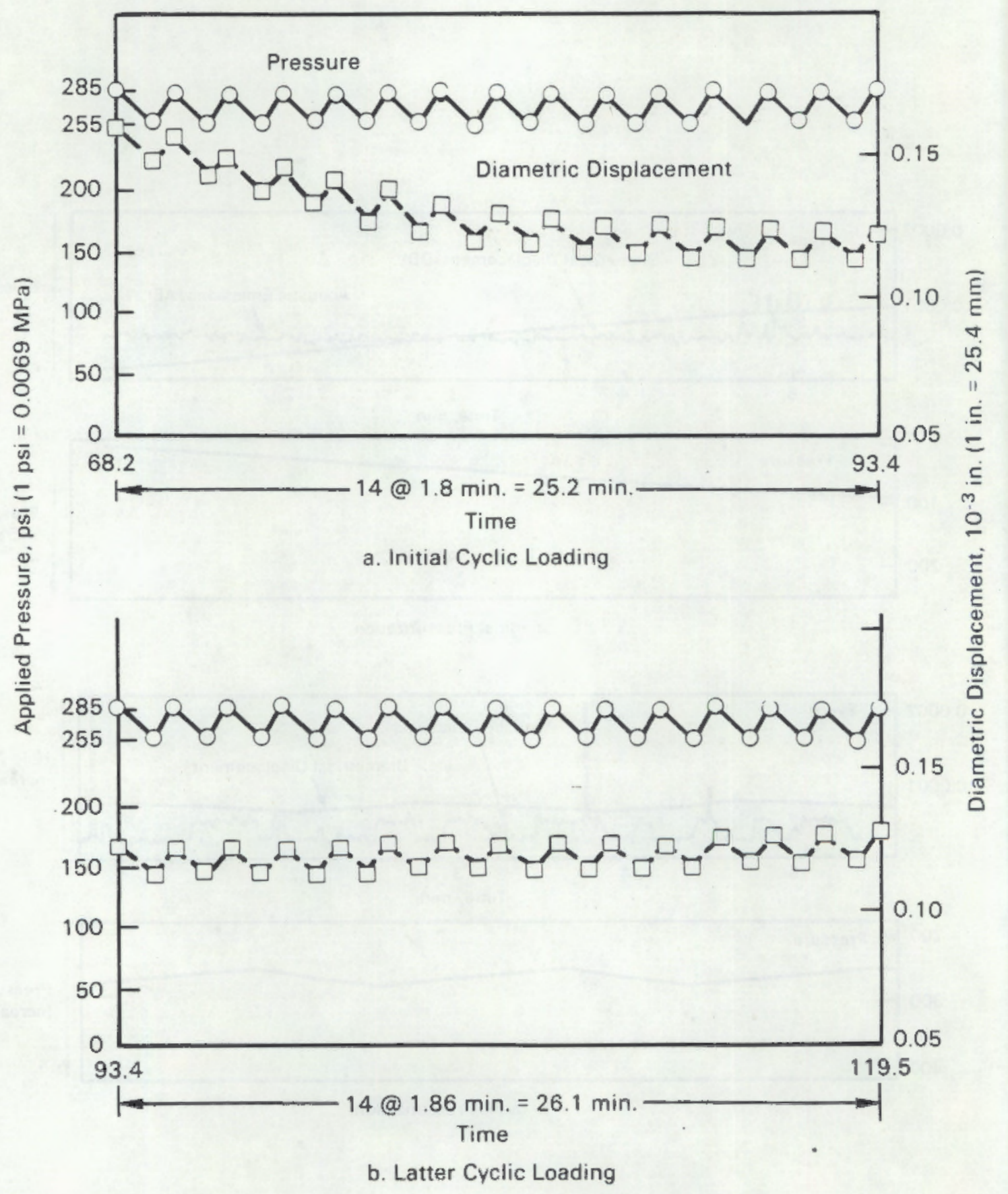

FIGURE 4.13. Transcribed Air-Pressurization Test Data - Cyclic Load Phase 


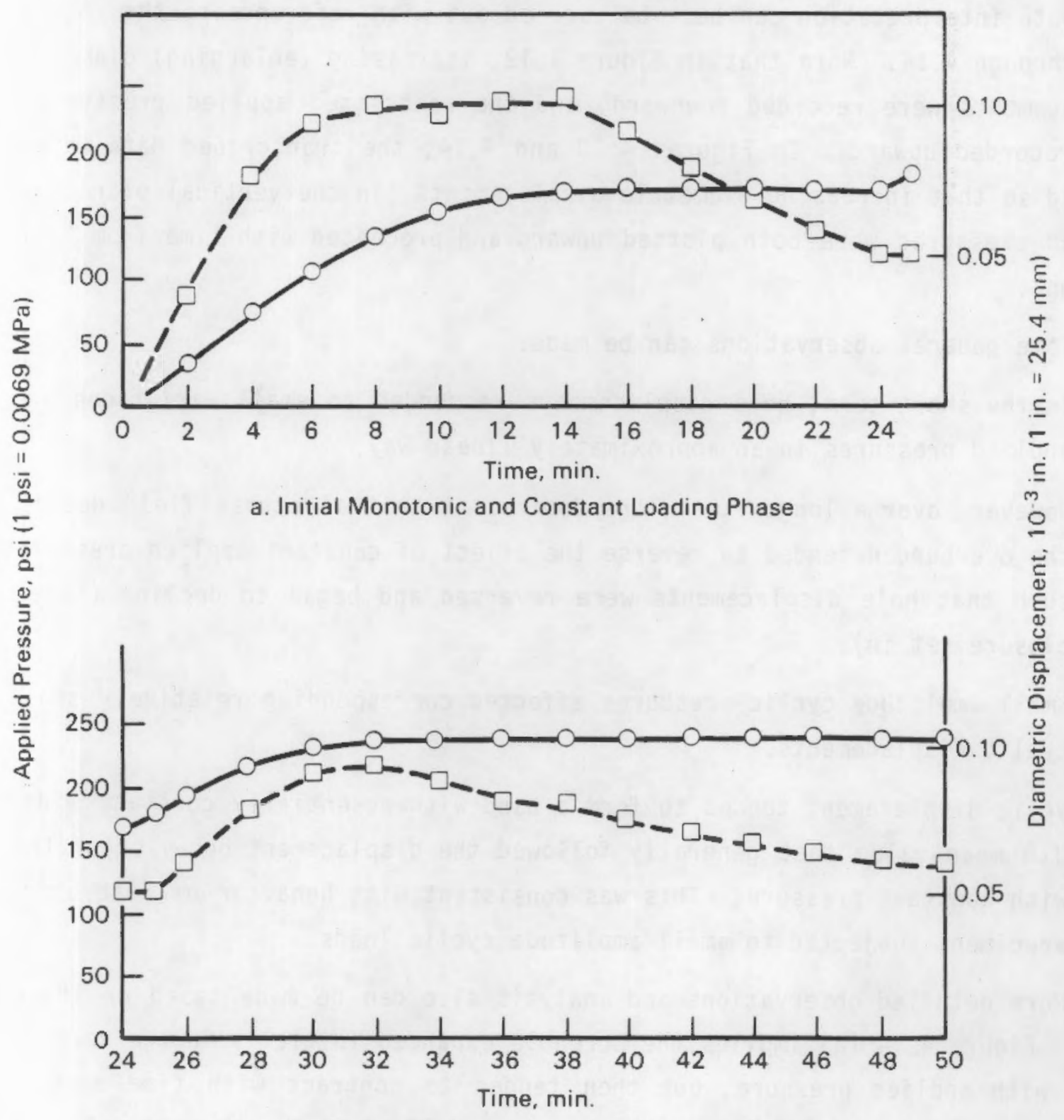

b. Latter Monotonic and Constant Loading Phase

FIGURE 4.14. Transcribed Air-Pressurization Test Data - Monotonic Increasing and Constant Load Phases 
exhibits significant background $A E$ requiring a certain level of experience with the site prior to interpreting $A E$ test data.

Data interpretation can best be carried out with reference to the Figures 4.12 through 4.14. Note that in Figure 4.12, increasing (enlarging) diametric displacements were recorded downward, and the associated applied pressures were recorded upward. In Figures 4.13 and 4.14 , the transcribed data were plotted so that increasing diametric displacements (in the vertical plane) and applied pressures were both plotted upward and proceeded with time from left to right.

Some general observations can be made.

- In the short term, hole displacements responded to small variations in applied pressures in an approximately linear way.

- However, over a longer term, the dominating initial stress field due to the overburden tended to reverse the effect of constant applied pressures such that hole displacements were reversed and began to decline (hole closure set in).

- Small amplitude cyclic pressures effected corresponding relatively small cyclic displacements.

The cyclic displacement tended to form a band with essentially constant width and with mean value that generally followed the displacement behavior of the hole with constant pressure. This was consistent with behavior of laboratory test specimens subjected to small amplitude cyclic loads.

More detailed observations and analysis also can be made based on these data. Figure 4.14 (a) implies the borehole expanded initially in the vertical plane with applied pressure, but then tended to contract with time once constant applied pressure was attained, around 12 min into the test. Figure 4.14 (b) is a continuation of (a) and indicates that an increment of hole expansion occurred in response to an additional pressure increment. This was followed by hole contraction once a larger magnitude of constant pressure was attained. 
Short-term deformation moduli can be calculated using the data of figure 4.14. Consider a hole reaction modulus, $K$, defined by

$$
K=\frac{\Delta P}{\Delta U}
$$

where $\Delta P$ is the increment of applied pressure and $\Delta U$ is the maximum value of corresponding diametric displacement.

Values of $K$ for the first and second pressure increments were 1651 and $1628 \mathrm{psi} / \mathrm{in}$. (0.45 and $0.44 \mathrm{MPa} / \mathrm{mm})$, respectively.

If the rock salt is assumed linearly elastic for short-term incremental loads, then a shearing modulus, G, can be derived from the test data by the relation

$$
G=\frac{\Delta P R}{2 \Delta U_{R}}=\frac{\Delta P R}{\Delta U_{D}}
$$

where $R$ is the radius of pressurized hole, and $\Delta U_{R}$ and $\Delta U_{D}$ are the increments of hole radial and diametric displacements, respectively.

With reference to Figure $4.14(a)$ for the first pressure increment and using data from the time interval over 1 to 4 min

$$
\mathrm{G}_{1}=1.9 \times 10^{6} \mathrm{psi}(13 \mathrm{MPa})
$$

By using Figure 4.14(b) for the time interval from 25 to 28 min during application of the second pressure increment

$$
\mathrm{G}_{2}=2.0 \times 10^{6} \mathrm{psi}(13.8 \mathrm{MPa})
$$

If a value of 0.25 for Poisson's ratio is assumed for the short-term small displacement response of the salt, the above values of $G$ can be used, respectively, to obtain

$$
E_{1,2}=4.8 \text { and } 5.1 \times 10^{6} \text { psi ( } 33 \text { and } 35 \mathrm{MPa} \text { ) }
$$

where $E$ is the short-term reaction modulus of the salt around the hole.

The definition of modulus of elasticity for rock salt varies. If the slope of the stress-strain curve of a reloaded specimen is used, then the value of 4.5 is reasonably consistent with values of modulus of elasticity previously reported for laboratory tests. 
Figure 4.13 represents data collected during the cyclic phase of the test. Approximately 18.2 min were used between the static and cyclic phases to obtain the pattern of cyclic loads pictured in this figure. Once set, the air pressurization control system maintained essentially repetitive loading cycles.

As previously noted, the general trend of the displacement band due to cyclic loads was similar to the displacement response following application of monotonic and steady loads. In particular, the shape of the approximate mean value of cyclic displacements in Figures $4.13(a, b)$ for $t=68$ to $96 \mathrm{~min}$ essentially duplicated the hole contraction (or relaxation) data of Figure 4.14 (b) for the time interval $t=32$ to $50 \mathrm{~min}$. This implied the rock salt relaxation behavior was essentially insensitive to repetitive cyclic load effects of relatively small amplitudes and time periods.

Following the assumed linear analysis for the monotonic loading phase, the amplitude of applied cyclic pressure and corresponding diametric displacement were used to obtain values of shear modulus, $G$. The values thus obtained ranged around

$$
G=3.5 \text { to } 4.4 \times 10^{6} \text { psi }(24 \text { to } 30 \mathrm{MPa}) \quad 4.6
$$

Thus, for assumed Poisson's ratio of 0.25

$$
E=8.8 \text { to } 10.9 \times 10^{6} \mathrm{psi}(61 \text { to } 75 \mathrm{MPa}) \quad 4.7
$$

A general observation can be made, i.e., the short-term periodic response of the salt was around twice as stiff as for monotonic loading. When compared to values of elastic moduli obtained from laboratory tests, these values were approximately larger by a factor of 2 to an order of magnitude.

Possible reasons for this lack of agreement included:

- The test hole was not in a state of plane strain.

- Overburden stress countered short-term hole pressurization effected displacements.

- Calibration of the hole caliper device was affected by emplacement in the test hole. 
Of these possible reasons only the last could be rechecked and this was done. No significant variations in caliper device performance were found when it was recalibrated in the lab with full-length instrumentation cables. A lack of fit of curvature of the caliper shoes with the borehole walls also could cause error in measuring cyclic diameter displacements.

\subsection{HIGH-PRESSURE OIL BOREHOLE TEST}

Following the previously described relatively low-pressure air pressurization test, a high-pressure oil pressurization test was designed and performed at the $C B$ mine site.

$0 i 1$ was used for the high-pressure test fluid because of safety concerns with a compressible fluid (gas) such as air. Data were collected relative to threshold operating conditions in pressurized caverns that could lead to hydraulic fracturing of the surrounding salt containment. Post-hydraulic fracturing performance of salt cavities with overburden pressures also was assessed.

The test site configuration consisted of three approximately parallel holes slant-drilled beneath a mine pillar (see figure 4.15). Hole diameters were approximately $2.5 \mathrm{in.}(64 \mathrm{~mm})$ and center-to-center distances were approximately $12 \mathrm{in.} \mathrm{(305} \mathrm{mm).} \mathrm{The} \mathrm{central} \mathrm{hole} \mathrm{was} \mathrm{pressurized} \mathrm{at} 500$ psi (3.5 MPa) increments, with each increment including an increasing, constant, and cyclic pressurization phase.

The initial oil pressurization test proceeded essentially as planned. No dramatic increases of $A E$ activity were detected up to hole pressure values of around 200 psi ( $13.8 \mathrm{MPa})$, including the cyclic phase with pressure varying between 1750 to 2000 psi $(12.1$ to $13.8 \mathrm{MPa})$. As the 0 il pressure was increased to approximately $2500 \mathrm{psi}(17.2 \mathrm{MPa}$ ), both the AE and diametric displacements recording pens went off-scale and the pressure decreased. This was interpreted as an indication of initial cross-borehole fracturing. Figure 4.16 depicts the recorded data corresponding to apparent fracturing of the salt. 


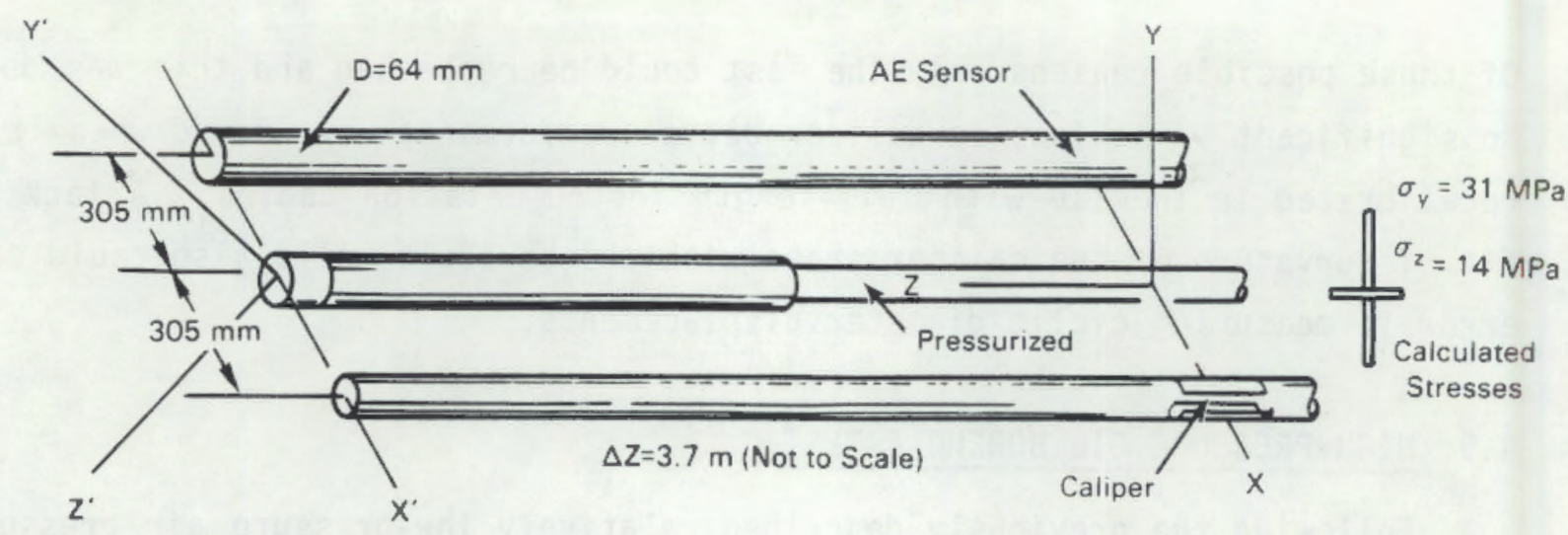

FIGURE 4.15. Configuration of Test Holes for Hydraulic Fracturing

Subsequently, during the same day of testing, pressure values were increased by pumping additional oit into the central hole. During the second pressurization, a peak pressure very close to the initial fracture pressure of 2500 psi (17.2 MPa) was attained. Thereafter, for four additional pressurizations, peak values of around 2200 to 2300 psi ( 15.2 to $15.9 \mathrm{MPa}$ ) were attained and could not be exceeded by pumping.

A second fracturing test was performed around 5 weeks later (Sept. 22 to 0ct. 29, 1981). The hole was pressurized to approximately 2250 psi (15.5 $\mathrm{MPa}$ ), whereupon fracturing symptoms were again evident. A second and sustained oil pumping effort yielded hole pressures ranging around 2500 psi (15.9 to $17.2 \mathrm{MPa}$ ) with AE bursts; however, a third effort yielded values of only 2100 psi ( $14.5 \mathrm{MPa})$. At this point, the tests were terminated.

Approximately 3 months following the initial hydraulic fracturing test, a final pressurization test was performed on the previously fractured three-hole system. The central hole was subjected to four major stages of cyclic pressure with minimum and maximum value ranges as follows:

- 1400 to 1950 psi ( 9.7 to $13.4 \mathrm{MPa}$ )

- 1400 to 1750 psi (9.7 to $12.1 \mathrm{MPa}$ )

- 1400 to 1700 psi (9.7 to $11.7 \mathrm{MPa})$

- 1150 to 1500 psi (7.9 to $10.3 \mathrm{MPa})$.

The test was performed over 4 hours with the second stage making up the major part of the test. 


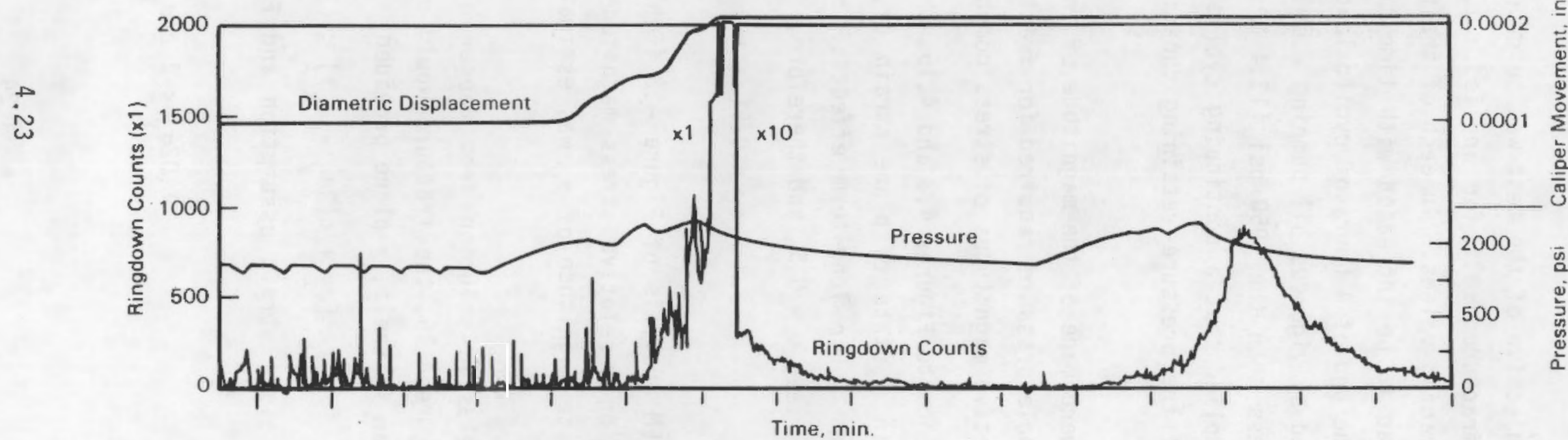

FIGURE 4.16. Recorded Test Data at Fracturing 
The main objective of the test was to determine possible leakage through the previously fractured salt for applied cyclic pressure less than the apparent hydrofracing values. In each of the four test stages, $0 i 1$ flow into the test hole had to be increased with time to maintain the desired peak pressure. At the end of 4 hours of cyclic loading, the maximum pressure that could be achieved by vigorous oil pumping was 1650 psi $(11.4 \mathrm{MPa})$; this was significantly less than the $1950 \mathrm{psi}(13.4 \mathrm{MPa})$ obtained at the beginning. These results implied that a continuing cyclic load resulted in progressive deterioration of the pressure retaining capacity of the previously fractured sait.

Estimates were made of the magnitude of in situ stress-state based on the combination of hole pressure required for fracture and a finite element method analysis of relative magnitudes of stress components.

With reference to Figures 4.3 and 4.15 , the central pressurized hole was assumed to be in a state of plane strain $(y, z)$, and unaffected by its neighboring holes. For long-term effects, the salt was assumed to be incompressible, i.e., $v=0.5$, and therefore,

$$
\sigma_{x}=0.5\left(\sigma_{y}+\sigma_{z}\right)
$$

From the FEM analysis of Figure 4.3 (Gehle 1980), the ratio of $\sigma_{y} / \sigma_{z}=$ 2.2. Note that only relative stress magnitudes were employed from the FEM analysis; absolute magnitude of $\sigma_{y}$ was estimated from pressure required for fracture.

Using an elastic solution from Jaeger and Cook, (1979, p. 389) and referring to Figure 4.15 , the fracture would occur in the salt in the $x, y$ plane rather than in the $z, x p l a n e$ provided

$$
\left[\sigma_{z}+v\left(3 \sigma_{y}-\sigma_{x}\right)\right]<\left(3 \sigma_{y}-\sigma_{x}\right)
$$

Using the plane strain assumption and FEM results previously cited yielded

$$
1.02 \sigma_{y}<2.27 \sigma_{y}
$$


where $v$ equals 0.25 was employed because of the short-term character of the applied fracturing pressure. The result of Eq. $4.10 \mathrm{implies}$ that salt will fracture in the $x, y$ plane normal to the hole axis. Also, by Jaeger and Cook (1979), fracture initiates for

$$
P \geq T+\left[\sigma_{z}+v\left(3 \sigma_{y}-\sigma_{x}\right)\right]
$$

where $p$ is the fracture pressure in hole and $T$ is the tensile strength of salt.

From laboratory indirect tension (Brazilian) tests, a reasonable value for $T$ is $220 \mathrm{psi}(1.5 \mathrm{MPa}$ ), and by previously described mine tests, $P$ is about 2500 psi (17.2 MPa). Employing these data and assumptions with Eq. 4.17 yielded,

$$
\sigma_{y}=(2500 \text { to } 220) / 1.02=2235 \mathrm{psi}(15.4 \mathrm{MPa})
$$

The value of $\sigma_{y}$ estimated here was approximately one-half the magnitude obtained by the FEM, as depicted in Figure 4.1. Several explanations are possible. For example,

- The overburden effects have been partially transferred from the site pillar to the mine abutment zone nearby.

- The term $\left(3 \sigma_{y}-\sigma_{x}\right)$ is excessive in Eq. 4.4 because it is derived from an elastic solution for stress concentration that is unlikely in plastic rock salt.

- The neighboring holes weakened the salt around the central hole and caused it to fail prematurely.

A more ideal hydrofracing test in rock salt would be conducted in a single hole at greater depth and would continuously monitor fluid flow rate into the hole for crack propagation study. As noted by Jaeger and Cook (1979), crack propagation, unlike initiation, is essentially independent of material properties and depends only upon the in situ stress-state. 


\subsection{CONCLUDING REMARKS}

A number of concluding remarks can be made based on the in situ pressure test program. These include:

- The in situ displacement response of rock salt indicates a good capability of salt to withstand cyclic pressure loads provided it is confined and essentially undisturbed.

- Confined rock salt retains significant pressure containment capability for a limited number of cycles following initial hydrofracture. However, this containment capability eventually deteriorates with continued cyclic loading.

- Acoustic emissions monitoring can be convenientiy used to identify hydraulic fracturing of rock salt. Additional work is needed to associate salt response via acoustic emissions with applied loads that are significantly lower than fracture pressures.

- For short-term, small amplitude cyclic pressure loads the corresponding salt displacement response is approximately linear. However, the long-term response is dominated by the mean value of the stress field, which is associated with the overburden and long-term mean value of hole pressure.

- Determination of the initial stress field in salt remains a problem to be solved prior to confidently assigning quantitative behavior values on the basis of in situ test data.

- The general trend was similar for rock salt displacement response during in situ and laboratory tests for cyclic pressure loadings.

- Rock salt beneath a mine pillar was essentially undisturbed and continuously confined. This salt zone was considered representative of salt around solution-mined caverns at depths greater than the mine floor elevation and thus, was used for test holes in the CAES study. 


\subsection{PERMEABILITY TESTS}

\subsection{LABORATORY PERMEABILITY TESTS PERFORMED}

Laboratory permeability tests on rock salt have been reported previously by Aufricht and Howard (1961) and by Sutherland and Cave (1980). They observed that rock salt permeability decreased with confining pressure and with cyclic load application.

Apparatus were designed for this study that allowed permeability testing of rock salt specimens in the same pressure cells used for mechanical response tests. Figure 5.1 is a schematic of the modified cell and enclosed 4 in. $x$ 4 in. (100 mm $\times 100 \mathrm{~mm})$ diameter $\times$ length salt specimen. Specimens were tested with constant flow rates of air under triaxial compression conditions. Air pressure values were monitored upstream and downstream of the specimen, along with flow rate, and used to calculate permeability (Scheidegger, 1960, p. 93).

$$
q=k / \mu\left(p_{u}^{2}-p_{d}^{2}\right) /\left(2 p_{u} L\right)
$$

where $q=$ flow monitored downstream of the specimen

$k$ = permeability

$\mu=$ dynamic viscosity of air

$P_{U}=$ pressure upstream

$p_{d}=$ pressure downstream

$L=$ length of specimen.

Figure 5.2 displays some early results obtained with the laboratory steady-flow apparatus. Test results were consistent with previous findings. with increasing confining pressures, the permeability of specimens rapidly decreased to immeasurably small values.

Specimen 2 of figure 5.2 was subjected to cyclically applied hydrostatic confining pressures following the steady-flow test. Pressure values were cycled between 1000 and 1500 psi $(6.9$ and $10.3 \mathrm{MPa})$. Air flow rates greater than $2 \mathrm{cc} / \mathrm{min}$ could not be detected after less than ten cycles. This behavior was consistent with cyclic load effects on rock salt permeability for laboratory tests. 


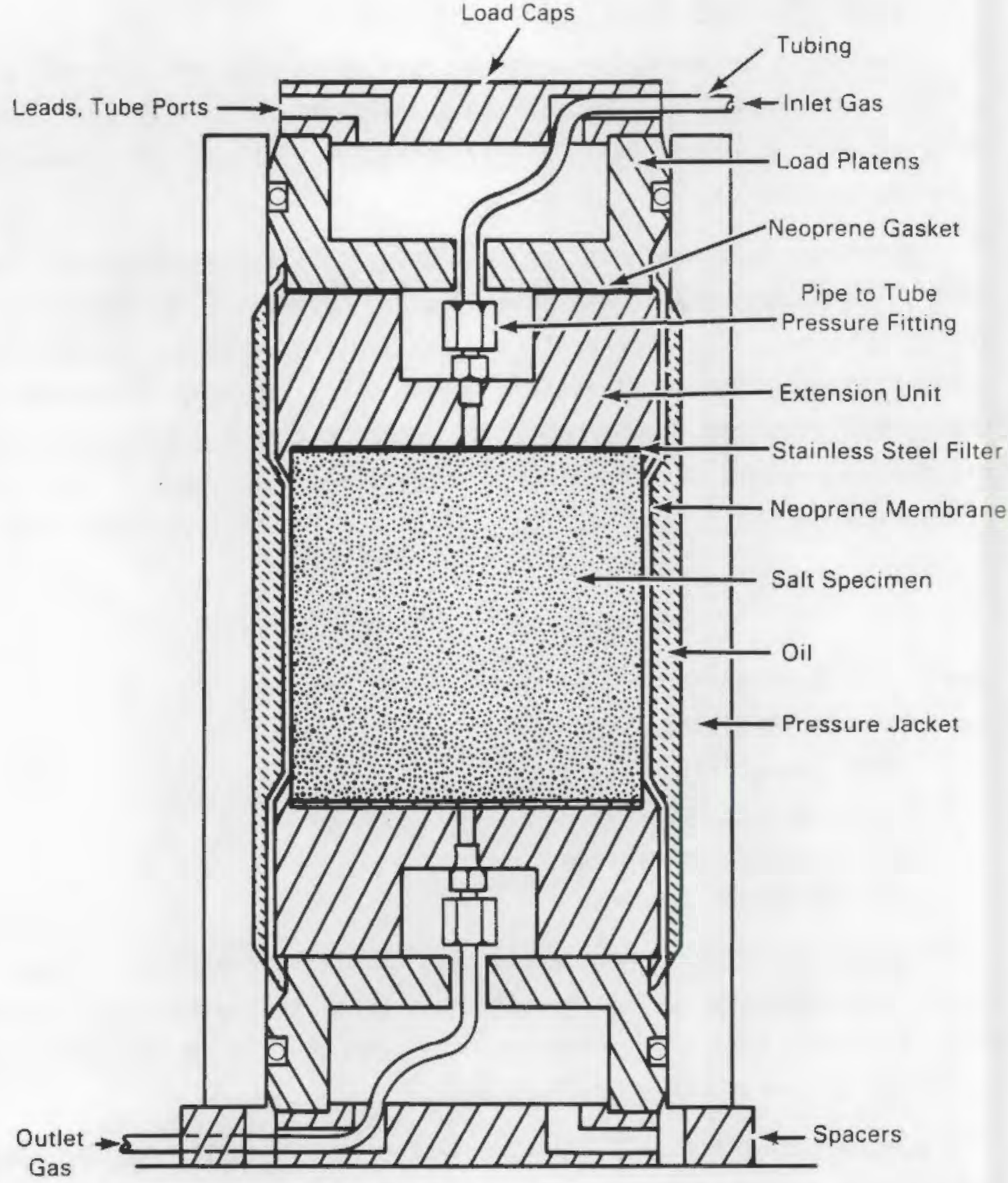

FIGURE 5.1. Permeability Test Cell 


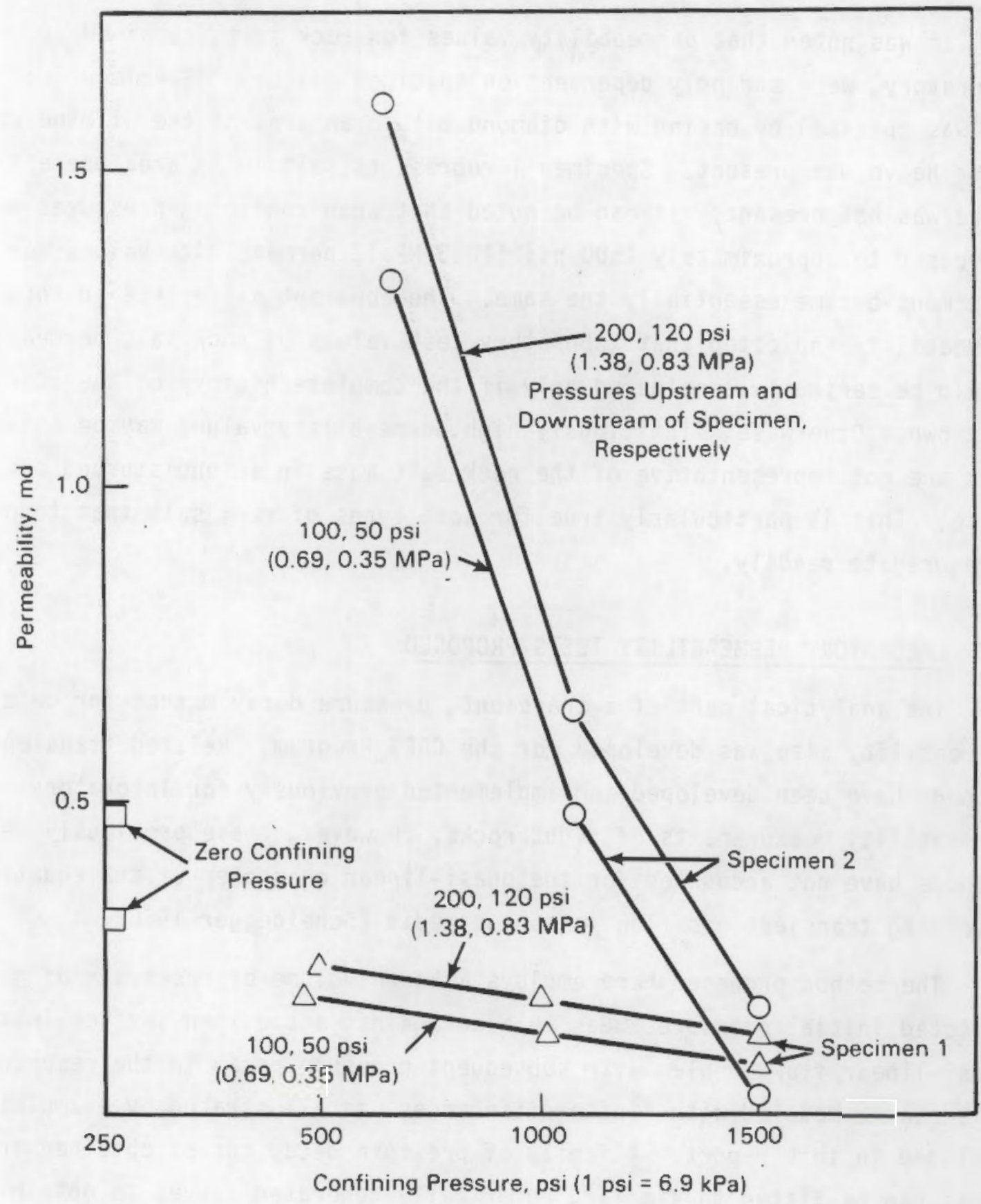

FIGURE 5.2. Permeability Versus Confining Pressure 
It was noted that permeability values for rock salt, obtained in the laboratory, were strongly dependent on specimen history. Specimen 2 of Figure 5.2 was obtained by coring with diamond bit in an area of the JI mine where floor heave was present. Specimen 1 represents salt in an area where floor heave was not present. It can be noted that when confining pressures were increased to approximately $1500 \mathrm{psi}$ (10.3 MPa), permeability values for both specimens became essentially the same. The apparent difference in rock salt permeability indicated that laboratory test values of rock salt permeability should be seriously considered only if the complete history of the specimens is known. Otherwise, fictitiously high permeability values may be obtained that are not representative of the rock salt mass in an undisturbed confined state. This is particularly true for some types of rock salt that tend to disaggregate readily.

\subsection{LABORATORY PERMEABILITY TESTS PROPOSED}

The analytical part of a transient, pressure decay method for determining permeability also was developed for the CAES Program. Related transient methods have been developed and implemented previously for laboratory permeability measurements of tight rocks. However, these previously related methods have not accounted for the quasi-linear character of the equation governing transient gas flow in porous media (Scheidegger 1960).

The method proposed here employs a known volume or reservoir of gas at a selected initial pressure. Gas release against a specimen surface initiates a quasi-linear flow problem with subsequent pressure decay in the reservoir. This can be modeled with finite differences, as illustrated by examples included in this report. A family of pressure decay curves obtained from tests can be fitted to similar, numerically generated curves to obtain a measure of permeability of the gas/rock system.

Pressure distributions for one-dimensional nonsteady gas flow through porous media is governed by (Scheidegger, 1960, p. 105).

$$
k \frac{\partial^{2}(p)^{2}}{\partial x^{2}}=2 c \mu \frac{\partial p}{\partial t}
$$


where $p=$ pressure

$c=$ effective porosity

$k$ = permeability

$\mu=$ dynamic viscosity

$x, t=$ spatial and temporal coordinates.

Equation 5.2 can be cast in the more convenient form

$$
\frac{\partial^{2}(P)^{2}}{\partial X^{2}}=H \frac{\partial P}{\partial t}
$$

where $P=\left(p-p_{0}\right) / \Delta p$

$X=x / r$

$H=2 c r^{2} / \Delta p K$

and

$$
P_{0}=\text { initial uniform reference pressure in media }
$$

$\Delta p=$ applied initial pressure increment on specimen boundary

$r=$ radius or cylindrical test specimen

$K=$ permeability parameter, $k / \mu$.

Consider a test procedure wherein an initial pressure increment is applied from a reservoir of known volume to the end of a cylindrical specimen. The subsequent pressure decay within the reservoir can be recorded as onedimensional gas flowing into the specimen. Assuming isothermal flow,

$$
\Delta p v=p_{b} v+\int p c d v o l
$$

where $P_{b}=$ time dependent pressure within reservoir contacting specimen

$v=$ volume of reservoir (known)

dvol = differential volume of specimen.

Introduce the additional terms and notations for convenience

$$
\begin{aligned}
a & =f l o w-t h r o u g h \text { area of specimen } \\
\ell & =\text { length of specimen } \\
A & =a / \pi r^{2} \\
L & =\ell / r \\
V & =v / \pi r^{3} \\
P_{b} & =P_{b} / \Delta p .
\end{aligned}
$$


Using these terms and those of 5.3, Eq. 5.4 can be written in the form

$$
P_{b}=1-\int \frac{P c A d X}{V}
$$

The integral of 5.5 is the pressure-weighted ratio of gas capacity in the specimen to reservoir volume.

Test sensitivity will increase directiy with the area to volume ratio $(A / V)$. Hence, specimen flow-through area and reservoir volume should be as large and small, respectively, as practical in testing specimens of low permeability.

The finite difference solution for the test gas pressure can be described with reference to the schematic of Figure 5.3 .

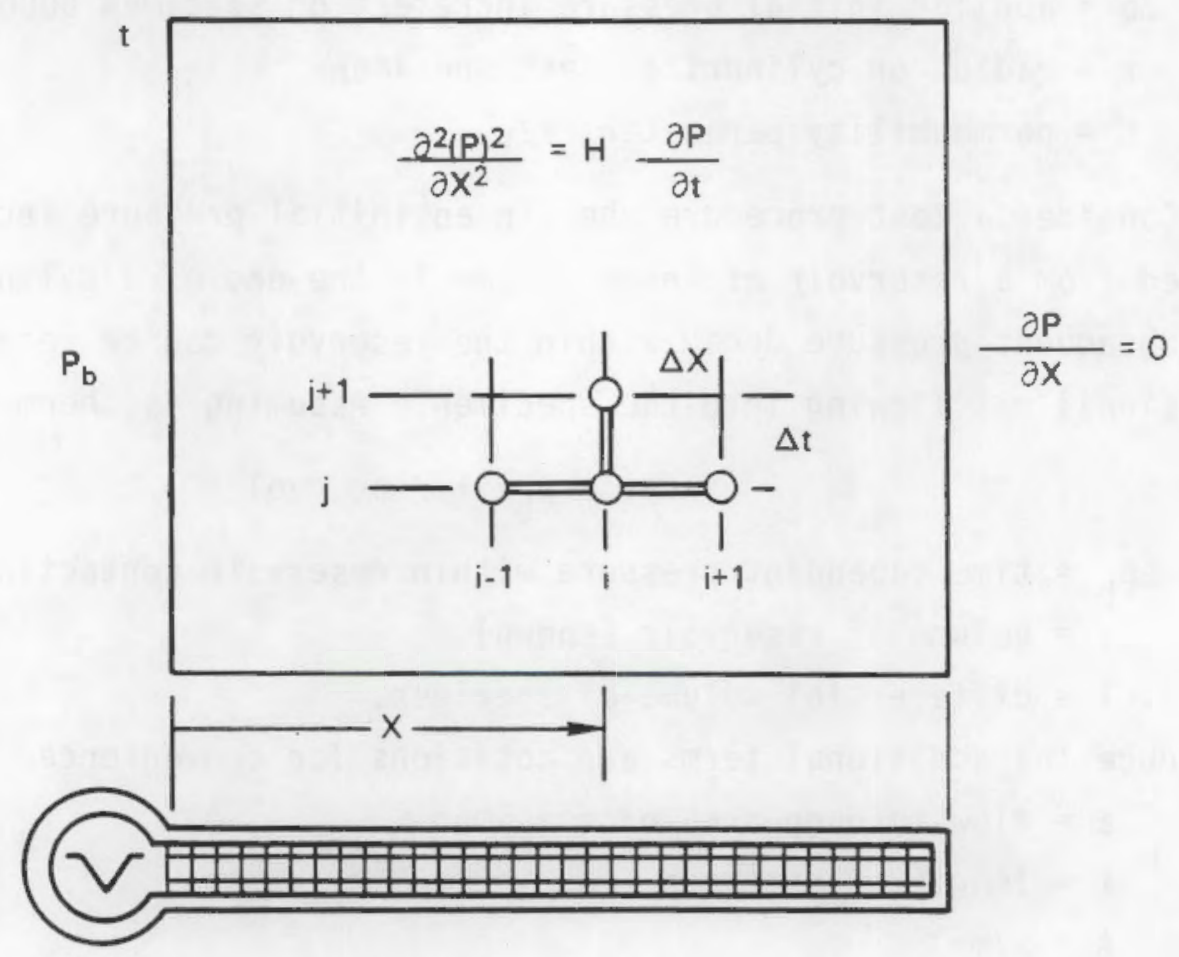

FIGURE 5.3. Specimen and Solution Doma in 
Initial conditions for a typical test specimen are

$$
\begin{aligned}
& P_{b}(0,0)=1 \\
& P(x, 0)=0 \text { for } 0<x \leq L
\end{aligned}
$$

with boundary conditions 5.5 and

$$
\frac{\partial P}{\partial X}(L, t)=0 \quad \text { (assumes specimen end closed) }
$$

An explicit difference algorithm can be written for pressure values at discrete points within the solution domain and equally spaced in directions of the $x$ and $t$ axes, respectively.

$$
[K]\left\{P_{t}^{2}\right\}=\frac{H}{\Delta t}[I]\left(\{P\}_{t+\Delta t}-\{P\}_{t}\right)
$$

where $[K]=$ coefficients matrix of the Eq. 5.3 spatial operator

$[I]=$ unit matrix

$\{P\}_{t},\{P\}_{t+\Delta t}=$ pressure values vectors at time $t, t+\Delta t$.

Using the notation depicted in Figure 5.3 , the following difference operator can be used for Eq. 5.7.

$$
P_{i, j+1}=\frac{\Delta t}{H \Delta X^{2}}\left(P_{i-1}^{2}-2 P_{i}^{2}+P_{i+1}^{2}\right)_{j}=P_{i, j}
$$

For stability of this well known explicit operator

$$
\Delta t \leq 1 / 4\left(H \Delta X^{2}\right)
$$

Boundary conditions can be represented by,

$$
\begin{aligned}
& P_{0, j+1}=1-\frac{C A \Delta X}{V} \sum\left(w_{i}, P_{i}\right)_{j} \\
& P_{L, j+1}=\frac{2 \Delta t}{H \Delta X^{2}}\left(P_{L-1}^{2}-P_{L}^{2}\right)_{j}+P_{L, j}
\end{aligned}
$$

where $w_{i}$ in $5.10(a)$ represents weighting coefficients associated with quadrature for points along $t=j$.

The radial form of the numerical solution is useful for analyzing permeability around boreholes or hollow cylindrical specimens. Accordingly, 
in Eq. 5.3 , replace the linear longitudinal operator by the radial form

$$
\frac{\partial^{2}}{\partial X^{2}}+\frac{\partial^{2}}{\partial R^{2}}+\frac{1}{R} \frac{\partial}{\partial R}
$$

and impose the boundary conditions for the borehole case

$$
p \rightarrow 0 \text { for } R \rightarrow \infty
$$

The finite difference forms for the interior explicit operator and interior boundary condition for the hole surface, respectively, are

$P_{i, j+1}=\frac{\Delta t}{H \Delta R^{2}}\left[\left(1-\frac{\Delta R}{2 R_{i}}\right) P_{i-1}^{2}-2 P_{i}^{2}+\left(1+\frac{\Delta R}{2 R_{i}}\right) P_{i+1}^{2}\right]+P_{i, j}$

and

$$
P_{i, j+1}=1-\frac{2 \pi C \Delta R}{V} \sum_{i}^{L}\left(R_{i} w_{i} P_{i}\right) j
$$

where $v=v / \pi r^{2}$

$v=$ reservoir volume per unit length of hole

$r=$ radius of hole

$L=\ell / r$ with $\ell$ the outer boundary of the numerical solution domain.

The extent of spatial solution domain, $L$, need only be sufficiently large such that numerical results for $P_{1, t}$ at the test hole boundary and reservoir are not affected in the area of interest in the solution. Thus, at the outer boundary, $R=L$ let

$$
P_{L, j+1}=0
$$

Figures 5.4 and 5.5 depict example solutions of $P_{b}$ for the previously described longitudinal and radial flow cases. Parameters used for the solutions are listed on each of the figures.

For implementation of this method, measured pressure decay in the reservoir would be compared to curves similar to those depicted. The closest matching curve could be used to obtain estimates of the ratio of effective porosity, C, and the permeability parameter, K, (Eq. 5.3). Frequently, the ratio $\mathrm{C} / \mathrm{K}$ is adequate information for gas flow problems. If separation of the parameter is required, additional experimental work is required using optical methods to estimate media porosity. 


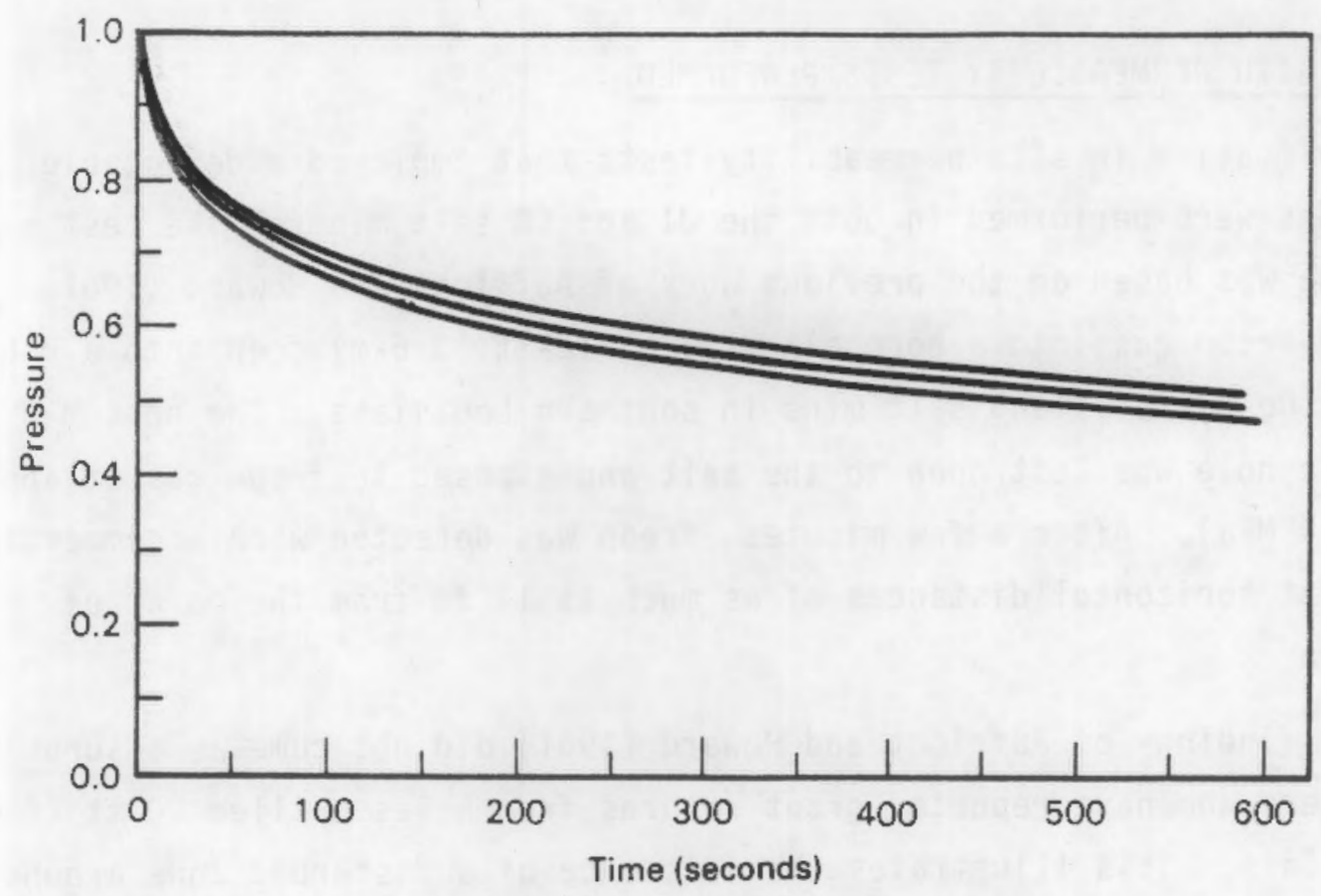

FIGURE 5.4. Pressure Decay for Longitudinal Flow

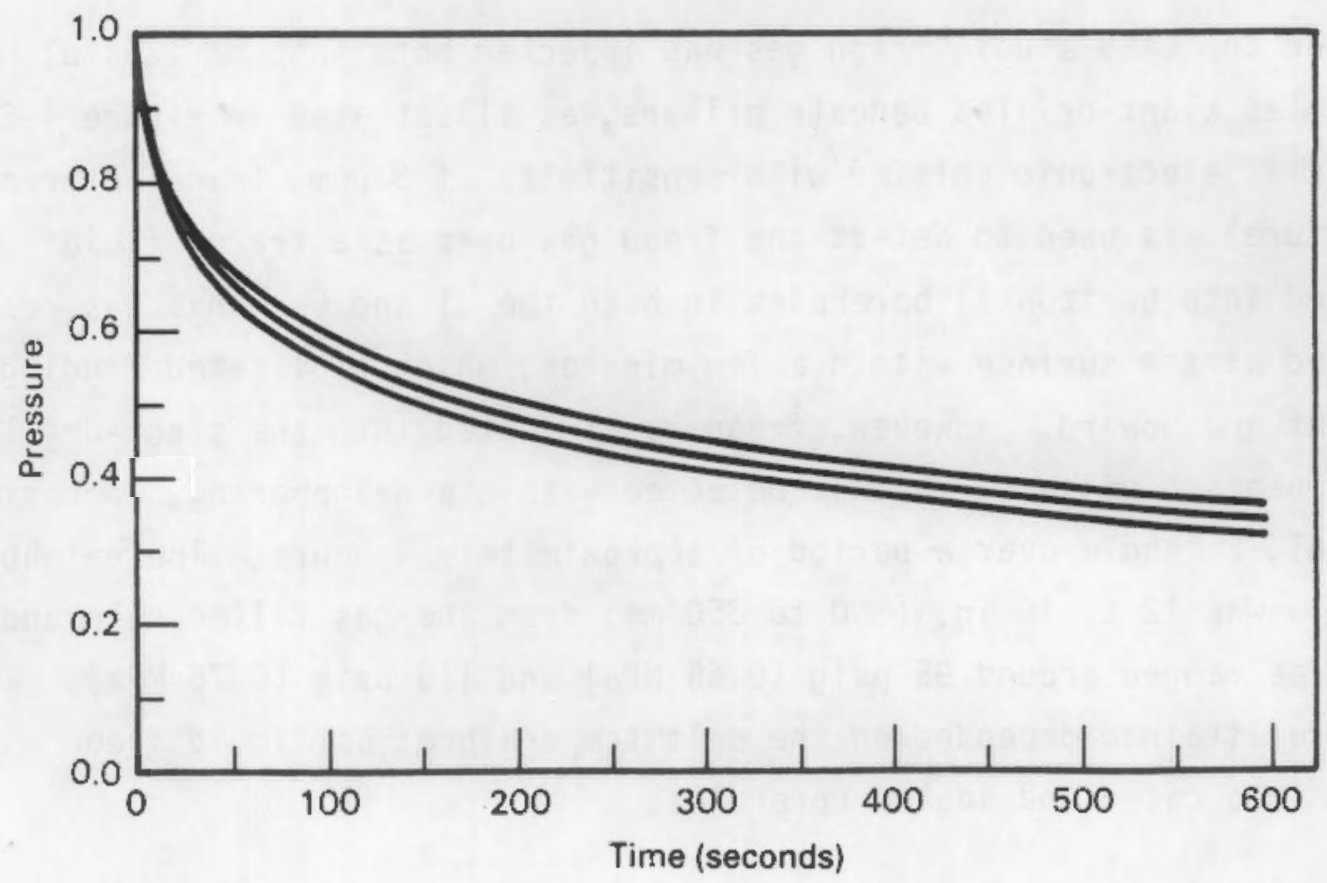

FIGURE 5.5. Pressure Decay for Radial Flow 


\subsection{IN SITU PERMEABILITY TESTS PERFORMED}

Qualitative in situ permeability tests that employed a detectabie tracer gas were performed in both the JI and CB salt mines. The test technique was based on the previous work of Aufricht and Howard (1961). They injected freon gas into a borehole drilled 12-ft (3.6-m) deep into a rib or face of the Weeks Island salt mine in southern Louisiana. The bottom $3 \mathrm{ft}$ (1 m) of the hole was left open to the salt and exposed to freon gas at about 60 psig (0.4 MPa). After a few minutes, freon was detected with a commercial sniffer at horizontal distances of as much as $14 \mathrm{ft}$ from the point of injection.

The findings of Aufricht and Howard (1961) did not come as a surprise to salt miners who have reported grout returns from holes drilled $20 \mathrm{ft}(6 \mathrm{~m})$ into pillars. This illustrates the existence of a disturbed zone around mined openings in salt wherein permeability is induced by lack of salt confinement or damage due to mining. Also, salt from different sources tends to disaggregate to varying degrees. This affects the depth of the disturbed, induced-permeable zone in different mines.

For the CAES study, freon gas was injected both into horizontal holes and into holes slant-drilled beneath pillars, as illustrated in Figure 4.3. A commercial electronic sniffer with sensitivity of $3 \mathrm{ppm}$, (manufacturer's literature) was used to detect the freon gas used as a tracer fluid. Gas injected into horizontal boreholes in both the JI and CB mines was readily detected at the surface within a few minutes, which replicated findings by Aufricht and Howard. However, freon gas injected into the slant-drilled holes, beneath pillars, was not detected within a neighboring, approximately parallel, borehole over a period of approximately 4 hours. The neighboring borehole was 12 to $14 \mathrm{in.} \mathrm{(300} \mathrm{to} 350 \mathrm{~mm}$ ) from the gas-filled hole and pressures ranged around $95 \mathrm{psig}(0.65 \mathrm{MPa})$ and $110 \mathrm{psig}(0.76 \mathrm{MPa})$. The pressure attained depended on the salt temperature, as liquid freon was simply poured into cased and sealed boreholes. 
Salt temperatures at the two sites were measured by sliding laboratorytype glass thermometers on strings into slant holes, plugging the holes for 3 to 4 hours, and then retrieving and reading the thermometers. Temperatures measured at the $\mathrm{JI}$ and $\mathrm{CB}$ sites were $89^{\circ} \mathrm{F}\left(32^{\circ} \mathrm{C}\right)$ and $92^{\circ} \mathrm{F}\left(33^{\circ} \mathrm{C}\right)$, respective$1 y$.

As part of the freon gas monitoring technique at the $C B$ site, the monitored neighboring borehole was fitted with a plastic tube to the bottom of the hole. Periodically, compressed air was injected at low flow rates into the bottom of the hole and the expelled air at the surface was monitored with the sniffer. Still no freon gas was detected in this qualitative cross-hole gas flow test. This appeared to illustrate the apparent low in situ permeability of relatively undisturbed and continuously confined rock salt. Figures 5.6 and 5.7 show test apparatus used for the situ tracer gas test in the CB mine.

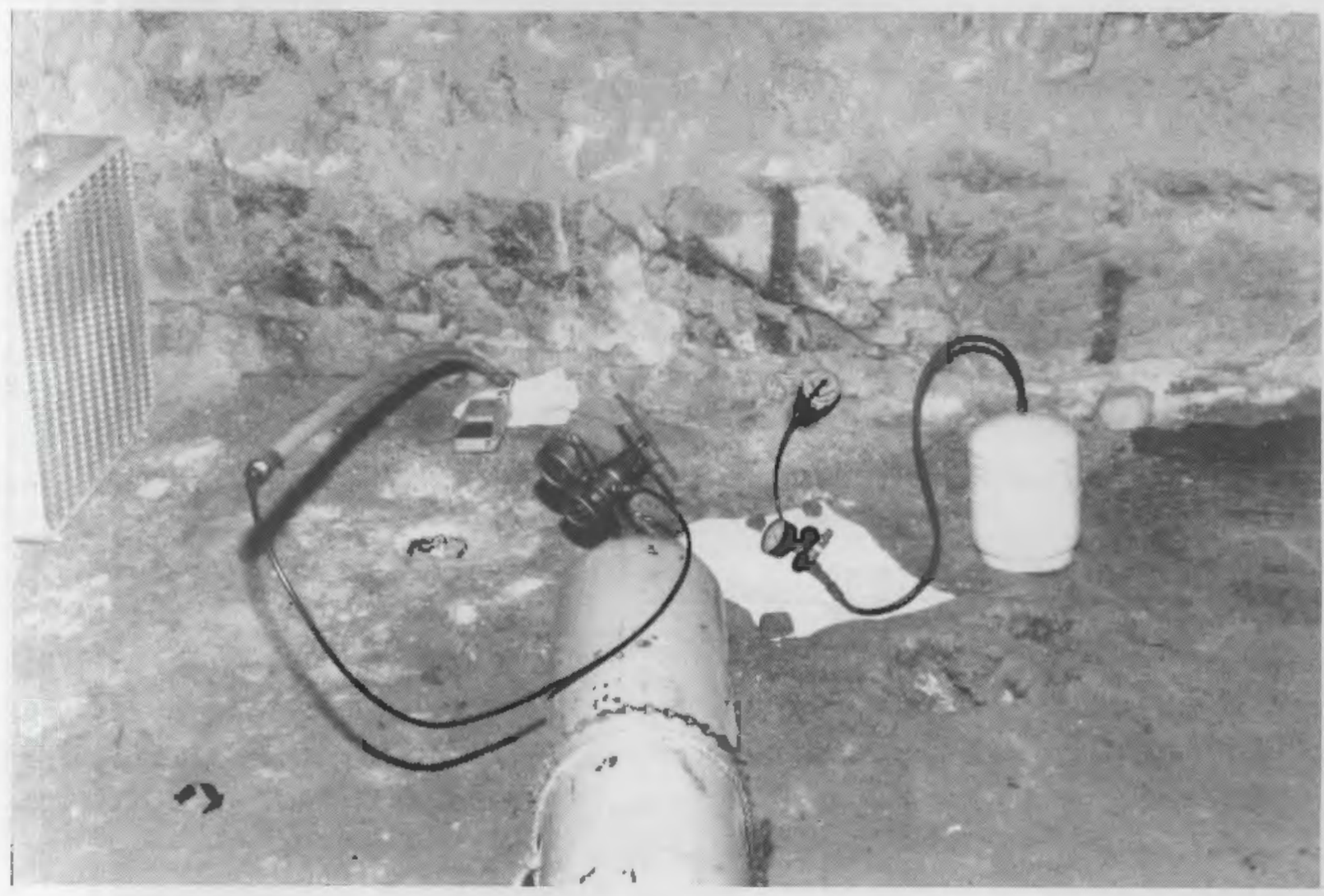

FIGURE 5.6. Apparatus for Tracer Gas Cross-Borehole Test 


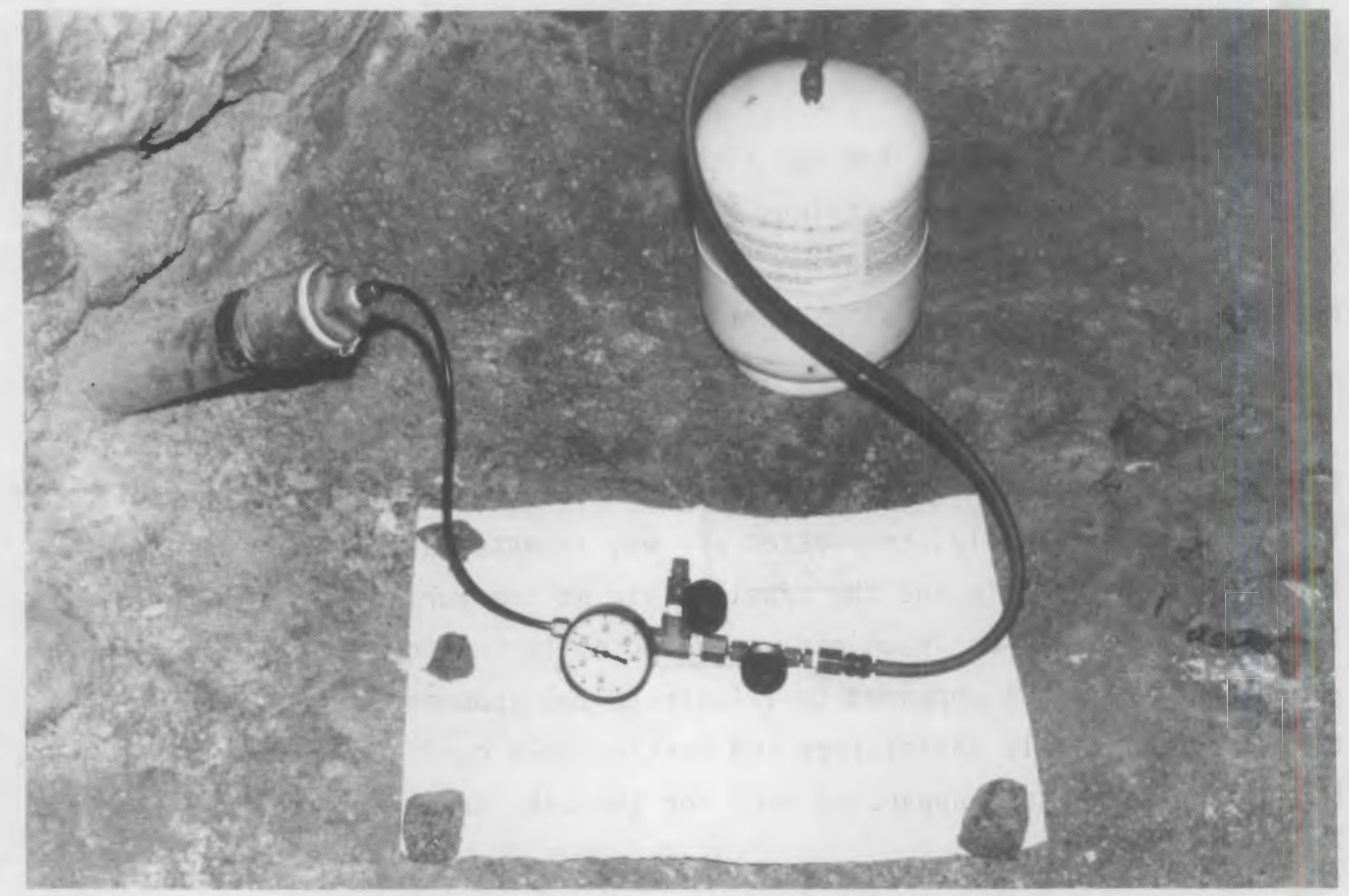

FIGURE 5.7. Freon Gas, Bottle Connected to Test Hole

It should be noted that most of the salt in the near-field around conventionally mined openings is not in a confined and undisturbed condition. As with other rock types, a disturbed zone apparently exists around openings mined in salt. The extent of the disturbed zone can be estimated using a combination of numerical modeling and in situ tests. Measurements of induced permeability could be used to delineate zones of salt disturbances that had practical implications for CAES and other kinds of storage in salt formations.

\subsection{IN SITU PERMEABILITY TESTS PROPOSED}

Quantitative in situ permeability tests in rock salt are more difficult to perform. An exact solution employing bipolar coordinates was derived for cross-borehole flow, assuming gas flow rates could be monitored (Gipson and Thoms 1981). However, the previously described qualitative test indicated cross-borehole flow rates in confined salt would be to low to measure, removing this as a practical method of testing. 
A transient method was outlined that employed the numerical solution for radial flow in Section 5.2 (Eqs. 5.11 through 5.14, Figure 5.5) and a borehole straddle packer. An initial-design straddle was developed and carried into the $C B$ mine for tests in boreholes of $2-i / 4-i n .(57-\mathrm{mm})$ diameter and $60-\mathrm{ft}$ (18.3-m) depth in the floor. Such boreholes are routinely drilled for blasting while bench mining in the $C B$ mine. They are available for tests onty for limited time periods between drilling and filling with explosives; thus, a reasonably fast permeability test is essential.

The initial-design straddle packer did not perform satisfactorily in the described hole because of air leakage between the rubber sleeves and the borehole wall. The walls displayed a helical spiral relief pattern caused by the action of the two-blade drag bit used in drilling. The packer sleeves apparently were not sufficiently compliant to seal against such a surface. A second-generation packer was designed but not implemented. It used materials based on successful packers developed by others (Warne et a1. 1979).

\subsection{CONCLUDING REMARKS}

The following remarks are based on the permeability related works described in this section. The laboratory and in situ tests form the basis for these remarks.

The apparent permeability of rock salt depends upon degree of disturbance, contact with brine, and confining pressure. Both the current status and the history of rock salt affects its permeability.

A correlation exists between the extent of the disturbed zone in the near field around mined openings in salt formations and the permeability induced by the mining of the openings. This offers possibilities for measuring the extent of the disturbed zone with pressure decay tests in boreholes.

Tracer gas flow was readily detected at mine pillar surfaces after injection into horizontal boreholes. This corroborated in situ test results. However, no cross flow could be detected between parallel boreholes at spacing of 12 to $14 \mathrm{in}$. (305 to $355 \mathrm{~mm}$ ) that were slant-drilled into confined and 
relatively undisturbed salt in mine floors beneath pillars. Further, these test holes were drilled dry; thus, salt glazing with surface impermeability was not introduced by brine contact.

Apart from economics, solution-mined openings appear most appropriate for CAES reservoirs in salt formations because the method results in both little disturbance of the surrounding salt and surface glazing from brine contact. Both of these features are highly desirable. 


\subsection{COMPLEMENTARY MODELING AND ANALYSIS}

\subsection{ROLE OF COMPLEMENTARY MODELING AND ANALYSIS}

The main purpose of this study was to perform laboratory and bench-scale field tests for CAES effects on rock salt. The major modeling effort for CAES was performed by others. Therefore, only limited modeling was performed for this study and was done to support planning and interpretation of tests described in other sections of this report. Sections 6.2 and 6.3 out 1 ine the salient features of two numerical solutions used directly in this study. Section 6.4 summarizes other solutions achieved but not implemented.

\subsection{TYPICAL CAES CAVERN}

The laboratory test program was planned to account for loading environments associated with CAES caverns in salt formations. Thus, the test series was selected to span stress-states at points in the salt surrounding a typical CAES cavern. General stress-state estimates were achieved with a simplified finite element method (FEM) model of a typical CAES cavern.

Figure 6.1 illustrates the solution obtained for stresses around a typical CAES cavern. Parameters assumed for the solution are indicated in the figure. We again note that this solution was obtained to furnish only a guide for selection of laboratory loading environments. A more sophisticated analysis certainly would be justified for design of CAES caverns with sitespecific data.

\subsection{STRESS DISTRIBUTION FOR TEST SITES IN SALT MINES}

The in situ pressure tests described in Section 4 were a major part of this study. An FEM analysis of the site and surroundings, using a program called CREEP (Gehle 1980), was performed to aid in interpretation of collected data. The site was in the CB mine in southern-Louisiana and boundary conditions were assumed on the basis of available mine data. 


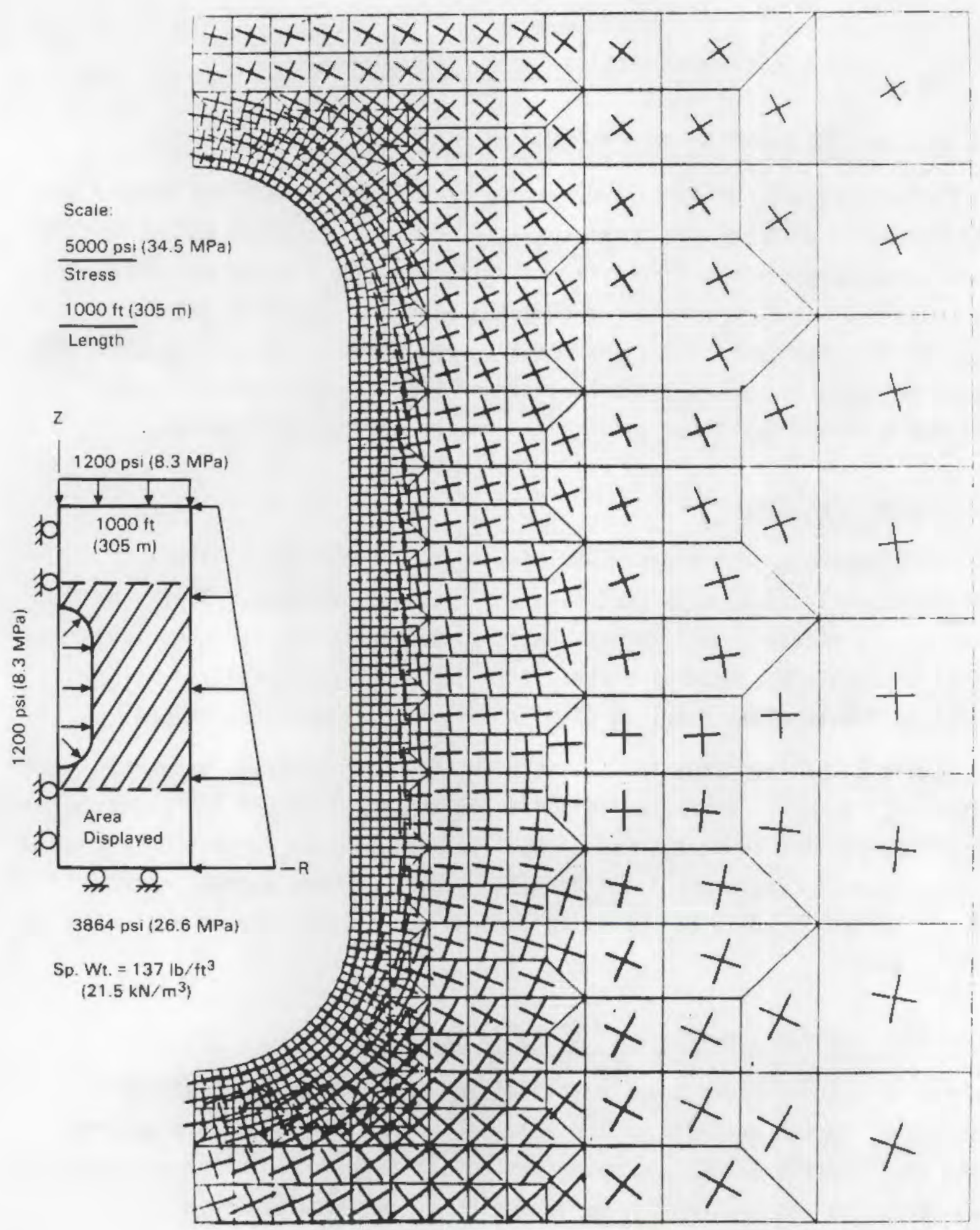

FIGURE 6.1. Stress Distribution Around a Typical CAES Cavern 
Figure 4.3 depicts results from a portion of the FEM analys is of the test site in the CB mine. Boundary conditions and other assumed data corresponded to effects of the overburden associated with depth and the tributary area of the pillar. This simple approach does not account for possible bridging or arching action over the mine within the salt dome. As noted in Section 4 , relative rather than absolute values of stresses obtained in the FEM analysis were considered more meaningful for this study.

\subsection{OTHER NUMERICAL AND ANALYTICAL SOLUTIONS}

A number of other analytical and numerical solutions were achieved under the auspices of this study. However, for various reasons, they were not implemented. These solutions are noted here, along with the reasons for their disregard.

A closed-form analytical solution was achieved for flow through porous media between two parallel boreholes (Gipson and Thoms 1981). The solution was obtained for analyzing crosshole gas flow in salt from pressurized to nonpressurized boreholes. In principle, an in situ permeability test could be performed using this solution in conjunction with parallel boreholes drilled into a salt formation. However, in practice, drilling parallel boreholes in rock formations is difficult. Furthermore, as noted in Section 5, gas flow through confined, undisturbed salt beneath a mine pillar was imperceptible as indicated by relatively sensitive instrumentation. Thus, the closed-form solution was not impiemented in this study.

A numerical, finite element solution was achieved for gas pressure distribution in salt around vertical boreholes drilled into salt in the mine floor. This solution was not used because the test hole configuration was changed from vertical boreholes to slanted holes beneath pillars, as indicated in Figure 4.3. Vertical boreholes were drilled in the initial early field work in the JI mine; however, it was determined that they were in a floor-heave prone area with open horizontal partings. Hence, the slant-hole test configuration was adopted. 
Time-dependent temperature distributions in salt specimens were analyzed for laboratory tests. Initial planning for laboratory tests included cycling of both thermal and applied stress effects. As testing proceeded, it became evident that thermal inertia of the specimen test apparatus would not permit thermal cycling of specimens at the same frequency as applied stresses. Thus, specimen testing was simplified to application of cycilic stresses at constant, approximate room temperature, followed by a constant, elevated temperature phase with the same stress loadings.

The time-dependent solution for specimen temperatures was not directly implemented for analys is of test data, but was useful for estimating transient thermal response of salt specimens. This information was used in deciding to simplify to constant elevated temperature tests. In addition to difficulties associated with the thermal inertia of the experimental apparatus, the analysis of effects of nonhomogeneous cyclic temperature fields in test specimens also appeared formidable. A procedure involving either periodic optical inspections or measurements of permeability variations to detect progressive rock salt fabric disaggregation might present a more appropriate course for cyclic thermal testing.

\subsection{CONCLUDING REMARKS}

Numerical and analytical solutions complementary to this study have been presented or noted. Though purposely limited in scope, the solutions were very valuable for planning tests and interpreting resulting data. 


\subsection{PROPOSED SITE-SUITABILITY FIELD TEST FOR CAES CAVERNS}

\subsection{NEED AND SIGNIFICANCE OF A FIELD TEST FOR SITING CAES CAVERNS IN SALT}

Design of efficient salt caverns for CAES reservoirs requires realistic estimates of cavern volume loss due to creep closure. This is not a simple task in rock salt, which has been described previously as a nonlinear, timedependent material.

A complete rock mechanics investigation for a proposed CAES site would incorporate triaxial cyclic laboratory tests of salt core specimens, numerical modeling, and field tests for predictive and design purposes. However, frequently, the in situ or initial stress-state in salt is assumed rather than measured because of the difficulty of measuring stress in salt. These assumed boundary conditions introduce an element of uncertainty in analysis based purely on laboratory testing and numerical modeling.

This section proposes a site-specific field test method for predicting closure of planned CAES caverns. It utilizes an exploratory borehole or boreholes and concepts of dimensional analysis and model theory. Basic elements of this method were proposed previously in papers relating to in situ salt tests and for caverns under static pressures (Thoms et al. 1977; Thoms et a1. 1982). The concepts presented here and discussed previousiy, extend the proposed test method to cyclic pressures, i.e., CAES reservoir applications. Closure of natural gas storage caverns with seasonal cyclic pressure variations also can be estimated by the field test method outlined in this study. It can be used readily in a complementary mode to laboratory testing and numerical modeling or it can be used directly on a first-estimate basis for judging suitability of salt formations for cavern siting.

\subsection{FACTORS AFFECTING CAVERN CLOSURE IN SALT FORMATIONS}

A number of factors affect closure of caverns in salt formations. Major factors include:

- difference between geostatic stress and cavern pressure

- mechanical properties of the salt formation 
- cavern configuration

- salt temperature.

Each of these factors will be briefly discussed.

Loading of the salt surrounding storage caverns is due to the difference between geostatic stress, $g$, in the salt formation and applied cavern pressure, $p$. The term $g-p$ has been called the pressure difference and effective overburden by Rohr (1974) and Thoms, Nathany and Gehle (1982), respectively. The latter name is after the effective stress concept of soil mechanics, but differs because confined rock salt displays insignificant effective porosity. Note the geostatic stress includes both overburden and any other initial stress effects on the salt formation. Figure 7.1 is a schematic of variations in effective overburden for some characteristic points in the sait around a noncompensated CAES cavern.

Mechanical properties of salt include the elastic response, transient creep phase, and long-term or steady creep phase behavior of the host salt formation. For cavern closure, the mechanical properties should include the

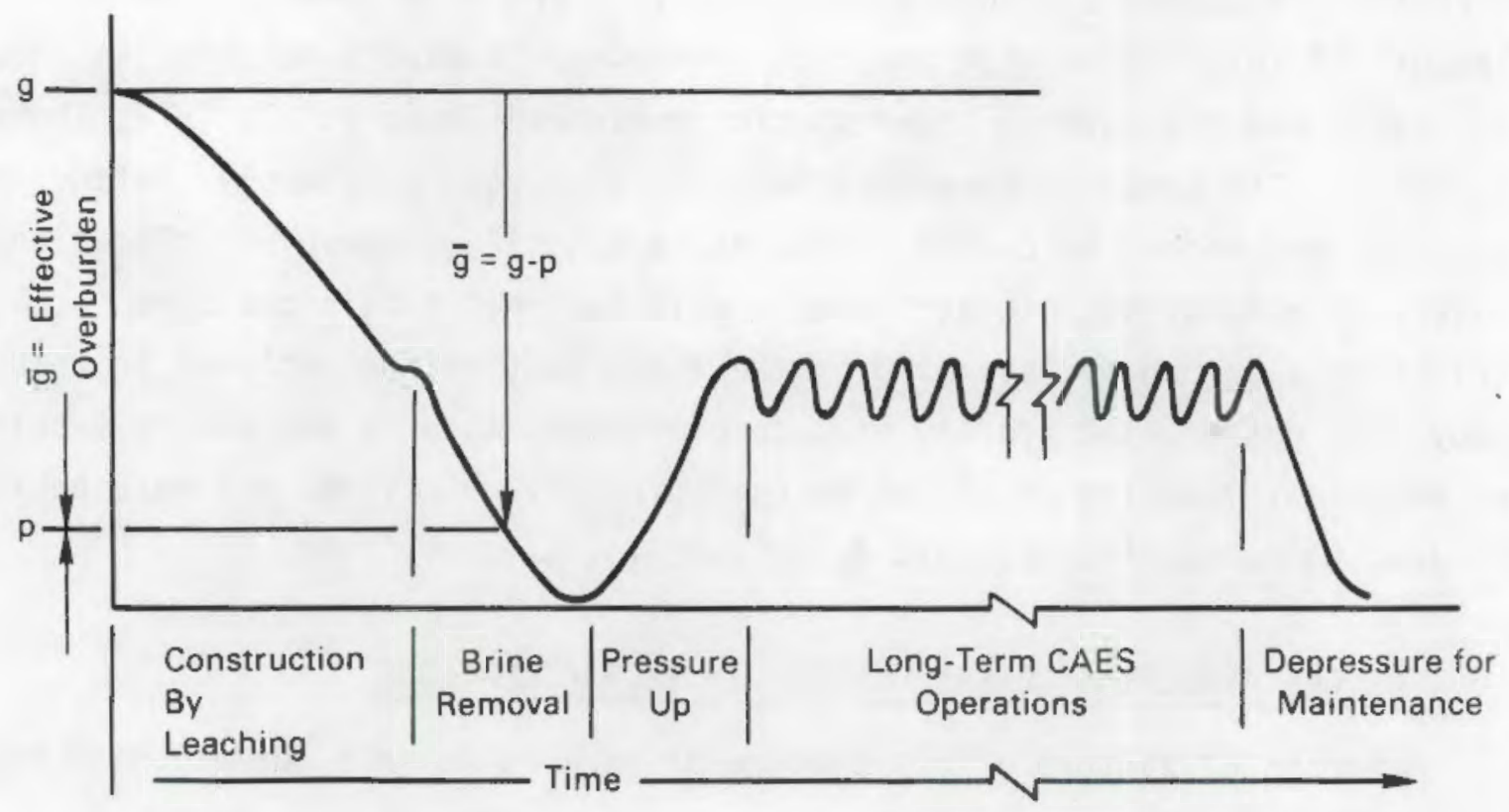

FIGURE 7.1. Effective Overburden for CAES Salt Cavern 
integrated behavior of the salt formation. Thus, composite effects of anhydrite and shales, if present, should be taken into account along with halite over the planned depth interval for caverns.

Cavern configuration is not as critical for stability in salt rocks as in hard rock due to the plasticity of salt. However, for any homogeneous media, spherical openings obviously will be more stable than cylindrical openings. For practical reasons, vertical cylindrical openings are usually designed and solution-mined for storage caverns. In principle, the most stable caverns would have a height/diameter $(H / D)$ ratio of one. But efficient utilization of salt dome space and economics of well drilling result in caverns with $\mathrm{H} / \mathrm{D}>2$ and larger. As $H / D$ increases, the caverns become somewhat less stable due to lack of end restraint and approach the behavior of vertical, essentially open-end cylinders. This latter case approximates the closure behavior of boreholes or mine shafts.

Rock salt creep behavior is strongly influenced by temperature. This has been thoroughly investigated in studies of radioactive waste disposal in salt. For example, Lomenick (1968) emphasized that elevated temperature strongly accelerates creep of rock salt and this has been re-emphasized by numerous, more recent studies. For CAES caverns, the stored air has low heat capacity and thermal conductance relative to the surrounding sait. Thus, only the very near surface salt would be affected by elevated temperatures and this probably would be insignificant. However, formation temperatures at similar depths vary between sait deposits and this must be taken into account.

\subsection{YIELD DEPTHS FOR SALT CAVERNS}

Exploratory boreholes drilled into salt formations exhibit obvious rapid increases in closure rates at certain depths, hereafter called yield depths. For medium and slender cylindrical caverns $(H / D \geq 2)$, the yield depths for caverns and boreholes will be approximately equal provided appropriate conditions are maintained. These conditions will be discussed later. 
As an example, the apparent yield depth for a brine-filled borehole in a Gulf Coast dome was approximately $3400 \mathrm{ft}(1036 \mathrm{~m})$ (Thoms et a1. 1982). If the brine was removed from the hole by air lift or bailer, thus increasing the effective overburden, $g-p$, the yield depth would become more shallow.

It should be emphasized that the yield depth depends on all four factors discussed in Section 2 and this implies dependence on site-specific conditions. Further, the planned use of the cavern must be known to accommodate future variations in the effective overburden. The combined data requirements of site-specific information and planned future use are consistent with all geotechnical design projects.

\subsection{DIMENSIONAL ANALYSIS OF VOLUME CHANGE FOR OPENINGS IN SALT}

Relations between field tests and salt cavern performance can be established through application of the general concepts of dimensional analysis and theory of physical models (Langhaar 1951). By this approach, let the system comprising the field test be the physical model and the planned storage cavern be the prototype. Modeling laws derived from the associated dimensional analysis yield relations for predicting cavern performance from appropriate field test data.

In general, the volume change of openings in salt at some time can be written as the sum of the elastic and time-dependent response.

$$
\Delta V(t)=\Delta V_{i}+\int_{0}^{t} \Delta \dot{V} d \tau
$$

where $\Delta V(t)=$ accumulated volume change at time, $t$, with reference to load application(s)

$\Delta V_{j}=$ immediate volume change with load

$\Delta \dot{V}=$ volume change rate.

The immediate and time-dependent volume change will be considered uncoupled. The volume change rate includes both transient and steady-state effects for this general analysis. 
A general relationship can be written for the immediate volume change in terms of the independent variables

$$
f_{1}\left(\Delta V_{i}, g-p, D, E, v\right)=0
$$

where $\Delta V_{i}=$ immediate volume change with load application,

$g-p=$ effective overburden due to difference in prevailing geostatic stress and cavern pressure load application. g includes both overburden and any other site-specific stress effect. $\left[\mathrm{FL}^{-2}\right]$

$D=$ characteristic length dimension, i.e., cavern diameter [L]

$E$ = effective reaction modulus, $\left[\mathrm{FL}^{-2}\right]$

$v=$ Poisson's ratio for salt, [1]

By dimensional analysis, Eq. 7.2 implies a relationship between dimensionless products.

$$
\frac{\Delta V_{i}}{D^{3}}=f_{\uparrow}\left(\frac{g-p}{E}, v\right)
$$

Modeling laws derived from 7.3 are

$$
\left(\Delta V_{i}\right)_{p}=\frac{D_{p}^{3}}{D_{m}^{3}}\left(\Delta V_{i}\right)_{m}
$$

provided

$$
(g-p)_{p}=\frac{E_{p}}{E_{m}}(g-p)_{m}, v_{p}=v_{m}
$$

For site-specific tests, $E_{p}=E_{m}$ and $\nu_{p}=\nu_{m}$. Then Equations 7.4 imply immediate volume changes of geometrically similar openings in salt vary as the cube of their diameters, provided differences in geostatic and applied pressures are maintained equal. In principle, this permits tests to be performed at shallower depths than planned for operational caverns, provided $\mathrm{g}$ is known, and that salt around the test cavern is adequately confined by the overburden. This is a direct result of assuming dependence on $g-p$ alone for 
$\Delta V_{i}$. An average value of $g$ would have to be assumed for the model to represent the effect of $g$ varying with depth over the height of an operational cavern.

Consider, now, the use of a vertical cylindrical opening, i.e., borehole, as the model for operational caverns. A borehole section can be isolated over an interval equal in depth and length to the height, $H$, of the planned storage cavern. This implies equality of material properties and geostatic stress for model and prototype, but distortion of geometry.

Use of a borehole for a model of a cylindrical cavern means

$$
\left(\frac{H}{D}\right)_{m}>\left(\frac{H}{D}\right)_{p}
$$

Associated model test data will be dominated by lateral closure effects; restraining effects of borehole ends will be small. Therefore, the model test data will be most representative of slender caverns, e.g., $H / D \geq 4$. However, it will always yield conservative estimates for cavern closure over the same depth interval. Equations 7.4 are modified to

$$
\left(\Delta V_{i}\right)_{p} \simeq \frac{H D_{p}^{2}}{H D_{m}^{2}}\left(\Delta V_{i}\right)_{m}=\frac{D_{p}^{2}}{D_{m}^{2}}\left(\Delta V_{i}\right)_{m}
$$

with the condition 7.4 (b) specializing to

$$
P_{p}=P_{m}
$$

since $g, E$, and $v$ are equal under these test conditions.

Equations 7.6 indicate that the immediate or elastic volume changes of boreholes and cylindrical caverns over the same depth intervals vary approximately as the square of their diameters, provided the same cavern test pressures are used.

Time dependent closure effects are of major interest for storage in salt caverns. They also are considerably more difficult to analyze. Consider a 
relationship between variables affecting the volume change rate indicated in Eq. 7.1 for geometrically similar openings in salt.

$$
f_{2}(\Delta \dot{V}, g-p, D, \Theta, t, \pi)
$$

where $\Delta \dot{V}=$ volume change rate related to a reference load application $\left[L^{3}\right.$, $\left.T^{-1}\right]$

$g-p=$ effective overburden history $\left[\mathrm{FL}^{-2}(\tau)\right]$

$D=$ cavern diameter $[L]$

$\theta=$ temperature in salt at a characteristic location, i.e., cavern midheight $[\mathbb{(})]$

$t=$ time from reference load application $[T]$

$\eta=$ viscosity of salt nonlinearly dependent on stress, temperature, and time $\left[\left(\mathrm{FL}^{-2}\right)^{\mathrm{a}}, \oplus^{\mathrm{b}}, \mathrm{t}^{\mathrm{c}}\right]$

Since four fundamental dimensions--force $(F)$, length ( $L)$, temperature $(T)$, and time $(t)$--occur in 7.7 , by dimensional analys is there exists a relationship between two-dimensional products

$$
\frac{\Delta \dot{V} t}{D^{3}}=f_{2}\left(\frac{(g-p)^{a}(\theta)^{b} t^{c}}{\pi}\right)
$$

where $a, b, c$ are site-specific, unknown salt response parameters. Equation 7.8 yields the prediction equation

$$
\Delta \dot{V}_{p}=\frac{D_{p}^{3} t_{m}}{D_{m}^{3} t_{p}} \Delta \dot{v}_{m}
$$

provided

$$
(g-p)_{m}^{a}=\frac{\left(\theta^{b} t^{c}\right)_{p} n_{m}}{\left(\theta^{b} t^{c}\right)_{m} n_{p}}(g-p)_{p}^{a}
$$


Consider the important special case where the same loading history, (g-o) versus time, is applied to the model field test cavern as planned for the prototype cavern. Then Eq. 7.9 (a) reduces to

$$
\Delta \dot{V}_{p}=\frac{D_{p}^{3}}{D_{m}^{3}} \quad \dot{v}_{m}
$$

and

$$
\int^{t} \Delta V_{p} d \tau=\frac{D_{p}^{3}}{D_{m}^{3}} \int^{t} \Delta \dot{V}_{m} d \tau
$$

at the same time after a reference loading.

Using a borehole as the model, let $D^{3} \rightarrow D^{2} H$ as noted previously. Then for identical cavern pressure and effective overburden histories, the associated volume change at any time varies approximately as the square of cavern diameters over a common depth interval. End effects again are essentially neglected with the borehole serving as a model cavern.

Predictions for long-term storage in caverns generally are 1 imited in usefulness if tests must be performed in real time. Laboratory creep tests of salt frequently are halted when specimens display steady-state displacement behavior. Field tests can be performed in a similar way, provided volume change of test openings, e.g. boreholes, can be monitored.

Following the transient phase of volume change, additional long-term change can be estimated as a simple product of the measured steady-state volume change rate and time interval of interest. Then the next phase of testing can be initiated to estimate other effects. It is recognized that some error is introduced by the method of estimating the nonlinear, fading memory response of salt; but, field test programs usually must be completed in relatively short time periods if they are to be useful for design purposes.

Cyclic pressure applications to boreholes in rock salt cause corresponding short-term "elastic" cyclic diametrical displacement response. However, the mean value of displacement with time exhibits long-term creep 
behavior generaliy similar to data plotted from constant load creep tests (Thoms and Gehle 1982). Based on these observations, it is proposed that performance of CAES caverns can be estimated by cyclic pressure applications to boreholes until the mean value of borehole volume change with time approximates a steady-state trend. Then long-term behavior again can be estimated by products of time intervals of interest and the steady-state mean volume change rate due to simulated CAES cyclic load applications.

\subsection{IMPLEMENTATION}

As a part of site investigations for storage projects, exploratory boreholes generally are drilled into salt formations to take cores for geological studies and to run geological logs (e.g., caliper, density, neutron). Guidelines for testing such boreholes to predict cavern performance are described here.

A cement plug and test pipe, as indicated in Figure 7.2 , should be set in the borehole as soon as practical after the hole has been completed. A plug is preferable to a packer for long-term pressure tests. The plug should be set in salt at the depth of the top of the planned cavern(s) and the test pipe brought to the surface where displaced brine can be monitored and stored in a holding tank.

The plug and test pipe, e.g., nominal 2 in., schedule 80 , can be installed with a smaller rig than the drilling/coring rig, if this is more economical. Provisions should be made to install a smaller pipe/tubing inside the test pipe for later air-blowout purposes. All pipe joints should be checked to withstand pressures equal to around 1.5 times the brine head at the total depth of the cavern. After the plug and test pipe/tubing are in place, the rig can leave the site.

Initially, some brine will be extruded through the pipe into the hoiding tank by hole closure over the test section. Off-the-shelf redundant instrumentation can be used to record reliable data on brine level in the holding tank. The test salt section and pipe system can be checked out for 


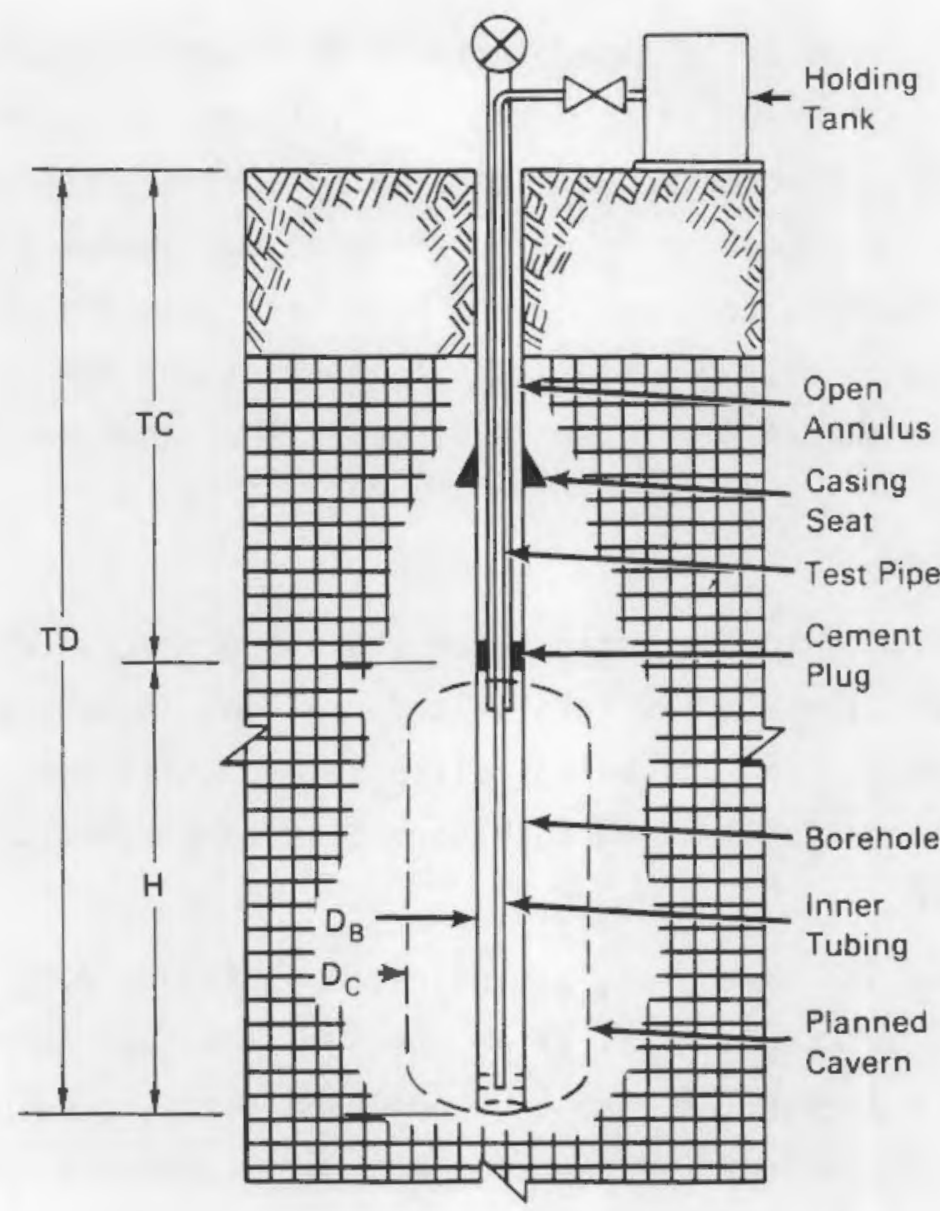

FIGURE 7.2. Borehole Testing Schematic

leaks by shutting off brine outflow and permitting pressure to increase. The pressure should not be permitted to exceed the hydrofrac limits at the plug depth for the salt formation at the site. (A larger frac gradient is generally used for dome salt than bedded salt).

At no time is the main casing seat endangered by any part of the test program. A constant brine head to atmosphere is maintained in the annulus test pipe and casing and above the test section plug. Thus, the hole casing is isolated from pressure variations at depth in the salt formation. Further, any salt fractured in the near-field around the test section would be later removed with solution-mining of caverns. 
After elevated pressure tests for leaks, the hole should be permitted to expel brine into the holding tank for some time. The brine expulsion rate should slow to a relatively constant value before the next phase.

Generally following the load history in Figure 7.1 , brine can be airlifted or blown out of the test section and the hole pressure permitted to decrease to atmospheric leve1s. If desired, this can be done by steps, with periodic volume checks. The state of atmospheric cavern pressure corresponds to maximum effective overburden, $g-p$, and represents a severe load condition. However, this condition can occur in noncompensated CAES and natural gas storage caverns and its effects should be checked. A7so, at this time the possible presence of explosive gases, e.g. methane, in the salt should be carefully monitored.

Volume change of the test section can be checked periodically by returning and then removing brine from the test section. Erosion of the test section should be avoided. Fluid volume in the holding tank can be used to measure hole volume changes. An essentially constant increment of hole volume change on each filling can be attributed to elastic response of the salt. Since the elastic volume change will be constant, it will not contribute to the time varying creep closure changes. Further, the elastic closure will be relatively small and constant, and thus, can be neglected for long-term effects.

After hole volume changes become relatively steady under constant atmospheric pressure, a cyclic phase can be initiated to test CAES effects on the salt. Following previous test patterns, the load cycles of an operational CAES plant can be simulated by a surface compressor. Hole volume can be checked by periodic refilling and removing brine from the hole into the holding tank. Air flow meters also should be used to obtain data that can be used with the gas law to estimate hole closure during cyclic loadings between brine refillings.

Ideally, the cyclic test phase should continue until hole behavior can be reliably characterized by a steady-state trend. Then the long-term 
performance of a CAES cavern at the site can be estimated on the basis of Eq. 7.10 of Section 7.4 .

After testing has been completed, the pipe and tubing can be freed from the plug and pulled out of the hole. The cement plug can be drilled out and the hole used for any further development at the site.

\subsection{CONCLUSION}

A field test method using exploratory boreholes has been outlined for estimating yield depths and creep closure of storage caverns in salt. The method has the advantage of incorporating planned cavern use and site-specific properties such as salt creep, initial or in situ stresses, and formation temperatures. Tests can be performed with hole casing seats fully protected for future developments.

The method does not account for possible interaction between neighboring caverns; however, complementary numerical modeling can be used to analyze this effect with data from the field test. Also, cavern roof falls and floor heaves cannot be predicted, but indications of general cavern instability should be obvious.

The field test method should be relatively inexpensive to perform, because only wel1-known oil-field/waterwell techniques and readily available equipment are required.

Time required to perform the tests will depend on planned cavern use, e.g., CAES, gas, or other storage. A reasonable estimate of long-term cavern performance should be possible after around 4 to 6 months of tests following completion of exploratory boreholes. 


\section{REFERENCES}

Aufricht, W. R., and K. C. Howard. 1961. "Salt Characteristics as They Affect Storage of Hydrocarbons." J. Pet. Tech., August, pp. 733-738.

Bieniawski, Z. T., and 1. Hawkes. 1977. "Suggested Methods for Determining Tensile Strength of Rock Materials." In Rock Characterization Testing and Monitoring, ed. E. T. Brown, pp. 120-121. Pergammon Press, Oxford, United Kingdom.

Gehle, R. M. 1980. Finite Element Analysis of Slow, Time-Dependent, RockSalt Deformations. M.S. Thesis, Louisiana State University, Baton Rouge, Louisiana.

Gipson, G. S., and R. L. Thoms. 1981. "On the Transport of Gaseous Matter through Permeable Media Between Cylindrical Cavities." Int. J. Engr. Sci., $19(8): 1095-1100$.

Jaeger, J. C., and N. G. W. Cook. 1979. Fundamentals of Rock Mechanics. 3rd ed., p. 389. Chapman and Hall, London, England.

Langhaar, H. L. 1951. Dimensional Analysis and Theory of Models. John Wiley and Sons, New York, New York.

Lomenick, T. F. 1968. Accelerated Deformation of Rock Salt at Elevated Temperature and Pressure and its Implications for High Level Radioactive Waste Disposal. Ph.D. Dissertation, University of Tennessee, Knoxville, Tennessee.

Obert, L. 1963. An Inexpensive Iriaxial Apparatus for Testing Mine Rock. Bureau of Mines Report 6332, U.S. Bureau of Mines, Denver, Colorado.

Rohr, H. U. 1974. "Mechanical Behavior of a Gas Storage Cavern in Evaporitic Rock." In Proc. 4th International Symposium on Salt. Vol. II. Northern Ohio Geological Society, Cleveland, Ohio.

Scheidegger, A. E. 1960. The Physics of Flow Through Porous Media. pp. 93-105. University of Toronto Press, Toronto, Ontario, Canada.

Sutherland, H. J., and S. P. Cave. 1980. "Argon Gas Permeability of New Mexico Rock Salt Under Hydrostatic Compression." Int. J. Rock Mech. Min. Sci. \& Geomech. Abstr. 17:281-288.

Thoms, R. L., and R. M. Gehle. 1982. "Experimental Study of Rock Salt for Compressed Air Energy Storage." In ISRM Symposium, Aachen, Rock Mechanics: Caverns and Shafts, ed. W. Wittke, pp. 991-1002. A. A. Balkema, Rotterdam, The Netherlands.

Thoms, R. L., T. A. Manning, L. K. Paile and R. M. Gehle. 1977. "Site Specific Study for Possible Ongoing Salt Dome Movement." In Energy Resources and Excavation Technology, Proc. 18th U.S. Symposium on Rock Mechanics, pp. 4B6.2 - 4B6.10. Colorado School of Mines Press, Golden, Colorado. 
Thoms, R. L., M. Mogharrebi and R. M. Gehle. 1982. "Geomechanics of Borehole Closure in Salt Domes." In Proc. Sixty-First Annual Convention, pp. 228-230. Gas Processors Association, Tulsa, Oklahoma.

Thoms, R. L., M. Nathany and R. M. Gehle. 1982. "Low-Frequency Cyclic Loading Effects on Rock Sa1t." In Rockstore 80, Proc. Inter. Symp. on Subsurface Space for Environmental Protection, Low Cost Storage and Energy Savings, ed. M. Bergman, Vol. 2. Pergammon Press, Oxford, United Kingdom.

Warne, L. K., R. R. Beasley, P. J. Langdon and A. K. Jacobson. 1979. Direct Measurement of Change in Width of Horizontal Fracture in 0 il Shale.

SAND-78-2008, Sandia Laboratories, Albuquerque, New Mexico. 


\section{DISTRIBUTION}

No of

Copies

QFFSITE

US Department of Energy

Attn: E. Reimers

Off. Energy Storage and Dist.

Forrestal Bldg, CE-141 5E-052

Washington, DC 20585

US Department of Energy

Attn: K. Klein

Off. of Energy Storage and Dist.

Forrestal Bldg, CE-141 5E-052

Washington, DC 20585

DOE Technical Information Center

US Department of Energy

P.0. Box 62

Oak Ridge, TN 37830

5 Applied Geomechanics Inc.

Attn: R. L. Thoms

PO Box 80619

Baton Rouge, LA 70898

Commonwealth Edison Co.

Attn: T. J. Maiman

Sta. Mech. Engr. Dept. Mgr.

36 FN West

PO Box 767

Chicago, IL 60690

Electric Power Research Inst.

Attn: B. Mehta

3412 Hillview Avenue

PO Box 10412

Palo Alto, CA 94303

Electric Power Research Inst.

Attn: R. B. Schainker

3412 Hillview Avenue

PO Box 10412

Palo Alto, CA 94303

Imre Gyuk

1201 Lyndale Drive

Alexandria, VA 22308
No of

Copies

Harza Engineering Co.

Attn: A. H. Barber

Director of Marketing

150 S. Wacker Drive

Chicago, IL 60606

Lawrence Livermore Laboratory

Attn: Tech. Info. Dept, $L-3$

University of California

PO Box 808

Livermore, CA 94550

5 Louisiana State University

Attn: R. E. Wilcox

Institute for Environmental Studies

Room 42, Atkinson Hall

Baton Rouge, LA 70803-5705

Office of Congressman

Sid Morrison

Attn: Kevin Billings

Legislative Assistant

1330 Longworth Bldg.

washington, DC 20515

Sandia Laboratories

Technical Library

Div. 3141

Albuquerque, NM 87185

Sargent and Lundy Engineers

Attn: W. C. Walke

Project Manager

55 East Monroe Street

Chicago, IL 60603

Tennessee Valley Authority

Energy Research Section

1360 Commerce Union Bank Bldg.

Chattanooga, TN 37401

United Engineers \& Constructors

Attn: E. Sosnowicz

Advanced Eng. Dept. $04 U 3$

30 South 17 th

Philadelphia, PA 19101 
No of

\section{Copies}

US Dept. of Interior

Attn: Lucy Howton

Natural Resources Library

Serial Branch

Gifts and Exchange Div.

Washington, DC 20240

University of California

Attn: T. L. Brekke

Dept. of Civil Engineering

1847 Yosemite Road

Berkeley, CA 94707

University of Massachusetts

Attn: 0. C. Farquhar

Dept. of Geology \& Geography

Morrill Science Center

Amherst, MA 01003

University of Michigan

Attn: Donald L. Katz

Dept. of Chemical Eng.

2042 E. Engr. Bldg.

Ann Arbor, MI 48109

Westinghouse Research \& Dev.

Attn: D. L. Ayers

1310 Beulah Road

Pittsburgh, PA 15235
No of

Copies

QNSITE

DOE Richland Operations office

D. R. Segna

18 Pacific Northwest Laboratory

T. J. Doherty

L. D. Kannberg (10)

Technical Information (5)

Publishing Coordination (2) 